\title{
EVOLUÇÃO DO ESTADO NUTRICIONAL DE CRIANÇAS DESNUTRIDAS E EM RISCO NUTRICIONAL EM PROGRAMA DE SUPLEMENTAÇÃO ALIMENTAR
}

\section{RITA MARIA MONTEIRO GOULART}

Tese de Doutorado apresentada ao Departamento de Saúde Materno-Infantil da Faculdade de Saúde Pública da Universidade de São Paulo para obtenção do Grau de Doutor

Área de concentração:

Saúde Materno-Infantil

ORIENTADOR:

PROF. DR. IVAN FRANÇA JUNIOR

São Paulo

2003

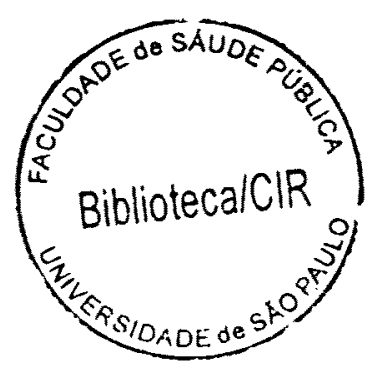


“... O acesso à alimentação é um direito humano em si mesmo, na medida em que a alimentação constitui-se no próprio direito à vida, negar este direito é, antes de mais nada, negar a própria condição para a cidadania...."

(Relatório do Brasil à Cúpula Mundial de Alimentação, Roma - 1994) 


\section{Dedicatória}

Dedico esta tese especialmente ao Elias, Thais e Guifherme, que sempre estiveram ao meu lado e sem os quais esta, ou qualquer outra conquista, não teriam razão de ser.

Aos meus familiares, por me mostrar a cada dia que eu sempre posso ter com quem contar, em especial à:

Minha querida mãe e sogra, Maria e Neusa;

Minha querida irmã e sobrinho: Edna e Vitor. 


\section{AGRADECIMENTOS}

Ao Professor Doutor Ivan França Júnior, pela orientação competente, objetiva, dedicada e pelo apoio constante demonstrado durante todo o decorrer deste estudo.

Ao professor Doutor Elias Estevão Goulart, por seu companheirismo, disposição e paciência principalmente demonstrados na estruturação do banco de dados.

À Professora Doutora Maria de Fátima Souza por seu apoio nas análises estatísticas.

Às Professoras Doutoras Maria Helena D’Aquino e Doris Lucia Martini Lei pelas importantes sugestões na banca de qualificação.

Ao Doutor Hermes Suini Sanchez e Dra. Silvia Suini Sanchez pela colaboração tão preciosa na revisão deste estudo.

À Secretaria Municipal de Saúde de Mogi das Cruzes, pela oportunidade de realização deste estudo.

À Universidade de Mogi das Cruzes, pela bolsa auxílio concedida e pelo apoio acadêmico.

Às estagiárias do curso de nutrição da Universidade de Mogi das Cruzes que durante alguns períodos participaram deste projeto. 
Às mães das crianças que concordaram e se dispuseram a participar do estudo, contribuindo com informações vitais para a concretização do mesmo.

Aos colegas do Departamento de Saúde Materno-Infantil pelo carinho e atenção dispensada ao longo desta jornada.

Na esperança de não ter omitido nenhum nome, agradeço a todos que de maneira direta ou indireta contribuíram para a realização deste estudo.

Finalmente, agradeço imensamente a Deus, que sempre esteve e sempre estará comigo por sua graça e bondade. 


\section{RESUMO}

GOULART, RMM. Evolução do estado nutricional de crianças desnutridas e em risco nutricional em programa de suplementação alimentar. São Paulo; 2003. [T'ese de Doutorado - Faculdade de Saúde Pública da USP].

Objetivos. Avaliar o impacto do Programa de Incentivo ao Combate às Carênciąs Nutricionais - ICCN nas crianças no Município de Mogi das Cruzes e os fatores associados à evolução nutricional. Métodos. Foram estudadas 724 crianças de 6 a 24 meses inscritas no ICCN, no período de jul/99 à jul/01. Para avaliar o estado nutricional utilizaram-se os índices peso/idade, peso/estatura e altura/idade, sendo consideradas eutróficas crianças com escore $\mathrm{z} \geq-1$; de risco $\geq-2$ e $<-1$, desnutrida moderada $<-2$ e $>-3$ e desnutrida grave $\leq-3$. As crianças foram acompanhadas por 12 meses, a evolução nutricional foi avaliada através da altura/idade, os resultados foram analisados como estudo de painel, sendo utilizado o "Generalized Estimating Equations" (GEE) para as análises univariada e multivariada. Avaliou-se como tendência significativa do escore z os coeficientes com $\mathrm{p}<0,05$. Resultados. Ao final a condição nutricional encontra-se melhor para todas as categorias, sendo que o impacto do programa foi maior quanto mais intensa a deficiência nutricional inicial. Observaram-se ganhos, em altura, de 1,12,0,82, 0,57 e 0,45 desvios-padrão para os desnutridos graves, moderados, risco nutricional e eutróficos, respectivamente. $O$ fator associado à evolução nutricional para todas as categorias, de forma independente, foi a freqüência ao programa. Para os desnutridos também estavam associados à evolução nutricional, a idade ao ingressar no ICCN, o peso ao nascer e o aleitamento materno. De forma negativa, a idade da mãe e a ausência de trabalho materno. Para as crianças em risco também mostrou-se associada a melhor evolução nutricional, a renda familiar. Conclusão. A experiência do ICCN em Mogi das Cruzes resultou efetivamente na melhora nutricional dos beneficiários. 


\section{SUMMARY}

Objectives. To evaluate the impact of the supplementary feeding program (ICEN), with the children of Mogi das Cruzes city and the factors associated to the nutritional evolution. Methods. The program studied 724 enrolled children with age between 6 and 24 month-old which were observed in the period from 1999 July to 2001 July. To evaluate their nutritional status, it has been used the following scores: weight/age, weight/height and age/height, as for it has been considered normal child the ones who showed their $\mathrm{Z}$ score $\geq-1$, child at risk for malnutrition with their $\mathrm{Z}$ score $\geq-2$ and $\leq-1$, moderate malnutrition with $\mathrm{Z}$ score $<-2$ and $>-3$ and severe malnutrition with $\mathrm{Z}$ core $\leq-3$. The children were observed for 12 months, the nutritional evolution were evaluated through the height/age score, the results were analyzed as panel study as it has been used the "Generalized Estimating Equations" for the univariate and multivariate analysis. It has been evaluated as $\mathrm{Z}$ score relevant trends the results with $\mathrm{p}<0,05$. Results. The nutritional condition were better for all categories as for the program's impact was higher as more intense became the initial nutritional deficiency. It has been observed the height gains from 1,12, $0,82,0,57$ and 0,45 for the severe malnutrition, the moderate malnutrition, child at risk and normal, respectively. The associated factor to the nutritional evolution was, for all categories, the program frequency. For the malnourished, the age in the inscription to the ICCN, the birth-weight and the breast feed were also associated to the nutritional evolution. Negatively, the mother's age and the absence of the maternal work. For the children at risk, it has been noticed that the family income was also associated to the nutritional evolution. Conclusion. The experience with the ICCN in Mogi das Cruzes city resulted effectively to the benefited nutritional improvement. 


\section{ÍNDICE}

1. INTRODUÇÃO _

1.1. Programas de Suplementação Alimentar____ 13

2. OBJETIVOS_ 21

3. MATERIAIS E MÉTODOS 22

3.1. Características da população estudada __ 22

3.2. Características dos recursos de saúde do município ___ 23

3.3. Tipo de estudo __ 23

3.4. População en estudo___ 23

3.5. Atividades desenvolvidas__ 24

3.5.1. Suplementação Alimentar ___ 24

3.5.2. Ã̧̧̃es Educativas __ 25

3.6. Avaliação do estado nutricional da criança ao ingressar no ICCN___ 26

3.7. Avaliação da evolução nutricional___ 30

3.8. Variáveis estudadas___ 31

3.9. Análise dos dados __ 35

3.10. Conduta Ética ___ 38

4. RESULTADOS_ 39

4.1. Características da população ___ 39

4.1.1. Características das crianças___ 39

4.1.2. Caracteristicas Sociais e Ambientais ___ 41

4.1.3. Caracteristicas Familiares____ 43

4.2. Avaliação do Estado Nutricional __ 47

4.3. Evolução do Estado Nutricional__

4.4. Fatores relacionados à recuperação nutricional__

5. DISCUSSÃO _ 75

5.1. Características da População ___ 81

5.2. Características das crianças ___ 83

5.3 Estado nutricional das crianças ao ingressar no ICCN___ 85

5.4 Evolução nutricional das crianças __ 86

5.5. Variáveis associadas à evolução nutricional das crianças ___ 89 
6. CONCLUSAOO 99

7. CONSIDERAÇÕES FINAIS 101

8. REFER $\hat{E} N C I A S$ BIBLIOGRÁFICAS 104 ANEXOS 123 


\section{LISTA DE TABELAS}

TABELA 01 -Correspondência entre alguns pontos de corte de escore z e de percentis.

TABELA 02 - Distribuição de crianças segundo sexo e faixa etária ao ingressar no ICCN. Mogi das Cruzes, 2002.

TABELA 03 - Distribuição de crianças segundo peso ao nascer. Mogi das Cruzes, 2002. 40

TABELA 04 - Distribuição em número e percentual das crianças segundo renda familiar. Mogi das Cruzes, 2002. 42

TABELA 05 - Distribuição em número e percentual de pais segundo escolaridade Mogi das Cruzes, 2002.

TABELA 06 - Distribuição em número e percentual de irmãos das crianças inscritas no ICCN. Mogi das Cruzes, 2002.

TABELA 07 - Distribuição em número e percentual de mães segundo início de prénatal e número de consultas. Mogi das Cruzes, 2003.

TABELA 08 - Distribuição (\%) de mães de crianças inscritas no ICCN, segundo estado nutricional. Mogi das Cruzes, 2002.

TABELA 09 - Distribuição em número e percentual de crianças segundo estado nutricional inicial pelo índice peso/idade e percepção da mãe. Mogi das Cruzes, 2002.

TABELA 10 - Distribuição em número e percentual de crianças segundo estado nutricional inicial pelo índice peso/idade. Mogi das Cruzes, 2002.

TABELA 11 - Distribuição em número e percentual de crianças segundo estado nutricional inicial pelo índice peso/altura. Mogi das Cruzes, 2002. 48

TABELA 12 - Distribuição em número e percentual de crianças segundo estado nutricional inicial pelo índice altura/idade. Mogi das Cruzes, 2002. 49

TABELA 13 - Variação do índice alturafidade em 12 meses de programa segundo estado nutricional inicial. Mogi das Cruzes, 2002. 50

TABELA 14 - Distribuição de crianças desnutridas graves segundo intervalos de variação de escore z. Mogi das Cruzes, 2002.

TABELA 15 - Distribuiçāo de crianças desnutridas moderadas segundo intervalos de variação de escore z. Mogi das Cruzes, 2002.

TABELA 16 - Distribuição de crianças em risco nutricional segundo intervalos de variação de escore z. Mogi das Cruzes, 2002.

TABELA 17 - Distribuição de crianças eutróficas segundo intervalos de variação de escore z. Mogi das Cruzes, 2002. 
TABELA 18 - Variaçĩo relativa do índice altura/idade (em escore z) em 12 meses de programa segundo variáveis relacionadas à criança e estado nutricional inicial - Análise Univariada. Mogi das Cruzes, 2002.

TABELA 19 - Variação relativa do índice altura/idade (em escore z) em 12 meses de programa segundo variáveis maternas e estado nutricional inicial Análise Univariada. Mogi das Cruzes, 2002.

TABELA 20 - Variação relativa do indice altura/idade (em escore z) em 12 meses de programa segundo variáveis paternas e estado nutricional inicialAnálise Univariada. Mogi das Cruzes, 2002.

TABELA 21 - Variação média do índice altura/idade (em escore z) em 12 meses de programa segundo renda faniliar, número de parentes, emprego no periodo e estado nutricional inicial-Análise Univariada. Mogi das Cruzes, 2002.

TABELA 22 - Variáveis selecionadas para ajuste no modelo multivariado no grupo de crianças desnutridas. Mogi das Cruzes, 2002.

TABELA 23 - Variáveis selecionadas para ajuste no modelo multivariado no grupo de crianças em risco nutricional. Mogi das Cruzes, 2002.

TABELA 24 - Variáveis selecionadas para ajuste no modelo multivariado no grupo de crianças eutróficas. Mogi das Cruzes, 2002.

TABELA 25 - Associação entre fatores relacionados à recuperação de crianças desnutridas - Análise Multivariada. Mogi das Cruzes, 2002.

TABELA 26 - Distribuição (\%) de crianças desnutridas segundo escolaridade e idade da mãe Mogi das Cruzes, 2002.

TABELA 27 - Distribuição (\%) de crianças desnutridas segundo escolaridade da mãe e peso ao nascer. Mogi das Cruzes, 2002.

TABELA 28 - Associação entre fatores relacionados à recuperação nutricional de crianças em risco de desnutrição-Análise Multivariada. Mogi das Cruzes, 2002.

TABELA 29 - Associação entre fatores relacionados à evolução nutricional de crianças eutróficas - Análise Multivariada. Mogi das Cruzes, 2002. 70 


\section{LISTA DE FIGURAS}

FIGURA 01 - Correspondência entre valores de escore z e percentis, em diferentes pontos de corte e sua posição relativa na Curva de Gauss. 28

FIGURA 03-Distribuição (\%) de mães segundo escolaridade. Mogi das Cruzes, 2002.

FIGURA 04-Médias dos escores z peso/idade das crianças ao ingressar no ICCN segundo estado nutricional. Mogi das Cruzes, 2002.

FIGURA 05-Médias dos escores z peso/altura das crianças ao ingressar no ICCN segundo estado nutricional. Mogi das Cruzes, 2002 48

FIGURA 06-Médias dos escores z da altura/idade das crianças ao ingressar no ICCN segundo estado nutricional. Mogi das Cruzes, 2002

FIGURA 07 - Tendência da média estimada do escore $Z$ segundo visita no grupo de crianças desnutridas graves no início do estudo. Mogi das Cruzes, 2002.

FIGURA 08 - Tendência da média estimada do escore $Z$ segundo visita no grupo de crianças desnutridas moderadas no início do estudo. Mogi das Cruzes, 2002.

FIGURA 09 - Tendência da média estimada do escore $Z$ segundo visita no grupo de em risco de desnutrição no início do estudo. Mogi das Cruzes, 2002._53

FIGURA 10 - Tendência da média estimada do escore $Z$ segundo visita no grupo de crianças eutróficas no inicio do estudo. Mogi das Cruzes, 2002.

FIGURA 11 - Evolução do escore z segundo visita para os grupos de crianças. Mogi das Cruzes, 2002.

FIGURA 12 - Valores ajustados no modelo para crianças desnutridas versus resíduo. Mogi das Cruzes, 2002.

FIGURA 13- Distribuição do resíduo do modelo para crianças desnutridas. Mogi das Cruzes, 2002.

FIGURA 14 - Valores ajustados no modelo para crianças em risco versus resíduo. Mogi das Cruzes, 2002.

FIGURA 15 - Distribuição do resíduo do modelo para crianças em risco nutricional. Mogi das Cruzes, 2002.

FIGURA 16 - Valores ajustados no modelo para crianças eutróficas versus resíduo.

Mogi das Cruzes, 2002. 74

FIGURA 17 - Distribuição do resíduo do modelo para crianças eutróficas. Mogi das Cruzes, 2002. 


\section{LISTA DE QUADROS}

QUADRO 01 - Contribuição dietética do suplemento em percentual das recomendações diárias segundo faixa etária.

QUADRO 02 - Diagnóstico nutricional segundo escore z. 29

QUADRO 03 - Variáveis dependentes. Mogi das Cruzes, 2002. 32

QUADRO 04 - Variáveis explanatórias relacionadas à criança. Mogi das Cruzes, 2002.

QUADRO 05 - Variáveis explanatórias relacionadas à familia. Mogi das Cruzes, 2002.

QUADRO 06 - Distribuição de crianças segundo percentual de abandono e estado nutricional ao ingressar no ICCN. Mogi das Cruzes, 2003. 


\section{INTRODUÇÃO}

A Desnutrição Energética Protéica (DEP) freqüentemente congrega diferentes significados. É considerada para alguns autores como "doença multifatorial" (ALMEIDA e col. 1999; VEGA-FRANCO 1999), como "doença social" (NOBREGA 1986; FISBERG e col. 1997) ou ainda "doença nutricional" (UNICEF 1987). Observando-se porém a origem de sua formulação como diagnóstico, nota-se que a preocupação em classificar a desnutrição surge na primeira metade da década de 50 na América Latina, caracterizando-se como uma medida de prognóstico do índice de mortalidade em crianças, com a introdução do critério de Gomez.

Em 1956 Gomez conduziu um estudo com crianças internadas e estimou, a partir do peso e da idade, o risco destas crianças evoluírem para o óbito. Assim, propôs uma classificação centrada na intensidade da desnutrição e, baseando-se na relação Peso/Idade, definiu diferentes graus de desnutrição (ONIS 2001) .

Sendo assim, a desnutrição, não só nos casos severos (kwashiokor e marasmo) representa um risco para a saúde da criança, uma vez que compromete os mecanismos de defesa do organismo (CHEN e col. 1980; TOMKINS 1986; LOPES e col. 1988). Vários trabalhos têm demonstrado sua associação aos processos de morbidade e mortalidade infantis.

Segundo TONTISIRIN e BHATTACHARJEE (2001), a desnutrição e a infecção são responsáveis por uma ampla proporção de morbidade que se observa nos países em desenvolvimento, especialmente entre os grupos de menor idade. Portanto, a desnutrição deve ser vista, segundo os autores, não só como um dos fatores causadores de doenças, mas também como causa da exacerbação de doenças que ameaçam a saúde das crianças.

PELLETIER e col. (1995), avaliando os efeitos da desnutrição na mortalidade infantil em 53 países em desenvolvimento, observaram que a 
desnutrição relacionou-se com mais da metade das mortes de crianças de 6 a 60 meses, sendo a maior parte delas atribuídas às formas leves e moderadas da desnutrição.

Nos países em desenvolvimento a prevalência da desnutrição em crianças até 60 meses, segundo peso/altura (déficit de peso - processo agudo) é de 8,0\%; segundo o índice altura/idade (déficit de crescimento - processo crônico), ' $32,0 \%$ e utilizando-se o índice peso para idade (déficit global), encontra-se uma prevalência de 27,0\% (UNICEF 2003).

Uma revisão de pesquisas representativas, realizadas em 241 países sobre a tendência da desnutrição infantil no mundo, concluiu que os casos de atraso de crescimento têm aumentado na África Oriental, mas tem diminuído na Ásia sudoriental, Ásia meridional, central e América do Sul; África setentrional e o Caribe mostram uma ligeira melhora; e na África ocidental e América central os progressos têm sido muito escassos (ONIS e col. 2000).

A Cúpula Mundial pela infância, realizada em 1990, determinou, como meta para todos os países, que a prevalência de formas moderadas e severas de desnutrição deveria ser reduzida à metade até o ano 2000 .

Historicamente tem sido observado nos países do Terceiro Mundo, um declínio progressivo na prevalência da desnutrição, avaliada segundo o indicador peso/idade, em menores de 5 anos de idade. As últimas evidências, geradas a partir do Global Database on Child Growth and Manutrition (WHO, 1997), indicam que somente a América Latina mostra uma tendência sustentada e significante de declínio a partir dos anos 80 . Se a manutenção dessa tendência for confirmada, a América Latina pode ter sido a única do globo a atingir a meta de redução de $50 \%$ na taxa da desnutrição na infância, até o ano 2000 (ASSIS e BARRETO 2000).

Esta tendência, observada na América Latina, é extensiva também ao Brasil, onde os dados de duas pesquisas de abrangência nacional, "O Estudo 
Nacional de Despesa Familiar - ENDEF", realizada em 1975 e a "Pesquisa Nacional sobre Saúde e Nutrição - PNSN", realizada em 1989, permitem analisar a evolução nutricional das crianças brasileiras no decurso dos 15 anos que separam os dois estudos. A primeira pesquisa registrou uma prevalência de desnutrição infantil de 18,4\% enquanto que, na segunda, essa taxa foi de $7,2 \%$, configurando uma queda de $61 \%$ na magnitude das formas mais severas de déficits ponderais no país.

Embora reduções expressivas na prevalência da desnutrição tenham sido observadas por todo o país, as regiões Norte e Nordeste, que apresentavam a maior prevalência de desnutrição em 1975, foram as que menos se beneficiaram deste declínio. O comportamento da desnutrição infantil nas áreas urbanas e rurais da população mostram que o declínio foi bem inferior nas áreas urbanas do Norte e nas áreas rurais do Nordeste, o que aprofundou as desigualdes existentes entre as regiões Norte e Nordeste das regiões do Centro-Sul do país (MONTEIRO e col. 2000c).

$O$ último inquérito de abrangência nacional, realizado pela Sociedade Civil Bem-Estar Familiar - BEMFAM, ocorreu em 1996 dando origem à Pesquisa Nacional sobre Demografia e Saúde (PNDS), na qual se constatou a mesma tendência de declínio observada na década anterior - de $7,2 \% \mathrm{em}$ 1989 para 5,7\% em 1996 - na prevalência do déficit do peso/idade. No entanto, mais uma vez se observa que enquanto o declínio de déficits ponderais para o país como um todo foi de $20,8 \%$, as reduções para as áreas urbana e rural foi de 17,9 e 14,0\%, respectivamente. Em relação as regiões, no Nordeste onde estavam concentrados os estratos populacionais com prevalências iniciais mais elevadas, foi encontrado maior declínio relativo à desnutrição. Segundo o índice peso/idade em 1989, a prevalência da desnutrição foi de $12,8 \%$ declinando para $8,3 \%$ em 1996, representando uma queda de $35,2 \%$. Para a região Norte a prevalência de desnutrição de $10,6 \%$ declinou para $7,7 \%$, o que representou uma redução de $27,3 \%$, enquanto na 
região Centro-Sul a prevalência de desnutrição se manteve estável na faixa de 4,0\% (MONTEIRO 2000).

A prevalência de desnutrição infantil entre menores de 5 anos no estado do Maranhão, medidas pelo peso/idade, também declinou de 49,7\% em 1991, para 39,3\% em 1996. Apesar da redução, o índice observado é muito alto, mantendo o Estado como detentor da situação nutricional mais crítica do país (TONIAL e SILVA 1997).

Para a cidade de São Paulo, três inquéritos antropométricos realizados com intervalos de cerca de dez anos (1974/75, 1984/85 e 1995/96) mostram a mesma tendência de declínio da desnutrição observada no país. Déficits de altura declinam do primeiro para o terceiro inquérito: $19,5,10,1$ e 2,4\%, respectivamente. Uma tendência semelhante de declínio é também observada nos déficits da relação peso/altura. Entretanto, deve-se considerar que nestes casos são menores - 5,5\%, 1,7\% e 0,6\% (MONTEIRO e CONDE 2000).

Os diferentes percentuais de prevalência e velocidade de declínio da desnutrição infantil, observados em diferentes regiões do país, mostram as desigualdades econômicas e regionais ainda presentes no Brasil.

Enquanto uma sociedade apresentar desnutrição infantil em percentuais acima de $2,3 \%$, limite aceito como normal, em razão de variações nos padrões genéticos, ela estará violando o direito humano básico da garantia de acesso universal à alimentação e nutrição adequada e suficiente que atendam às necessidades nutricionais.

O direito da criança à alimentação é reconhecido em instrumentos internacionais de direitos humanos desde 1924. No entanto, a Convenção sobre os Direitos da Criança de 1989 é reconhecida como o tratado de direitos humanos mais amplamente ratificado. A Convenção estabelece, como lei internacional, todos os direitos para garantir a sobrevivência, 0 desenvolvimento e a proteção da criança. O artigo 24 determina que os 
Estados devem reconhecer o direito da criança ao "mais alto padrão de saúde possível" e devem promover medidas para a implementação desse direito.

Entre outras providências básicas, os Estados são obrigados a garantir assistência médica e cuidados de saúde a todas as crianças, com ênfase nos cuidados básicos de saúde; a combater as doenças e a desnutrição através da provisão de alimentos nutritivos adequados, de água limpa para beber e de saneamento adequado e a transmitir, às famílias, informações sobre as vantagens do aleitamento materno (UNICEF 2000).

Quando o Estado não consegue garantir estes direitos, certamente estará se responsabilizando pelo ônus das conseqüências geradas pela desnutrição infantil a curto, médio e longo prazo. Estas conseqüências dependerão da intensidade, dứação e faixa etária em que ela se fizer presente na infância.

Em curto espaço de tempo a desnutrição expõe a criança a uma maior vulnerabilidade a doenças infecciosas, em razão da falta de resposta orgânica adequada aos microorganismos agressores. Isto leva a um elevado grau de morbidade, sendo necessária, muitas vezes, a utilização da rede de saúde de atenção secundária ou mesmo terciária (hospitalização).

Os distúrbios intestinais ocupam lugar de destaque na ocorrência de enfermidades infecciosas em crianças com comprometimento do estado nutricional e em número de intercorrências e internações hospitalares, acometendo, principalmente, crianças de 6 a 24 meses (WATERLOW 1992).

Caso a desnutrição seja prolongada, comprometerá o crescimento e o desenvolvimento da criança. A desnutrição intra-uterina e pós-natal contribui de maneira efetiva para a diminuição do potencial de crescimento com reflexos na estatura (MARTORELL e col. 1988; NOBREGA 1997; SIT e YEUNG 1999; GOPALAN 2000). 
KELLER e FIMORE (1983) relatam que crianças que sofreram desnutrição severa em idades precoces, provavelmente terão comprometimento do crescimento na vida adulta.

Atualmente está claro que baixo peso e baixa estatura aumentam significativamente o risco de enfermidades e morte, mesmo controlando-se 0 ambiente social e fisico nos quais estas crianças estão inseridas. Também está claro que a desnutrição aumenta o risco de infecções independentemente do status socioeconômico (TOMKINS 2000).

Não há consenso, na literatura, quanto às alterações intelectuais,: enquanto alguns autores defendem a idéia de que a redução do nível intelectual encontrada em crianças com condições socioeconômicas precárias é resultado da desnutrição presente em idades precoces (WINICK e col. 1975; CAMPANA e col. 1977; POLLITT e col. 1997; POLLITT 2000; WALKA e POLLITT 2000), outros defendem que a mesma resulta da falta de estímulo freqüente em famílias de baixo poder aquisitivo (STEIN e col. 1972; FISBERG e col. 1997). De qualquer forma, tanto a desnutrição precoce como a falta de estímulo são modulados pela baixa condição socioeconômica.

Segundo BELLAMY (1998), a desnutrição em crianças pequenas desestimula a motivação e a curiosidade e reduz as atividades ligadas aos atos de brincar e explorar. Estes efeitos, por conseguinte, comprometem o desenvolvimento mental e cognitivo, reduzindo os níveis de interação das crianças com o meio ambiente e com as pessoas responsáveis por elas.

A desnutrição na fase adulta está associada ao comprometimento das funções reprodutivas em mulheres (KRAMER 1987; KLEBANOFF e YIP 1987; MONDINI e MONTEIRO 1998) e redução da capacidade de trabalho (FERRO-LUZZI e col. 1992; ONIS e col. 2001).

Finalmente, é importante reconhecer, como MONTEIRO (2000), que as conseqüências de médio e longo prazo da desnutrição infantil atuam como obstáculos aos esforços da sociedade na busca do desenvolvimento, 
destacando-se os custos envolvidos no tratamento da desnutrição e de suas complicações, com conseqüente pressão sobre recursos de saúde escassos, dificuldades adicionais para o progresso da escolarização da população e as limitações decorrentes, na idade adulta, na produtividade da força de trabalho.

Face à alta prevalência que a desnutrição apresenta em sociedades menos privilegiadas do ponto de vista socioeconômico e aos efeitos deletérios que pode causar à saúde das crianças, muitos esforços foram realizados a fim de se estabelecer seus determinantes para que, a partir deste conhecimento fossem propostas ações de intervenção eficazes para seu controle. Neste sentido, vários modelos teóricos de causalidade têm sido propostos (SHANK 1978; JONSSON 1981; VALENTE 1989; UNICEF 1990).

Para este estudo propõe-se um modelo simplificado dos determinantes e das medidas de prevenção da desnutrição, utilizando-se como referência o esquema da "História Natural da Doença" proposto por LEAVEL \& CLARK (1976) e o esquema proposto pela UNICEF (1990) nas "Causas da Desnutrição e Mortalidade". Esta escolha se deu em razão de que, ao longo deste modelo explicativo, é possível focalizar as ações de intervenção, entre elas a suplementação alimentar, objeto deste estudo. Na página seguinte o modelo simplificado está representado. 


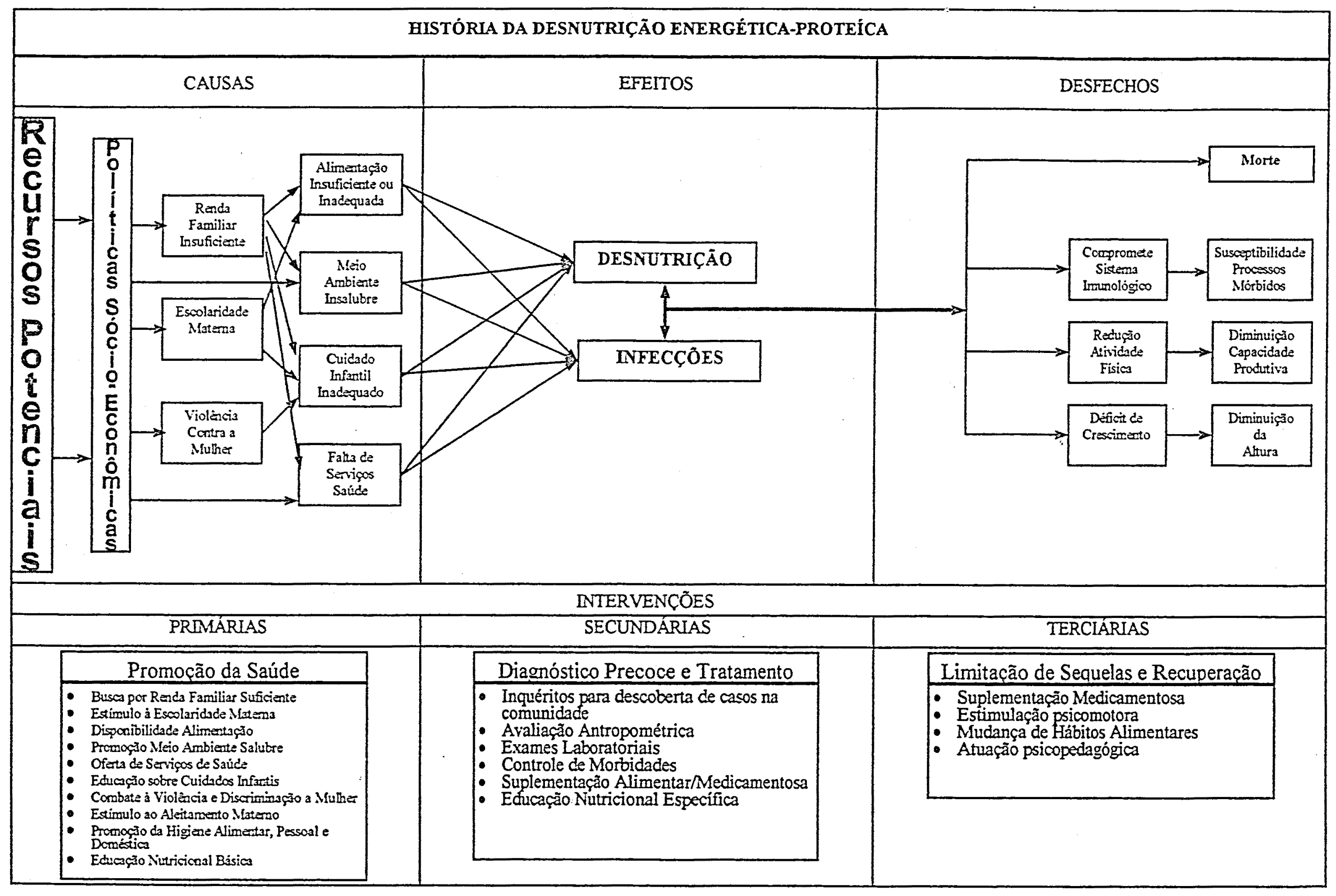


$\mathrm{O}$ acesso a serviços essenciais de saúde, como assistência médica e saneamento básico, à alimentação e aos cuidados infantis determina a formação de quatro vertentes na estrutura do modelo que leva ao binômio desnutrição/infecções.

A primeira vertente representada pela alimentação inadequada ou insuficiente é modulada pelo nível de renda e pela escolaridade materna. A escolaridade materna reflete o menor ou maior acesso à informação e, conseqüentemente, ao melhor ou pior aproveitamento dos recursos alimentares disponíveis. O grau de instrução sobretudo das mulheres, reconhecidamente pode ter efeitos favoráveis sobre a saúde materno-infantil. A educação, em nível secundário e superior, é uma das vias mais importantes para que as mulheres possam fazer escolhas saudáveis e ter uma melhor condição social (FNUAP, 1994). A renda, por sua vez, determina o acesso dos indivíduos aos bens e serviços essenciais, como alimentação, moradia, saneamento, assistência à saúde e, conseqüentemente, estarão influenciando o cuidado infantil.

As condições do meio ambiente, segunda vertente, são dependentes das políticas socioeconômicas que vão orientar os investimentos governamentais em relação à fatia do orçamento público destinado ao setor social, além da renda.

$\mathrm{Na}$ terceira vertente relacionada ao cuidado infantil encontra-se a escolaridade materna, mencionada anteriormente. É interessante lembrar que maior nível de escolaridade pode contribuir, entre outros fatores, para melhor utilização de serviços públicos de saúde e consequentemente propiciar maior proteção à criança. Ainda segundo CARDOSO (1995), a forma como a mulher dedica seu tempo de atenção aos filhos, seja diretamente, ou delegando a terceiros este cuidado, certamente é influenciada pelo seu grau de instrução. Recentemente a literatura tem mostrado que a violência e a discriminação contra a mulher podem 
condicionar o cuidado com a criança e exercer forte influência no estado nutricional da mesma. Mais uma vez a renda exerce influência direta no cuidado infantil à medida em que a família dispõe de maior ou menor condição financeira para o atendimento das necessidades básicas da criança.

$\mathrm{Na}$ quarta vertente, a falta de serviços de saúde e, conseqüentemente, o acesso à assistência médica e imunização, pode levar ao surgimento de enfermidades ou agravos à saúde que resultará no complexo desnutrição/infecção; por sua vez também está condicionada às políticas socioeconômicas e ao direcionamento orçamentário para o setor saúde.

Finalmente, é importante lembrar que as causas que levam à desnutrição são numerosas, em geral interrelacionadas e ultrapassam este modelo explicativo simplificado. No entanto, ao se procurar entender os determinantes da desnutrição é importante ressaltar que as causas básicas da desnutrição se enquadram, fundamentalmente, no contexto das políticas socioeconômicas do país, derivadas dos recursos potenciais disponíveis e também que haverá melhor ou pior condição de vida e saúde para a comunidade em função do maior ou menor grau de organização destas estruturas políticas

Assim, populações submetidas aos maiores níveis de pobreza e menores índices de escolaridade estarão expostas aos maiores riscos de saúde. O trabalho em saúde pública implementa ações preventivas para minimizar os efeitos destes riscos, cujos resultados poderão ser mais efetivos dependendo do grau de comprometimento da saúde e do direcionamento adequado destas ações que foram modeladas neste esquema em três níveis de classificação: prevenção primária, secundária e terciária.

A prevenção primária pressupõe o estabelecimento de ações que visam interceptar os fatores que desencadeiam a desnutrição, sendo elas: 
- Promoção da saúde:

- busca por renda familiar suficiente ao atendimento das necessidades;

- estímulo à escolaridade materna;

- disponibilidade de alimentação suficiente e adequada;

- promoção de meio ambiente salubre;

- oferta de serviços de saúde;

- educação sobre os cuidados infantis adequados;

- combate à violência e à discriminação contra a mulher;

- estímulo ao aleitamento materno;

- promoção da higiene alimentar, pessoal e doméstica;

- imunização;

- educação nutricional básica.

A prevenção secundária deve ser realizada quando da presença da desnutrição e compreende:

- Diagnóstico precoce e tratamento imediato:

- inquéritos para descoberta de casos na comunidade;

- avaliação antropométrica;

- exames laboratoriais;

- oferta de suplementação alimentar;

- controle de morbidades;

- educação nutricional específica;

- intervenção medicamentosa.

Na prevenção terciária as ações são destinadas a reduzir o comprometimento e promover a recuperação e compreende: 
- Limitação de seqüelas e recuperação:

- oferta adequada de medicamentos para controle das morbidades;

- estimulação psicomotora;

- mudança de hábitos alimentares;

- oferta adequada de alimentação;

- atuação psicopedagógica.

Neste modelo ainda foram incluídos os possíveis desfechos da desnutrição. Quando os fatores determinantes não são controlados e as ações de intervenção inexistem ou não conseguem ser efetivas para evitar a progressão da desnutrição e/ou infecção, a criança pode evoluir ao óbito ou apresentar seqüelas futuras que comprometerão sua qualidade de vida.

Estas conseqüências deletérias podem ser relacionadas com a maior susceptibilidade às doenças, com redução da capacidade de realização de atividades fisicas e produtivas e/ou com a baixa estatura. Nestes casos, as açōes terciárias serão necessárias para a recuperação do estado nutricional e de saúde e para a redução das seqüelas e incapacidades.

Quando os fatores determinantes não são controlados em sua totalidade, caso as intervenções secundárias sejam efetivas, a criança pode ser beneficiada e ter amenizado ou interrompido o curso da desnutrição, restabelecendo a normalidade de saúde e crescimento.

As ações governamentais brasileiras observadas ao longo dos últimos 20 anos têm promovido uma redução importante na desnutrição infantil, conforme citado anteriormente, através da melhoria de vários indicadores tais como: progressos moderados na renda familiar, expansão de serviços públicos de saneamento, saúde e educação, redução nos índices de fertilidade e natalidade, com famílias menos numerosas e, finalmente, deslocamento crescente da população para as áreas urbanas do país onde, de modo geral, são melhores as oportunidades de emprego e de renda, caracterizado, de 
acordo com o modelo aqui proposto, como ações primárias preventivas e de promoção da saúde (MONTEIRO e col. 2000c).

No entanto estamos distante do ideal, uma vez que importante parcela da população infantil ainda apresenta déficit nutricional.

\subsection{Programas de Suplementação Alimentar}

Historicamente, a distribuição de alimentos para grupos populacionais vulneráveis por meio dos serviços de saúde tem sido a estratégia adotada para melhoria das condições de vida e saúde nos países não desenvolvidos (CASTRO 2000).

O Brasil tem adotado esta prática, isto é, tem implementado programas de suplementação alimentar para crianças desnutridas desde a década de 40. No entanto estes programas tornaram-se mais abrangentes a partir da criação do Instituto de Nacional de Alimentação e Nutrição (INAN).

Em 1972, o governo criou o INAN vinculado ao Ministério da Saúde, com objetivo de auxiliar na formulação de uma política nacional de alimentação e nutrição, propor o Programa Nacional de Alimentação e Nutrição - PRONAN, promover e fiscalizar a sua execução e avaliar os resultados.

Embora situado como atividade emergencial e transitória, a suplementação alimentar constituiu-se, a partir de então, em parte central do conjunto de ações propostas pelo governo para o controle da desnutrição através dos diversos programas criados pelo INAN (MONTEIRO e MEYER, 1988).

O I PRONAN (1973-1974) teve sua execução prejudicada por dificuldades administrativas (SILVA 1994). A partir de 1976, com a implementação do II PRONAN, a suplementação alimentar a crianças 
menores de cinco anos ganha gradativamente dimensões nacionais. Os gastos governamentais com esses programas cresceram substancialmente no período de 1976-1987, chegando em 1987 a representar 5,6\% dos gastos totais em saúde e $0,14 \%$ do PIB brasileiro. Por ocasião da realização da PNSN (1989) evidenciou-se que $24,3 \%$ (cerca de três milhões de crianças) estavam matriculadas em pelo menos um programa de suplementação alimentar (MONTEIRO e col.2000c).

No entanto, a avaliação da eficiência do PRONAN no período em que esteve em plena atividade (1976-1989), tanto em conjunto como em cada um do seus componentes, é inviável. Para a maioria dos programas de suplementação alimentar no Brasil, dispõe-se apenas de dados oficiais sobre cobertura, quantidade de alimento, distribuição regional e custos, e não de dados sobre o desempenho real, ou seja, a melhoria das condições nutricionais das crianças beneficiadas por estes programas.

PELIANO (1992) ao realizar uma avaliação crítica dos programas de suplementação alimentar no Brasil, chega as seguintes constatações: o não direcionamento dos programas federais para os grupos mais pobres e biologicamente mais vulneráveis da população, a dissociação dos programas de nutrição infantil da prestação de serviços básicos de saúde, a inscrição nos programas oficiais não garantiam o recebimento dos alimentos e tão pouco era privilegiado em termos geográficos o atendimento nas áreas mais pobres, onde se concentrava os maiores contingentes de crianças com déficits nutricionais.

A literatura tem mostrado a importância e as dificuldades da avaliação dos programas de intervenção. Avaliar os resultados destes programas tem sido um valioso instrumento prático para determinar 0 alcance dos resultados esperados, bem como para avaliar se o programa deve ser reformulado ou reforçado a fim de maximizar seus efeitos. Segundo 
HABICHT e col. (1999), o principal objetivo de se avaliar estes programas consiste em que os resultados devem servir para influenciar decisões.

No Brasil, pouco tem sido feito no sentido de avaliar os resultados obtidos junto à população beneficiária, por não existir um processo contínuo de avaliação dos programas de suplementação alimentar. Quando existe esta avaliação, geralmente é realizada por pesquisadores interessados e não são vinculadas e sistematizadas no planejamento e na execução dos programas (CHAVES e col. 1989).

Ao longo de 20 anos alguns pesquisadores se dedicaram a avaliar os resultados efetivos dos programas de suplementação alimentar, desenvolvidos em diferentes regiões do país, a saber : BENICIO e col. 1981; KALIL e col. 1981; SIGULEM 1981; LEI 1986; TADDEI 1987; PUCCINI 1988; CHAVES e col. 1989; SANTOS, 1990; LERNER e col. 1991; SANTOS FILHO 1991, PUCCINI e col. 1996; GOULART, 1998; GUTIERREZ e col. 1998; CASTRO, 1999; SOARES e PARENTE 2001.

Não só em nosso meio as avaliações são pouco freqüentes, AUSTIN, citado por TADDEI (1987) em um levantamento de 140 programas de intervenção nutricional executados em vários países, somente $23 \%$ dispunham de informações referentes a impacto nutricional.

BEATON e col. (1982), a partir de uma extensa revisão sobre os programas de suplementação alimentar nos países do Terceiro Mundo, concluíram que os custos destes programas eram mais elevados do que os beneficios observados no estado nutricional medidos pelas mudanças antropométricas.

Entre as dificuldades citadas nas avaliações epidemiológicas dos programas de suplementação alimentar destaca-se a possibilidade de apresentar vieses, entre os vários tipos citados na literatura destaca-se: de seleção, de aferição e de confundimento/modificação de efeito. 
Entende-se por viés de seleção uma distorção no estimador do parâmetro de efeito causada pela maneira como os elementos são selecionados.

BEHAR (1991), realizando uma análise crítica dos programas de nutrição aplicados na América Latina, concluiu que os maiores problemas estão ligados à escassez de critérios para selecionar os beneficiários e, por consegüinte, para se alcançar as crianças mais necessitadas.

SCHILLING (1990), avaliando programas de suplementação alimentar realizados na Ásia, África e Brasil, concluiu que, em relação à cobertura, os segmentos da população que mais necessitariam do suplemento são justamente aqueles que não são alcançados pelos programas.

Uma extensa revisão sobre experiências de programas de suplementação alimentar realizada em vários países sugere que, freqüentemente, a seleção de beneficiários não consegue alcançar toda a população de risco, uma vez que são estabelecidos critérios de seleção que podem ser geográficos, socioeconômicos ou individuais que culminam em erros de inclusão e exclusão, isto é, incluem os não necessitados e/ou excluem os que realmente necessitam do suplemento (GHASSEMI 1992).

No Brasil, somados às dificuldades citadas, os programas de suplementação alimentar sempre estiveram sob a coordenação de diversos Ministérios (Saúde, Educação e Cultura, Trabalho, Agricultura e Ação Social), o que propiciou a superposição de beneficios e beneficiários. Como agravante, no Brasil observa-se a adoção de interesses políticos para seleção de beneficiários. SILVA (1994), ao avaliar o Programa Nacional de Leite para Crianças Carentes - PNLCC, constatou que o atendimento dos beneficiários se concentrou nas regiões Sudeste e Sul com forte predomínio das áreas urbanas (detentora do maior colégio eleitoral do país) em detrimento das crianças do Norte e Nordeste, região onde se concentravam as crianças com os maiores déficits nutricionais. Além disso, a cobertura do 
Programa Nacional de Alimentação Escolar - PNAE foi de 91\% na região Sudeste contra $57 \%$ no Nordeste, favorecendo os escolares de maior renda.

Estes problemas na seleção dos beneficiários comprometem a avaliação dos programas, principalmente quando se inclui, desproporcionalmente, os casos menos graves, o que tende a subestimar 0 impacto.

Em segundo lugar aparece o viés da aferição, também denominado de viés de informação que se caracteriza pela utilização de informações incorretas e, assim, obtém-se resultados com tendências discrepantes da realidade estudada.

A Organização Mundial da Saúde - OMS (1983) definiu o efeito dos programas de suplementação alimentar como a melhora no estado nutricional dos beneficiários e propôs que as medidas de peso e altura, relativas à idade, fossem usadas para avaliar a presença ou ausência desse efeito. Portanto a medição precisa destes dados é fundamental para a correta avaliação do estado nutricional dos beneficiários e da sua evolução.

$O$ peso pode sofrer rápidas e intensas modificações em curtos intervalos de tempo; já a altura é um parâmetro mais estável que o peso, porque não se modifica rapidamente, nem sofre redução. A altura é ganha progressivamente e qualquer atraso no crescimento linear torna-se mais permanente do que o peso (SEONE e LATHAM 1971).

Uma limitação importante nestes estudos tem sido a mensuração do comprimento ou altura em crianças pequenas. Em um estudo realizado no Rio Grande do Sul com crianças de 12 a 36 meses de idade, foram observadas diferenças médias nas medições realizadas entre observadores de $0,02 \mathrm{~kg}$ para peso (cerca de $2 \%$ de um desvio padrão) e $0,47 \mathrm{~cm}$ para altura (cerca de 15\% de um desvio-padrão) (VICTORA e col. 1998).

A acuidade na tomada de medidas antropométricas pode, portanto, comprometer a análise dos resultados, subestimando ou superestimando os 
efeitos dos programas na recuperação dos déficits nutricionais dos beneficiários.

Por último, tem-se o viés de confundimento, resultante da avaliação incorreta dos resultados encontrados, em função da desconsideração de outros fatores pertinentes e que interferiram no estudo.

Os programas de suplementação alimentar para crianças desnutridas, por questões éticas, não permitem a adoção de grupo-controle (TADDEI, 1987). Desta forma os resultados medidos sobre o impacto na recuperação nutricional dos beneficiários são questionados se poderiam ser atribuídos à suplementação alimentar ou a outros fatores que modulariam o crescimento infantil e que podem se modificar ao longo do seguimento.

Dentre estes fatores podem figurar, entre outros, alterações na renda familiar durante o período de exposição ao programa, episódios de doenças, idade da criança no início da intervenção, informações que se não levantadas e avaliadas podem comprometer a análise do impacto dos programas.

Portanto, é imprescindível que estes fatores sejam considerados a fim de se evitar conclusões errôneas sobre os efeitos dos programas de suplementação.

O problema alimentar e nutricional existente no nosso país tem origem basicamente social, o que descarta a possibilidade de solução pela mera atuação de programas de suplementação alimentar (MONTEIRO 1988). No entanto esta política tem sido mantida na agenda governamental como atividade "emergencial" e "transitória", direcionada para melhoria das condições de saúde e nutricional das crianças mais carentes até que mudanças reais na estrutura socioeconômica do país ocorram.

Os programas governamentais de assistência alimentar à população infantil sofreram grandes modificações no período 1989-1996. Nos primeiros anos da década (durante o governo Collor), assistiu-se, no plano federal, à descontinuidade generalizada desses programas. A partir de 1993, o governo 
federal procura retomar a ação da suplementação alimentar, tentando imprimir a ela características que corrigissem as deficiências evidenciadas pela PNSN - 1989 (MONTEIRO 2000). Desde esforço surgem novos programas, entre os quais destaca-se o Incentivo ao Combate às Carências Nutricionais - ICCN, objeto deste estudo.

Em 1999 o Ministério da Saúde, por intermédio do ICCN, um dos componentes do PAB (Piso de Atenção Básica), busca a atenção à saúde nutricional da criança. A assistência oferecida por esse grupo é composta por um conjunto de ações, dentre as quais figura a suplementação alimentar às crianças em risco nutricional. De acordo com o Parágrafo único do Artigo $4^{\circ}$ da Portaria GM/MS 709 de 11 de junho de 1999, "são consideradas crianças em risco nutricional aquelas situadas abaixo de percentil 10 da relação peso/idade, segundo o cartão da criança utilizado na rotina dos serviços de saúde".

O recursos do ICCN são repassados diretamente do Fundo Nacional de Saúde para o Fundo Municipal de Saúde, em parcelas mensais. O montante de recursos repassado a cada município corresponde a um valor de $R \$ 180,00$ (cento e oitenta reais) por criança ao ano. O Ministério da Saúde estima, por município, o número de crianças em risco nutricional, segundo modelo estatístico de predição do estado nutricional elaborado pelo NUPENS/USP (BENICIO e MONTEIRO, 1997) .

As iniciativas destinadas à prevenção e à recuperação de desnutridos combinam ações de alimentação e nutrição com ações básicas de saúde. Além de ter assegurada a distribuição de alimentos, as crianças atendidas devem ser acompanhadas mensalmente a fim de se monitorar seu crescimento e de se avaliar seu estado nutricional (MINISTÉRIO DA SAÚDE 2000a)

Para acompanhar o desempenho deste programa, o Ministério da Saúde estabeleceu que a avaliação do estado nutricional, medido através do peso dos beneficiários fossem registrados mensalmente no Sistema de 
Vigilância Alimentar e Nutricional (SISVAN). Assim, a coleta de informações provenientes do nível municipal deverá subsidiar a avaliação do real impacto do programa em nível nacional, propiciando conhecer a efetividade alcançada no conjunto do país.

O município de Mogi das Cruzes, localizado na região leste da Grande São Paulo, aderiu ao ICCN e implantou, a partir de julho de 1999, o Programa de Combate às Carências Nutricionais. Através da estimativa do NUPENS/USP, as crianças em risco nutricional somaram um total de 5501.

Tendo em vista o exposto, este estudo pretende avaliar o impacto do ICCN no município de Mogi das Cruzes, investigando a evolução nutricional das crianças atendidas ao longo de um ano e os fatores a ela associados.

Este estudo se justifica face a:

- Necessidade de avaliação do programa, conforme preconizado pelo Ministério da Saúde, pois este conhecimento contribuirá para o planejamento e execução de ações pertinentes ao controle da desnutrição;

- Necessidade do conhecimento dos fatores que influenciam o impacto dos programas de suplementação alimentar na evolução nutricional dos beneficiários, afim de subsidiar a implementação de futuras ações que possam, juntamente com os programas, serem efetivas no controle da desnutrição.

\footnotetext{
${ }^{1}$ Informação verbal da Secretaria da Saúde do Município.
} 


\section{OBJETIVOS:}

Avaliar o impacto do programa nacional de recuperação nutricional, Incentivo ao Combate às Carências Nutricionais - ICCN, entre as crianças, de diferentes categorias de estado nutricional, residentes no Município de Mogi das Cruzes.

Avaliar os fatores associados, positiva ou negativamente à evolução do estado nutricional. 


\section{MATERIAIS E MÉTODOS:}

\subsection{Características da população estudada:}

O estudo foi realizado no município de Mogi das Cruzes, situado na região leste da Grande São Paulo, a $53 \mathrm{~km}$ da capital. Com uma área total de $727,1 \mathrm{Km}^{2}$, o município de Mogi das Cruzes ostenta a posição de maior município da Região da Grande São Paulo, sendo ultrapassado somente pela própria capital.

O município é subdividido administrativamente em 8 distritos. São eles: Sede, Braz Cubas, Jundiapeba, Cezar de Souza, Sabaúna, Biritiba Ussu, Taiaçupeba e Quatinga (este último criado em 1997, após contagem da população feita pelo IBGE em 1996).

A população residente, segundo tal contagem, era de $312.685 \mathrm{mil}$ habitantes. Foi registrado um número de 79.399 domicílios particulares permanentes, com média de 3,9 moradores por domicílio.

O perfil de renda em Mogi das Cruzes é dado pelos resultados da Pesquisa Origem/Destino realizada no mês de agosto de 1996, pela Emplasa, através da Universidade de Mogi das Cruzes (FAEP), com apoio técnico e metodológico do Metrô/SP. Com relação à renda, 53,3\% da População Economicamente Ativa (PEA) apresentam um rendimento de até quatro (4) salários mínimos, sendo que apenas $13,2 \%$ recebem mais de onze (11) salários mínimos.

A média de anos de estudo do chefe de família é de 8,2 anos. Deste conjunto, $4,7 \%$ são analfabetos, $23,2 \%$ estudaram menos de 4 anos e, $28 \%$ da população tem de cinco a sete anos de estudo, pois não concluíram a $8^{2}$ série do $1^{\circ} \mathrm{Grau}$. 


\subsection{Características dos recursos de saúde do município:}

O município conta com 20 Unidades Básicas de Saúde (UBS), 3 unidades médico-odontológicas em escolas municipais, 2 unidades volantes e 3 centros de saúde-escola mantidos pela Prefeitura e conveniados com a Universidade de Mogi das Cruzes.

$\mathrm{Na}$ área da saúde, a população de Mogi das Cruzes é assistida por 2 hospitais da rede pública, 3 privados e 1 filantrópico, oferecendo 503 leitos e 4 UTIs além de diversas clínicas, consultórios e laboratórios particulares das mais variadas especialidades.

\subsection{Tipo de estudo:}

Trata-se de um estudo para avaliação do impacto de um programa de suplementação alimentar do tipo quase-experimental por não dispor de grupo controle. Devido às dificuldades por princípios éticos e operacionais de se manter um grupo controle, as crianças observadas ao final de 12 meses foram as mesmas observadas no início do acompanhamento. As análises descrevem as mudanças antropométricas ocorridas, longitudinalmente, com estas crianças.

\subsection{População em estudo:}

A população estudada foi composta pelo universo das crianças com idade igual ou inferior a 24 meses desnutridas e/ou em risco de desnutrição, atendidas nas Unidades Básicas de Saúde do Município de Mogi das Cruzes e inscritas no Programa de Incentivo ao Combate às Carências Nutricionais (ICCN), no período de julho de 1999 à julho de 2001.

Do total de crianças inscritas no período estudado (742), foram excluídas 2 crianças encaminhadas ao ICCN antes dos seis meses de idade, 
em razão das mães serem portadoras do vírus HIV, e 16 crianças (2,5\%) que não permaneceram no programa pelo tempo mínimo de seis meses, o que totalizou 724 crianças acompanhadas neste estudo.

Os critérios de inscrição no programa obedeceram à Portaria GM/MS $\mathrm{n}^{\circ} 709$ de 11 de junho de 1999. Vale destacar, em relação à faixa etária e período de permanência, o que se segue:

"Todàs as crianças inscritas na recuperação nutricional deverão receber a suplementação alimentar por pelo menos 12 meses e até que completem, no mínimo, 24 meses de idade. Ou seja, o desligamento da suplementação ocorrerá aos 24 meses de idade para as crianças inscritas antes de 01 ano de idade (crianças inscritas entre 6 e 12 meses de idade) e 12 meses após a inscrição para as demais crianças (crianças inscritas entre 13 e 23 meses de idade)."

\subsection{Atividades desenvolvidas:}

As atividades desenvolvidas junto às famílias das crianças inscritas no ICCN incluíam a suplementação alimentar e ações educativas.

\subsubsection{Suplementação Alimentar:}

Como suplemento alimentar foi fornecido leite em pó integral em cotas mensais de $3,5 \mathrm{~kg}$ (7 latas) e 1 lata de óleo de soja por criança/mês.

A orientação quanto à administração deste suplemento para a criança está descrita a seguir:

- 4 mamadeiras/dia $\rightarrow 200 \mathrm{ml} /$ mamadeira $\rightarrow$ volume total: $800 \mathrm{ml} /$ dia

- 1 colher de chá $(2,5 \mathrm{~g})$ de óleo de soja/mamadeira $\rightarrow$ volume total: $10 \mathrm{~g} /$ dia

O valor energético, em calorias, do leite em pó e do óleo, atinge aproximadamente $580 \mathrm{Kcal} /$ dia e o conteúdo protéico $28,8 \mathrm{~g} / \mathrm{dia}$, se 
consumido integralmente pela criança na diluição e quantidade recomendadas.

A contribuição do suplemento fornecido, em percentual de adequação das necessidades diárias para cada idade, é apresentada no Quadro 01.

QUADRO 01 - Contribuição dietética do suplemento em percentual das recomendações diárias segundo faixa etária.

\begin{tabular}{|c|c|c|c|c|c|c|c|}
\hline $\begin{array}{l}\text { Idade } \\
\text { Adequacăo }\end{array}$ & $\begin{array}{l}\text { Média de } \\
\text { peso } \\
\text { (*)kg }\end{array}$ & $\begin{array}{l}\text { Necess } \\
\text { de ene } \\
\text { (Kcal/h } \\
(* *)\end{array}$ & de & \% adequação & $\begin{array}{l}\text { Necessic } \\
\text { proteina } \\
(\mathrm{g} / \mathrm{kg})\end{array}$ & & $\%$ \\
\hline \multicolumn{8}{|l|}{ Meses } \\
\hline $6-9$ & 8,5 & 95 & 810 & 71,6 & 1,65 & 14,0 & 205,7 \\
\hline $9-12$ & 9,5 & 100 & 950 & 61,0 & 1,50 & 14,3 & 201,4 \\
\hline $12-24$ & 11,0 & 105 & $1: 150$ & 50,4 & 1,20 & 13,2 & 218,2 \\
\hline $24-36$ & 13,5 & 100 & 1.350 & 42,9 & 1,15 & 15,5 & 185,8 \\
\hline
\end{tabular}

Fonte: Organización Mundial de la Salud. Necesidades de energia y proteinas. Ginebra. 1985.

(*) Dados do NCHS: média no ponto médio do intervalo de idade

(**) Dados do quadro 21 (Informe da FAO/OMS, 1985) até 1 ano de idade e do quadro 23 de 1 - 10 anos.

O criança recebia o suplemento alimentar a cada comparecimento no serviço, o que deveria perfazer um total de $42 \mathrm{~kg}$ de leite (84 latas) e 12 latas de óleo de soja por criança ao longo de 12 meses de programa. Como não ocorreram falhas na entrega da suplementação, exceto no mês de julho de 2000, no entanto, no mês seguinte a criança recebeu duas cotas (julho e agosto), somente não recebeu esta quantidade a criança que eventualmente faltou à consulta.

\subsubsection{Ações Educativas:}

No Brasil, o Ministério da Saúde, com mais intensidade a partir da década de 80 , vem promovendo junto à rede pública os cartões de crescimento hoje denominado Cartão da Criança. Através do registro de peso na curva contida neste cartão é possível para a mãe visualizar e acompanhar o crescimento dos seus filhos, além de propiciar um maior contato das mães 
com os profissionais de saúde, favorecendo a adoção de um comportamento preventivo quanto à utilização dos serviços de saúde e introduzindo as mães em outras ações de promoção de saúde (UNICEF, 1987).

Entre as atividades educativas desenvolvidas no ICCN em Mogi das Cruzes, as mães eram orientadas a acompanhar a evolução das crianças através do registro do peso para idade no Cartão da Criança, com verificação mensal.

Neste mesmo cartão, verificava-se as consultas realizadas na UBS e a vacinação, sendo a mãe estimulada a manter atualizada a vacina e a periodicidade da consulta médica. Desenvolvia-se palestras com as mães abordando temas diversos, tais como: parasitoses intestinais, anemia ferropriva, diarréia e soro caseiro, alimentação adequada para idade, aleitamento materno, aproveitamento de alimentos não convencionais, entre outros.

Adicionalmente, orientava-se o preparo e a diluição da mamadeira, os cuidados higiênico-sanitários com os alimentos, assim como os cuidados de higiene com a criança.

\subsection{Avaliação do estado nutricional da criança ao ingressar no ICCN:}

No nível populacional, a identificação do estado nutricional infantil é realizada a partir das medidas antropométricas de peso e estatura e da idade por serem dados objetivos e de fácil obtenção (SAWAYA, 1997). Obtidos o peso e a estatura, existem diferentes classificações do estado nutricional de acordo com a idade, entre elas, destacam-se: o percentil e escore $z$.

O Ministério da Saúde (MS) preconiza, para avaliação do estado nutricional das crianças, a utilização em serviços de saúde do peso em relação à idade em comparação aos percentis da curva NCHS, nas seguintes categorias para o diagnóstico nutricional:

- Sobrepeso: maior ou igual ao Percentil 97 ( $\geq$ p97); 
Adequado: entre percentil 97 e percentil 10 (inclusive) (p97-p10)

Risco nutricional: entre percentil 10 e percentil 3 (inclusive) $(p 10-p 3)$

Desnutrição: menor que o percentil $3(<\mathrm{p} 3)$.

Propõe que os serviços devem ser organizados de forma a acolher prioritariamente as crianças desnutridas (abaixo de p3) e recomenda vigilância especial nos casos de traçado insatisfatório de todas as crianças, sobretudo nas crianças em risco nutricional (entre p3 e p10). O objetivo da ação é a intervenção precoce e, consequentemente, uma reversão mais rápida e eficaz (ENGSTROM 2002).

A equipe da Área de Alimentação e Nutrição do MS ao propor o ICCN recomendou que fossem inscritas as crianças que apresentassem o peso para idade abaixo de percentil 10 ou curva de crescimento (cartão da criança) com inclinação descendente ou horizontalizada por três consultas consecutivas (MINISTÉRIO DA SAÚDE 2000a).

O escore $z$, outra forma de classificar o estado nutricional, conforme mencionado, representa a variabilidade de um determinado parâmetro entre os indivíduos. Ele representa a distância, medida em unidades de desvio padrão, que os vários valores daquele parâmetro podem assumir na população em relação ao valor médio que a mesma representa.

$\mathrm{O}$ escore $\mathrm{z}$ de uma parâmetro individual, qualquer que seja: peso, estatura, perímetro cefálico, etc. é a relação da diferença entre o valor medido naquele indivíduo e o valor médio da população de referência dividida pelo desvio padrão da mesma população, representado pela fórmula:

Escore $\mathbf{z}=\frac{\text { (valor observado para o indivíduo })-\left(\text { valor da média do referencial }{ }^{*}\right)}{}$

Desvio-padrão da população de referencia*

*O valor da média assim como do desvio padrão são aqueles de referência para o mesmo grupo de idade e sexo 
A Figura 1 representa a correspondência entre percentil (p) e o escore $\mathrm{Z}$, para os principais pontos de corte habitualmente utilizados na definição de risco, tendo por base a distribuição normal (ou curva de Gauss), a qual se aplica para a maioria dos parâmetros antropométricos utilizados no acompanhamento do crescimento (MINISTÉRIO DA SAÚDE 2002).

FIGURA 01 - Correspondência entre valores de escore $z$ e percentis, em diferentes pontos de corte e sua posição relativa na Curva de Gauss.

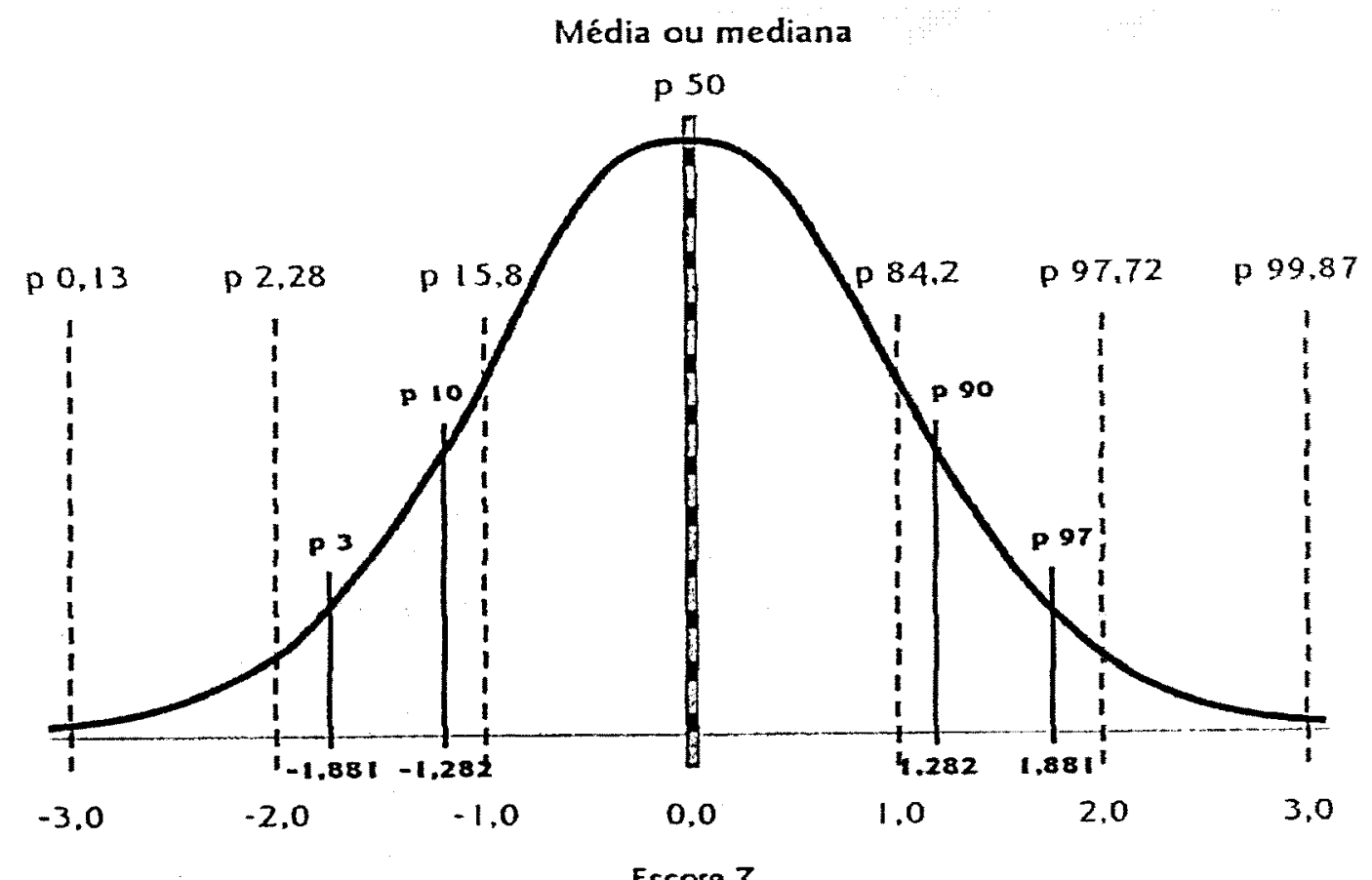

Escore Z

Os principais pontos de corte utilizados de escore $\mathrm{z}$ e de percentis estão representados a seguir na Tabela 01: 
TABELA 01 - Correspondência entre alguns pontos de corte de escore $z$ e de percentis.

\begin{tabular}{cccc}
\hline $\begin{array}{c}\text { Percentis (mais } \\
\text { usados) }\end{array}$ & Escore Z & Percentis & $\begin{array}{c}\text { Escore Z } \\
\text { (mais usados) }\end{array}$ \\
\hline 10 & $-1,29$ & 15,80 & -1 \\
3 & $-1,88$ & 2,28 & -2 \\
1 & $-2,33$ & 0,13 & -3 \\
\hline
\end{tabular}

Neste estudo optou-se pelo uso do escore $z$, para avaliar o estado nutricional e a evolução nutricional, uma vez que este tipo de classificação padroniza as medidas antropométricas, independentemente da idade, além de ser amplamente utilizado na avaliação do estado nutricional de crianças beneficiadas por programas de suplementação alimentar (LEI e col 1989; SANTOS FILHO 1991; VASCONCELOS 1996; GOULART 1998; CASTRO 1999) e recomendado pela Organização Mundial da Saúde (WHO 1995).

O padrão de referência utilizado foi o National Center for Health Statistic (NCHS), elaborado a partir de dados obtidos de crianças brancas, americanas, de classe média, através de estudos longitudinais realizados nos Estados Unidos de 1929 a 1975, e adotado pelo Ministério da Saúde como referência para a população brasileira.

Para diagnóstico do estado nutricional foram definidos os valores de escore Z, conforme Quadro 02 (WHO 1995):

QUADRO 02 - Diagnóstico nutricional segundo escore z.

\begin{tabular}{|l|l|}
\hline Diagnóstico & Escore $z$ \\
\hline Eutrófico & Igual ou superior $a-1(\geq-1)$ \\
\hline Risco & De -2 a menos que $-1(\geq-2 e<-1)$ \\
\hline Desnutrição Moderada & Menor que -2 e superior $a-3(<-2 e>-3)$ \\
\hline Desnutrição Grave & Igual ou inferior $a-3(\leq-3)$ \\
\hline
\end{tabular}

Fonte: Ferreira (2000) adaptado de Barros \& Victora

$\mathrm{O}$ estado nutricional foi avaliado segundo o escore $\mathrm{z}$, para os índices peso/idade, altura/idade e peso/altura, uma vez que refletem processos diferentes. 
O crescimento linear medido pelo índice antropométrico altura/idade, tradicionalmente conhecido como índice de desnutrição passada ou pregressa, reflete o passado de vida e de condições de saúde da criança submetida, por longo período, à situação de pobreza, principalmente no que diz respeito ao seu padrão de doenças e sua alimentação deficiente.

O peso/idade pode estar relacionado tanto com o passado nutricional da criança como com problemas atuais que resultem em perda de peso ou ganho insuficiente de peso, sendo, portanto, um índice que pode refletir deficiência conjunta de peso e de altura.

Por sua vez, o peso/altura indica o estado nutricional atual, expressando a relação da massa corporal para estatura, a harmonia das dimensões. Pode ser eventualmente utilizado como complementar ao diagnóstico nutricional, não devendo ser usado isoladamente, dispensa 0 conhecimento da idade. Avalia o déficit ou excesso de peso (sobrepeso) em relação à altura (POST e col. 1999; LEI e col. 2002; MINISTÉRIO DA SAÚDE/OPAS 2002).

\subsection{Avaliação da evolução nutricional:}

Para avaliar a evolução nutricional das crianças durante a exposição ao ICCN selecionou-se o índice altura/idade, por apresentar maior sensibilidade em detectar desvios das dimensões corporais determinadas pela desnutrição e pelo fato do crescimento linear, medido por este índice, ser o que se apresenta mais comprometido nas crianças brasileiras (MINISTÉRIO DA SAÚDE/OPAS, 2002).

Segundo ONIS e col. (2001) o atraso do crescimento, evidenciado através da altura para idade, é o que melhor reflete os efeitos cumulativos a longo prazo de uma alimentação deficiente e o de infecçōes recorrentes. 
Destaca-se que em razão dos déficits estaturais requererem um prazo mais longo e insidioso de carência nutricional para ocorrerem, ele é considerado um índice menos sensível a pequenas oscilações nutricionais como no caso do peso para idade.

Como os programas de suplementação alimentar são propostos com 0 objetivo de recuperar crianças que apresentam déficits nutricionais, a exemplo do critério proposto por CASTRO (1999) para avaliar a evolução nutricional de crianças inscritas no programa "Leite é Saúde" no município do Rio de Janeiro, adotou-se como efeito positivo do programa variações médias do índice altura/idade significativamente superiores a zero escore $\mathrm{z}$ $(0,0)$.

Considerando que as crianças foram inscritas no ICCN por estarem desnutridas ou em risco nutricional por não apresentarem o ritmo de crescimento esperado para idade e sexo, a partir do momento que sua evolução é superior à prevista pelo padrão de referência, após uma intervenção, este resultado poderia ser considerado positivo e o objetivo do programa atingido.

\subsection{Variáveis estudadas:}

Foram separadas em três grupos: variáveis dependentes, variáveis explanatórias relacionadas à criança e variáveis explanatórias relacionadas à família, conforme descrito a seguir: 
QUADRO 03 - Variáveis dependentes. Mogi das Cruzes, 2002.

\begin{tabular}{|l|l|l|}
\hline Variáveis dependentes & Metodologia para obtenção dos dados & Categorias \\
\hline Peso ao entrar no programa & $\begin{array}{l}\text { Medido em balança eletrônica pediátrica } \\
\text { "Filizola" com divisão de 5,0 g e capacidade } \\
\text { máxima de } 15 \mathrm{~kg} \text { - Modelo Baby }\end{array}$ & $\begin{array}{l}\text { Contínua, expresso em } \\
\text { escore z }\end{array}$ \\
\hline $\begin{array}{l}\text { Pesos subsequentes até } \\
\text { completar } 12 \text { meses de } \\
\text { programa }\end{array}$ & $\begin{array}{l}\text { Medido em balança eletrônica pediátrica } \\
\text { "Filizola" com divisão de 5,0 g e capacidade } \\
\text { máxima de } 15 \mathrm{~kg} \text { - Modelo Baby }\end{array}$ & $\begin{array}{l}\text { Contínua, expresso em } \\
\text { escore z }\end{array}$ \\
\hline Estatura ao entrar no programa & $\begin{array}{l}\text { Medida em antropômetro de madeira seguindo as } \\
\text { técnicas recomendadas (World, 1995) }\end{array}$ & $\begin{array}{l}\text { Contínua, expresso em } \\
\text { escore z }\end{array}$ \\
\hline $\begin{array}{l}\text { Estaturas subscquentes até } \\
\text { completar } 12 \text { meses de } \\
\text { programa }\end{array}$ & $\begin{array}{l}\text { Medida em antropômetro de madeira seguindo as } \\
\text { técnicas recomendadas (World, 1995) }\end{array}$ & $\begin{array}{l}\text { Continua, expresso em } \\
\text { escore z }\end{array}$ \\
\hline
\end{tabular}

QUADRO 04 - Variáveis explanatórias relacionadas à criança. Mogi das Cruzes, 2002.

\begin{tabular}{|l|l|l|}
\hline $\begin{array}{l}\text { Variáveis Explanatórias } \\
\text { Relacionadas à criança }\end{array}$ & Metodologia para obtenção dos dados & Categorias \\
\hline Peso ao nascer & $\begin{array}{l}\text { Informado pela mãe e confirmado através da } \\
\text { Declaração de Nascido Vivo, fornecido pelo } \\
\text { hospital por ocasião do nascimento da criança }\end{array}$ & $\begin{array}{l}\text { Categorias de Peso: } \\
\text { Baixo: } 2500 \mathrm{~g} \\
\text { Inadequado:2500-2999g } \\
\text { Adequado: } \geq 3000 \mathrm{~g}\end{array}$ \\
\hline Idade na inclusão no programa & $\begin{array}{l}\text { Calculado a partir da data de inclusão no } \\
\text { programa menos a data de nascimento }\end{array}$ & $\begin{array}{c}\text { Categorizado em meses } \\
6-11 \text { meses } \\
12-24 \text { meses } \\
>24 \text { meses }\end{array}$ \\
\hline Aleitamento Materno & Tipo e tempo de aleitamento oferecido & $\begin{array}{l}\text { Materno Exclusivo } \\
\text { Materno Predominante } \\
\text { Materno Complementar } \\
\text { Artificial }\end{array}$ \\
\hline Internação no periodo & Informado pela mãe & $\begin{array}{l}\text { Sim } \\
\text { Não }\end{array}$ \\
\hline
\end{tabular}


QUADRO 05 - Variáveis explanatórias relacionadas à família. Mogi das Cruzes, 2002.

\begin{tabular}{|c|c|c|}
\hline $\begin{array}{l}\text { Variáveis Explanatórias } \\
\text { Relacionadas à Familia }\end{array}$ & Metodologia para obtenção dos dados & Respectivas Categorias \\
\hline Estado nutricional materno & $\begin{array}{l}\text { Obtido através do peso e estatura da mãe no } \\
\text { ingresso da criança ao ICCN }\end{array}$ & \begin{tabular}{|lr} 
IMC & \\
Desnutrida & $<18,5$ \\
Eutrofica & $18,5-24,9$ \\
Sobrepeso & $25-29,9$ \\
Obesidade & $\geq 30,0$ \\
\end{tabular} \\
\hline Escolaridade da mãe e do pai & Anos de estudo & $\begin{array}{l}\text { Sem estudo } \\
1-4 \text { anos } \\
>4 \text { anos }\end{array}$ \\
\hline Renda familiar & $\begin{array}{l}\text { Renda total mensal da familia em salários } \\
\text { mínimos }\end{array}$ & $\begin{array}{l}<1 \text { s.m. } \\
1-3 \text { s.m. } \\
>3 \text { s.m. }\end{array}$ \\
\hline Idade materna & Informação referida pela mãe & $\begin{array}{l}<20 \text { anos } \\
20-40 \text { anos } \\
>40 \text { anos }\end{array}$ \\
\hline Trabalho materno & Atividade exercida pela mãe fora do lar & $\begin{array}{l}\text { Sim } \\
\text { Não }\end{array}$ \\
\hline Número de filhos & Foram considerados os filhos vivos & $\begin{array}{l}\text { Até } 3 \\
>3\end{array}$ \\
\hline Constituição familiar & $\begin{array}{l}\text { Foi considerado o número de pessoas que moram } \\
\text { com a criança }\end{array}$ & $\begin{array}{l}<3 \text { pessoas } \\
\geq 3 \text { pessoas }\end{array}$ \\
\hline Condições de habitação & $\begin{array}{l}\text { Foram considerados: } \\
\text { Casa } \\
\text { Água tratada } \\
\text { Esgoto } \\
\text { Coleta de Lixo } \\
\text { Poço } \\
\end{array}$ & $\begin{array}{l}\text { Própria, alugada, coletiva, } \\
\text { cedida } \\
\text { Sim, não } \\
\text { Sim, não } \\
\text { Sim, não } \\
\text { Sim, não } \\
\end{array}$ \\
\hline Plancjou a gravidez & Informação referida pela mãe & $\begin{array}{l}\text { Sim } \\
\text { Não }\end{array}$ \\
\hline Filho magro & Percepção da mãe em relação ao filho & $\begin{array}{l}\text { Sim } \\
\text { Não }\end{array}$ \\
\hline Situação da gestação & $\begin{array}{l}\text { Realização de Pré-Natal } \\
\text { Tempo de Gestação } \\
\text { Inicio de Pré-natal } \\
\text { Número de Consultas } \\
\end{array}$ & \begin{tabular}{|l|} 
Sim \\
Não \\
Termo \\
Pré-termo \\
Continua \\
Continua \\
\end{tabular} \\
\hline $\begin{array}{l}\text { Aquisição de trabalho por } \\
\text { algum membro da familia no } \\
\text { período em que a criança } \\
\text { permaceceu no programa }\end{array}$ & $\begin{array}{l}\text { Informação referida pela mãe e/ou responsável ao } \\
\text { final de } 12 \text { meses de programa }\end{array}$ & $\begin{array}{l}\text { Sim } \\
\text { Não }\end{array}$ \\
\hline
\end{tabular}

${ }^{*} \mathrm{IMC}=$ peso $(\mathrm{kg}) /$ altura ${ }^{2}(\mathrm{~m})$ 
A tomada das medidas antropométricas e a aplicação da entrevista com as mães (anexo 1) foram realizadas por alunas da $4^{\text {a }}$ série do Curso de Nutrição da Universidade de Mogi das Cruzes, devidamente treinadas e supervisionadas pela autora do projeto.

O local, onde se realizava a entrega do suplemento (leite e óleo) e o atendimento mensal às crianças, era o Centro Esportivo aberto à comunidade próximo à Prefeitura que foi designado pela Secretaria de Saúde. Ali havia também um centro de atendimento médico aos funcionários da prefeitura e, como havia espaço suficiente, ficou centralizado neste local o estoque do suplemento alimentar.

A tomada de peso foi feita usando-se balança eletrônica pediátrica digital FILIZOLA com capacidade para $15 \mathrm{~kg}$ e divisões de $5,0 \mathrm{~g}$; a tomada de comprimento foi feita usando-se antropômetro de madeira comercial, seguindo as recomendações adequadas para esta faixa etária (WHO, 1995).

A tomada de peso foi realizada com a criança despida. A seguir é descrito o método utilizado para a tomada do comprimento das crianças até 24 meses, acompanhado da ilustração do antropômetro utilizado.

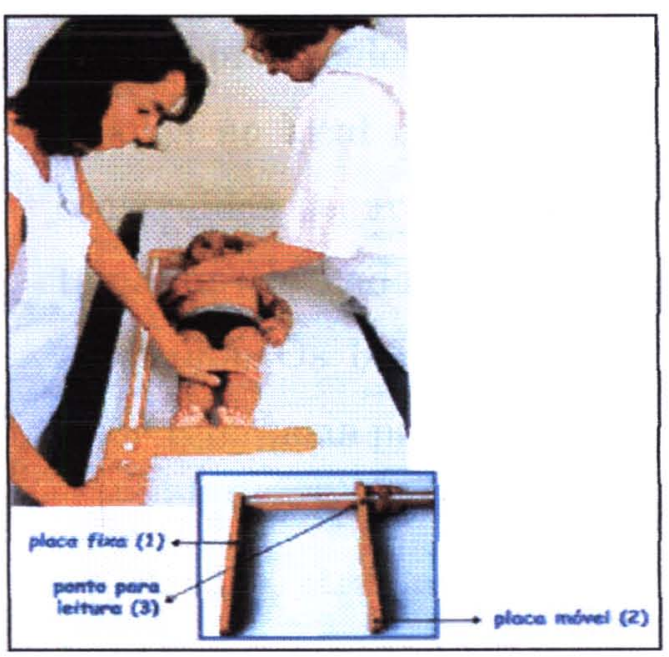

Fonte: Coleção Vencendo a Desnutrição (3) Abordagem clinica e preventiva. Ed. Salus Paulista, 2002.
Para medir o comprimento utilizou-se um antropômetro horizontal em madeira com fita métrica de $100 \mathrm{~cm}$ e escala de $1 \mathrm{~mm}$. Há duas placas de madeira acopladas à régua de madeira graduada $\mathrm{em} \mathrm{cm}$ formando ângulos de $90^{\circ}$, uma delas é fixa onde se encontra a marca zero, e onde foi encostada a cabeça da criança. A outra é móvel para que possa ajustar-se aos pés da criança e permitir a leitura do seu comprimento. 
Para crianças maiores de $\mathbf{2 4}$ meses foi medida a altura (criança em pé) utilizando-se fita métrica com divisões em centímetros e subdivisões em milímetros, afixada na parede sem rodapé, e um esquadro de madeira com um ângulo de $90^{\circ}$.

\subsection{Análise dos dados:}

Para a criação do banco de dados, utilizou-se o programa EPI INFO v. 6.0. A avaliação do estado nutricional foi realizada através do programa EPINUT, sendo este um dos módulos do EPI INFO (DEAN e col. 1994). Posteriormente, para análise dos dados foi utilizado o programa STATA (STATA CORP 2003).

O banco foi estruturado de modo a permitir a análise de medidas repetidas, criando-se uma chave que identifica cada indivíduo e seus vários registros ao longo do tempo.

Inicialmente foram construídos dois bancos de dados no programa EPI INFO para o registro das informações, sendo um com os dados das crianças e das famílias e outras varáveis descritivas (conforme quadros 04 e 05) e 0 outro com os dados antropométricos (peso e estatura) obtidos a cada visita da criança ao local de distribuição do leite (Quadro 03). Estes bancos foram construídos separadamente, pois a quantidade de variáveis e, portanto, o tamanho de cada registro, era maior do que o máximo suportado pelo programa. Os bancos tiveram o número de prontuário, único no sistema, como referência para seu controle e posterior junção.

A inserção dos dados foi realizada através de dupla digitação pelas estagiárias, treinadas para esta operação, sendo verificados em sua totalidade. Utilizou-se também o programa CHECK, integrante do EPI INFO para o controle de entrada dos dados, através da delimitação das faixas possíveis dos valores digitados para cada tipo de variável. 
Adicionalmente para análise da consistência do banco de dados foram verificadas as ocorrências das indicações de erros do EPINUT (Flags), com especial atenção para os valores extremos (pesos e alturas inferiores a $-\mathbf{5}$ escore $\mathrm{Z}$ do padrão NCHS), para os quais foram observadas as medidas subsequentes para detectar "variações improváveis" de peso (ganho ou perda diária superior a $100 \mathrm{~g}$ ) e de altura (perda ou ganho superior a $5 \mathrm{~cm}$ mensal), não tendo sido necessário exclusão de dados.

Após esta verificação os bancos foram exportados pelo programa EPI INFO, gerando arquivos do tipo DBASE IV, os quais foram, em seguida, importados no programa ACCESS como bancos tipo MDB.

Dentro do programa ACCESS foram construídos os módulos de programação para tratamento e geração da saída das tabelas com os campos e formatos adequados para a importação pelo programa STATA v.8.0. Os códigos associados aos módulos referidos estão listados no anexo 7 .

Foi definida como variável dependente contínua a medida do escore $\mathrm{z}$ para altura/idade nos grupos de desnutrido, risco e eutrófico. Há que se destacar que a terminologia "comprimento para idade" é proposta para uso com crianças menores de 24 meses em razão de que sua tomada é feita com a criança deitada. Para crianças maiores de 24 meses (29) foi tomada a altura e optou-se neste estudo pela utilização da terminologia "altura para idade" para todas as crianças afim de padronizar a linguagem.

As médias do escore $\mathrm{z}$ para altura/idade foram descritas segundo as variáveis explanatórias selecionadas, conforme descrito anteriormente.

Os dados foram analisados como estudo de painel. Este estudo pode ser considerado um tipo de estudo de coorte prospectivo onde as informações são vistas para um mesmo conjunto de pessoas (painel) em múltiplos intervalos de tempo, Ele é um estudo longitudinal que permite o acompanhamento de variáveis de interesse e as possíveis correlações com 
outras variáveis. A ordenação temporal dos eventos sob observação facilita a investigação das relações entre causas e efeitos (KELSEY e col. 1996).

Utilizou-se a técnica de regressão linear múltipla com o modelo de equações de estimativas generalizadas (GEE - Generalized Estimating Equations) para distribuição normal. Este modelo é, adequadamente, aplicável para ajustar dados em amostras dependentes, controlando os efeitos de auto-correlação (HORTON e col. 1999).

As variáveis ajustadas no modelo foram selecionadas através do valor de $\mathrm{p}$ do teste de Wald (STATA CORP 2003), calculado na análise univariada. Foram ajustadas, no modelo multivariado, todas as variáveis que tiveram no teste de Wald valor de $\mathrm{p}$ igual ou menor que 0,25 .

Este corte em 0,25 para o valor de p para o ajuste da variável no modelo vem no sentido de não tornar muito restrito a entrada de variáveis neste, pois a associação observada em uma análise mais simples pode ser modificada na presença de outras variáveis. Por outro lado, é necessário o cuidado para não ser excessivo o número de variáveis, pois pode-se ocasionar prejuízos à modelagem (HOSMER e LEMESHOW 1989).

A modelagem partiu de um modelo simples para um mais complexo, passo a passo, ajustando-se as variáveis no modelo em ordem de importância estatística, ou seja, do menor valor de p para o maior.

Para estimar a importância de uma variável para o modelo utilizou-se a diferença da deviance do modelo com a variável analisada e sem ela; com este valor estimou-se o valor assintótico do Qui quadrado e a probabilidade (p) correspondente (STATA CORP 2003).

Avaliou-se como tendência significativa do escore $\mathrm{z}$ os coeficientes cujo valor do $p$, no teste de Wald, fossem menor do que 0,05 e, também, pela precisão da estimativa do coeficiente (intervalo de confiança de 95\%), calculados para cada categoria das variáveis presentes no modelo. 
Para as variáveis que mostraram associação com uma tendência significativa do escore $\mathrm{z}$ no modelo final, discutiu-se a força da associação pela sua contribuição para o resultado final, considerando-se o valor do coeficiente maior do que zero.

Considerou-se que uma variável era de confundimento quando, após o ajuste multivariado, o valor do coeficiente caiu ou elevou-se em $15 \%$ do valor obtido na univariada (GREENLAND 1989).

\subsection{Conduta Ética:}

O projeto foi aprovado pelo Comitê de Ética da Faculdade de Saúde Pública da Universidade de São Paulo.

Os responsáveis pelas crianças foram convidados a participar do estudo e assinar o termo de consentimento (anexo 2). As pessoas eram informadas quanto ao seu direito de recusa e que a não participação não implicaria em nenhuma restrição ao programa, ou seja, o acesso à suplementação alimentar bem como aos cuidados nutricionais.

As crianças foram pesadas e medidas, receberam o suplemento alimentar e os responsáveis receberam orientação quanto ao preparo da mamadeira (diluição do leite em pó e acréscimo de óleo afim de aumentar o aporte calórico), quanto à alimentação adequada para idade com estímulo a oferta de alimentos ricos em ferro e a não substituição da refeição de sal por leite.

Crianças que necessitaram de atenção especial, por exemplo portadoras de deficiência física com dificuldades de locomoção, foram encaminhadas para a Secretaria da Saúde Municipal, onde receberam o atendimento da Assistência Social para as providências necessárias. 


\section{RESULTADOS:}

Neste capítulo os resultados são apresentados em quatro módulos; o primeiro refere-se às "Características da População"; no segundo é apresentada a "Avaliação do Estado Nutricional" das crianças ao ingressarem no Programa de Incentivo ao Combate às Carências Nutricionais (ICCN); no módulo três são apresentados os resultados referentes à evolução nutricional das crianças acompanhadas longitudinalmente por 12 meses com o título "Evolução do Estado Nutricional"; no quarto módulo são apresentados os "Fatores Associados à Recuperação Nutricional" das crianças.

\subsection{Características da população:}

Os dados sócio-demográficos apresentados referem-se ao momento de inscrição da criança no ICCN, à exceção da variável trabalho novo, que foi verificada no momento da alta da criança e a ocorrência de internação verificada ao longo do acompanhamento.

\subsubsection{Características das crianças:}

Neste tópico é apresentada a distribuição das crianças por sexo e faixa etária ao entrar no programa, assim como informações sobre o peso ao nascer e tipo de aleitamento oferecido nos primeiros seis meses de vida.

TABELA 02 - Distribuição de crianças segundo sexo e faixa etária ao ingressar no ICCN. Mogi das Cruzes, 2002.

\begin{tabular}{rrrrrrr}
\hline \multirow{2}{*}{$\begin{array}{c}\text { Faixa etária } \\
\text { (meses) }\end{array}$} & \multicolumn{2}{c}{ Feminino } & \multicolumn{2}{c}{ SEXO } & \multicolumn{2}{c}{ Total } \\
& $\mathbf{N}$ & $\mathbf{\%}$ & $\mathbf{N}$ & $\mathbf{\%}$ & \multicolumn{1}{c}{$\mathbf{N}$} & \multicolumn{1}{c}{$\%$} \\
\hline $6-11$ & 132 & 32,2 & 101 & 32,2 & 233 & 32,2 \\
$12-24$ & 262 & 63,9 & 200 & 63,7 & 462 & 63,8 \\
$>24$ & 16 & 3,9 & 13 & 4,1 & 29 & 4,0 \\
\hline Total & 410 & 100,0 & 314 & 100 & 724 & 100,0 \\
\hline
\end{tabular}


Verifica-se na Tabela 2, que a composição, segundo a faixa etária, é semelhante entre meninos e meninas, sendo que cerca de 2/3 das crianças estão na faixa etária de 12 a 24 meses $(63,8 \%)$.

Em relação ao tempo de gestação $78,1 \%$ (N 566) nasceram a termo, 21,9\% (N 158) foram pré-termo. A distribuição do peso ao nascer para o conjunto das crianças, cuja informação pode ser examinada através da Declaração de Nascido Vivo (DN), pode ser vista na Tabela 3:

TABELA 03 - Distribuição de crianças segundo peso ao nascer. Mogi das Cruzes, 2002.

\begin{tabular}{ccc}
\hline Peso ao nascer $(\mathrm{g})$ & $\mathrm{N}$ & $\%$ \\
\hline$<2500$ & 159 & 23,7 \\
$2500-2999$ & 228 & 34,1 \\
$\geq 3000$ & 282 & 42,2 \\
\hline Total & 669 & 100,0 \\
\hline
\end{tabular}

Obs:55 crianças $(8,2 \%)$ não dispunham da informação

A Tabela 3 mostra que $57,8 \%$ das crianças tiveram peso ao nascer inferior a $3000 \mathrm{~g}$. Chama também a atenção o percentual elevado $(23,7 \%)$ de crianças que nasceram com baixo peso $(<2500 \mathrm{~g})$. A média do peso ao nascer encontrada foi de 2850 g. e o desvio padrão $595 \mathrm{~g}$.

Em relação ao aleitamento, do total de crianças estudadas, $83,5 \%$ foram amamentadas enquanto $16,5 \%$ não receberam leite materno.

Ao se investigar o tempo de aleitamento materno exclusivo, $18,7 \%$ receberam como única fonte de alimento o leite materno pelo período de 3 a 5 meses; este percentual reduziu-se para $1,7 \%$ no sexto mês. Por outro lado, em relação ao aleitamento predominante ${ }^{2}, 18,6 \%$ das crianças receberam além do leite materno, água, chá e suco no primeiro mês de vida, e ainda, em

${ }^{2}$ aleitamento predominante: leite materno + água + chá ou suco de frutas 
relação ao aleitamento complementar ${ }^{3}$ observou-se que $21,2 \%$ das crianças amamentadas já recebiam leite de vaca no primeiro mês de vida.

\subsubsection{Características Sociais e Ambientais:}

Como as condições ambientais se refletem na qualidade de vida dos indivíduos, estas foram avaliadas através do registro de informações relativas a saneamento básico, como demonstrado na Figura 2 .

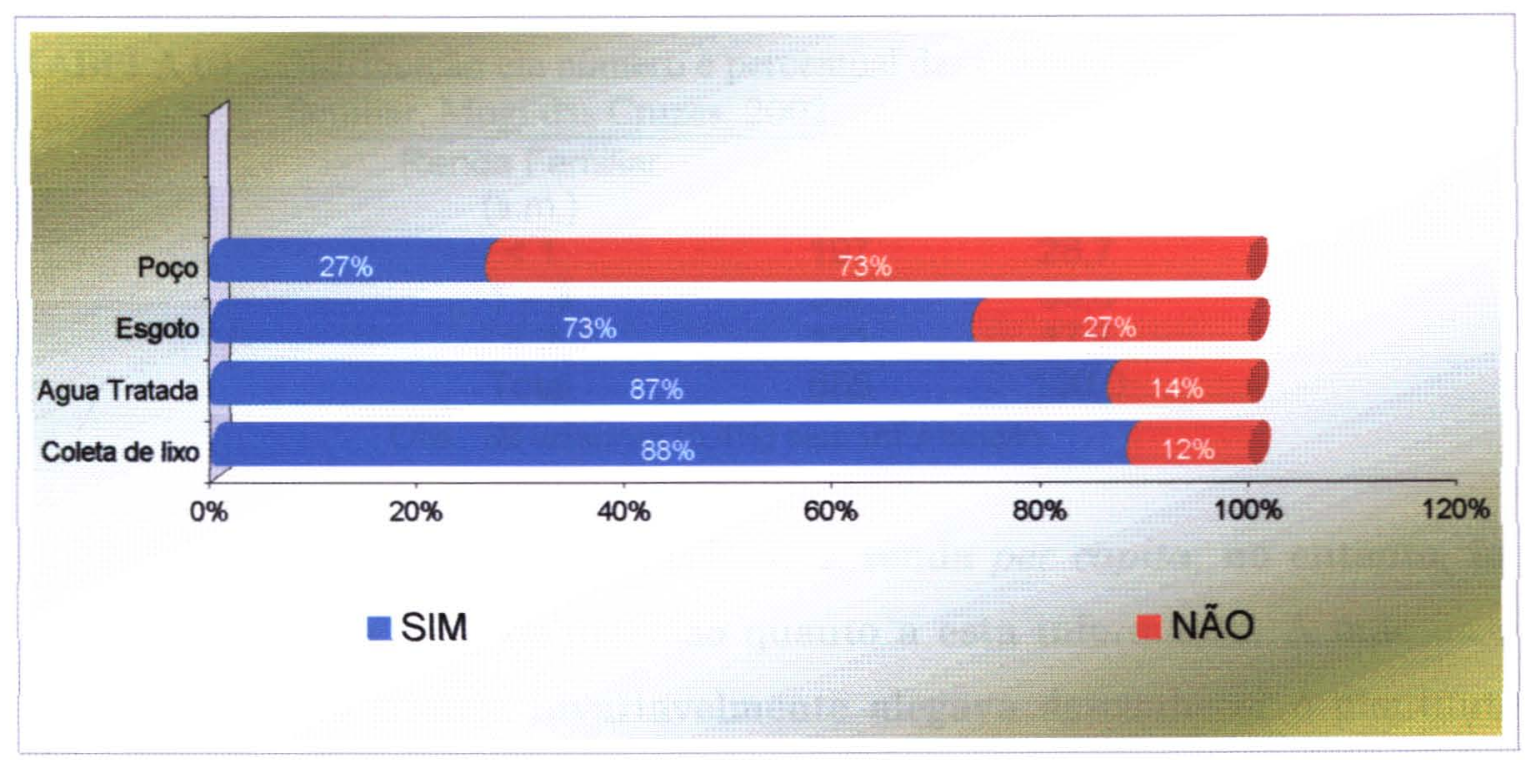

FIGURA 02 - Distribuição (\%) de famílias segundo saneamento básico. Mogi das Cruzes, 2002.

Percebe-se na população estudada uma menor cobertura da rede de esgoto (27,0\%) comparada ao acesso das famílias à água tratada e coleta de lixo. É interessante observar que não somente entre as famílias que não dispunham de água tratada, mas também uma parte daquelas que tinham a disponibilidade do serviço, referiram possuir poço e utilizar a água para

\footnotetext{
${ }^{3}$ aleitamento complementar: leite materno + leite de vaca + outros alimentos
} 
todas as atividades domésticas, na ausência da água de abastecimento público.

Ainda foi investigado o tipo de habitação da família, sendo que 5,7\% moram em casa de madeira. Do total das famílias estudadas, $45 \%$ residem em casa própria, $33 \%$ doada, $19 \%$ pagam aluguel e $3 \%$ residem em casa cedida temporariamente por parentes, amigos ou pela prefeitura.

Os resultados obtidos em relação à renda familiar podem ser vistos na Tabela 4:

TABELA 04 - Distribuição em número e percentual das crianças segundo renda familiar. Mogi das Cruzes, 2002.

\begin{tabular}{ccc}
\hline $\begin{array}{c}\text { Renda Familiar } \\
\text { (s.m.) }\end{array}$ & $\mathrm{N}$ & $\%$ \\
$<1$ & 197 & 28,7 \\
$1-3$ & 367 & 53,6 \\
$>3$ & 121 & 17,7 \\
\hline Total & 685 & 100,0 \\
\hline
\end{tabular}

Obs.: 39 crianças $(5.4 \%)$ sem informação

Inicialmente pretendia-se coletar a renda per capita, no entanto, foi muito freqüente a falta de precisão quanto a esta informação. A mãe ou o responsável pela criança invariavelmente alegava desconhecer o montante recebido na família, mas sentia-se mais segura (o) em relação à faixa de renda. Ainda, o percentual de desempregados foi elevado e, em sua maioria, realizavam "serviços informais" tais como: ajudante de pedreiro, vendedor ambulante, faxineira, passador de roupa, entre outras, o que propiciava uma renda mensal flutuante.

Verifica-se maior freqüencia de famílias com renda entre 1 e 3 salários mínimos (53,6\%); somadas às famílias de menor renda totalizam $82,3 \%$ da população estudada.

Ainda é importante considerar a densidade familiar na questão da renda. Ao se investigar o número de pessoas que moravam com a criança, 
observou-se que $43,0 \%$ das famílias eram compostas por até três pessoas e $57,0 \%$ por famílias com quatro ou mais pessoas. A média de moradores por domicílio foi de 3,7 pessoas.

\subsubsection{Caracteristicas Familiares:}

A educação materna foi verificada e categorizada em anos de estudo conforme demonstrado na Figura 3:

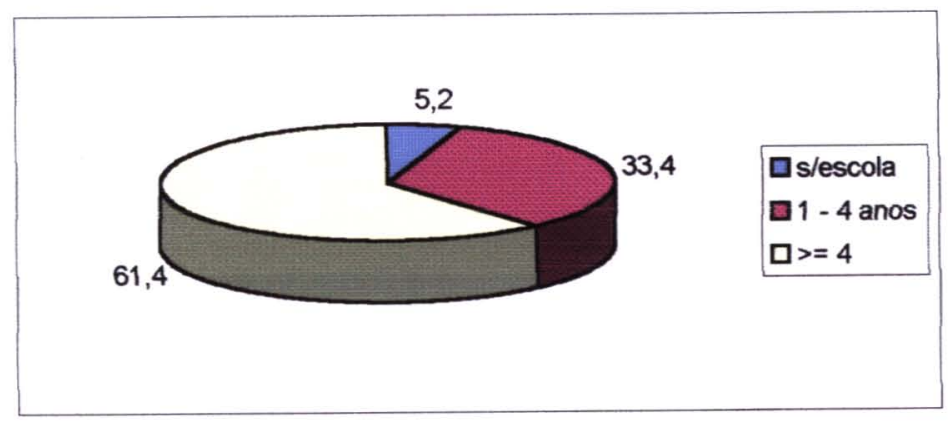

Obs: 19 crianças $(2,7 \%)$ não dispunham de informação.

FIGURA 03 - Distribuição (\%) de mães segundo escolaridade. Mogi das Cruzes, 2002.

Observa-se na Figura 3 que aproximadamente $40 \%$ das mães das crianças inscritas no ICCN não teve instrução ou só teve até quatro anos de estudo, sendo importante destacar que entre as mulheres com maior escolaridade apenas $15,4 \%$ completou o ensino fundamental.

Foi investigado se o pai morava com a criança, o que ocorreu em $86,6 \%$ dos casos. A escolaridade paterna pode ser vista na Tabela 5:

TABELA 05 - Distribuição em número e percentual de pais segundo escolaridade.

Mogi das Cruzes, 2002.

\begin{tabular}{ccc}
\hline Anos de escolaridade & $\mathrm{N}$ & $\%$ \\
\hline Sem escolaridade & 48 & 7,7 \\
$1-4$ & 181 & 28,8 \\
$>4$ & 398 & 63,5 \\
\hline Total & 627 & 100,0 \\
\hline
\end{tabular}

Obs.: 97 crianças $(13,4 \%)$ sem informação. 
É possível verificar, nas diferentes faixas de escolaridade, uma distribuição relativamente uniforme entre pais e mães, sendo que $36,5 \%$ dos pais apresentaram até 4 anos de estudo.

A situação de trabalho materno mostrou que somente $20,0 \%$ (145) exerciam atividade fora de casa. Em relação a idade, 13,5\% das mulheres apresentavam menos de 20 anos, enquanto $83,1 \%$ encontravam-se na faixa etária de 20 a 40 anos e apenas 3,4\% tinham mais de 40 anos de idade.

Foi verificado também o número de irmãos das crianças estudadas o que pode ser visto na Tabela 6:

TABELA 06 - Distribuição em número e percentual de irmãos das crianças inscritas no ICCN. Mogi das Cruzes, 2002.

\begin{tabular}{crc}
\hline Número de irmãos & $\mathrm{N}$ & $\%$ \\
\hline Nenhum & 208 & 28,7 \\
1 & 194 & 26,8 \\
$2-3$ & 280 & 38,7 \\
$>3$ & 42 & 5,8 \\
\hline Total & 724 & 100,0 \\
\hline
\end{tabular}

A Tabela 6 mostra que a maioria das crianças estudadas $(55,5 \%)$, não possuía irmãos ou tinha apenas um, sendo encontrada a média de 3,0 filhos por família.

Ao se verificar a realização do pré-natal, 90,8\% referiram tê-lo feito; foi investigado o número de consultas e o período da gestação em que o mesmo foi iniciado. Os resultados podem ser vistos na Tabela 7: 
TABELA 07 - Distribuição em número e percentual de mães segundo início de pré-natal e número de consultas. Mogi das Cruzes, 2003.

\begin{tabular}{|c|c|c|c|c|c|c|c|c|}
\hline \multirow{3}{*}{$\begin{array}{l}\text { Início do pré- } \\
\text { natal (mês) }\end{array}$} & \multicolumn{8}{|c|}{ Número de Consultas } \\
\hline & \multicolumn{2}{|c|}{ Até 3} & \multicolumn{2}{|c|}{4 a 5} & \multicolumn{2}{|c|}{$\geq 6$} & \multicolumn{2}{|c|}{ Total } \\
\hline & $\mathrm{N}$ & $\%$ & $\mathrm{~N}$ & $\%$ & $\mathrm{~N}$ & $\%$ & $\mathrm{~N}$ & $\%$ \\
\hline$\leq 3$ & - & - & 71 & 16,2 & 366 & 83,8 & 437 & 66,4 \\
\hline 4 & 5 & 3,7 & 89 & 66,4 & 40 & 29,9 & 134 & 20,4 \\
\hline 5 & 6 & 15,4 & 27 & 69,2 & 6 & 15,4 & 39 & 5,9 \\
\hline$\geq 6$ & 15 & 31,3 & 33 & 68,8 & - & - & 48 & 7,3 \\
\hline Total & 26 & 4,0 & 220 & 33,4 & 412 & 62,6 & 658 & 100,0 \\
\hline
\end{tabular}

A média de consultas de pré-natal apresentada pela mulheres estudadas foi de 6,2 com desvio padrão de 2,4 . Observa-se que $66,4 \%$ das mulheres iniciaram o pré-natal no primeiro trimestre e $62,6 \%$ tiveram seis ou mais consultas, o que está de acordo com a recomendação do MINISTÉRIO DA SAUDE (2000b).

Em relação ao tipo de parto, embora tenha predominado o parto normal (71,1\%), foi elevado o percentual de cesáreas (27,7\%); em 1,2\% das mulheres foi realizado fórceps.

Foi verificado junto à mãe se a gravidez havia sido planejada e $81,0 \%$ das mães responderam a esta questão (N 585). Deste total, $62,7 \%$ referiram que não a planejaram.

Para avaliação do estado nutricional das mães foi medido o peso e a estatura daquelas que compareceram ao serviço, o que totalizou 510 (70.4\%). O estado nutricional foi calculado, utilizando-se o Índice de Massa Corporal (IMC), conforme pode ser visto na Tabela 8:

TABELA 08 - Distribuição (\%) de mães de crianças inscritas no ICCN, segundo estado nutricional. Mogi das Cruzes, 2002.

\begin{tabular}{cc}
\hline Estado nutricional & $\%$ \\
\hline Baixo Peso & 6,0 \\
Eutrófica & 58,0 \\
Sobrepeso & 24,2 \\
Obesidade & 11,8 \\
\hline Total & 100,0 \\
\hline
\end{tabular}


A avaliação da situação nutricional das mães por meio do Índice de Massa Corporal mostra que $36,0 \%$ apresentam sobrepeso ou obesidade, com apenas $6,0 \%$ de prevalência de baixo peso. Este resultado chama a atenção, especialmente se considerar aos resultados referentes à prevalência da desnutrição entre as crianças estudadas.

A percepção da mãe, quanto ao estado nutricional da criança ao ingressar no programa, foi avaliada através da pergunta: "a senhora acha que seu filho é magro?”. Responderam a esta questão $75 \%$ das mães e os resultados podem ser vistos na Tabela 9:

TABELA 09 - Distribuição em número e percentual de crianças segundo estado nutricional inicial pelo índice peso/idade e percepção da mãe. Mogi das Cruzes, 2002.

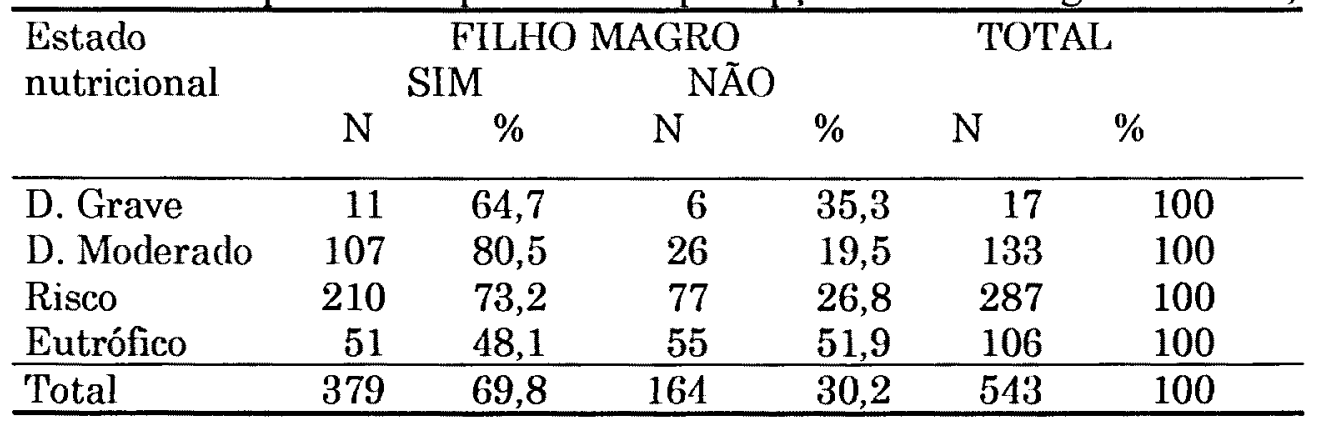

Para avaliar a percepção das mães foi utilizado o índice peso para idade da criança, uma vez que a questão se referia ao peso. É interessante observar que $21,3 \%$ das mães de crianças desnutridas não reconheciam comprometimento nutricional em seus filhos. Este resultado pode refletir, em certo grau, a dificuldade destas mães em relação ao manejo e cuidado das crianças desnutridas.

Por outro lado, também é elevado o percentual de mães de crianças eutróficas que referiram acreditar que seus filhos eram magros (51,9\%). Este resultado pode decorrer do fato da criança ter sido inscrita em um programa de suplementação alimentar, o que consequentemente pode ter induzido este resultado. 


\subsection{Avaliação do Estado Nutricional:}

O estado nutricional das crianças foi avaliado através dos três índices peso/idade, altura/idade e peso/estatura.

$\mathrm{O}$ índice peso/idade reflete o estado nutricional atual, porém não permite que se diferencie o déficit atual do crônico ou passado. $O$ estado nutricional das crianças e a média de escore $\mathrm{z}$, ao ingressarem no ICCN, medidos através deste índice, pode ser visto na Tabela 10 e Figura 4:

TABELA 10 - Distribuição em número e percentual de crianças segundo estado nutricional inicial pelo índice peso/idade. Mogi das Cruzes, 2002.

\begin{tabular}{ccc}
\hline Estado Nutricional & $\mathrm{N}$ & $\%$ \\
\hline Eutrófico & 138 & 19,0 \\
Risco & 386 & 53,3 \\
D. Moderado & 175 & 24,2 \\
D. Grave & 25 & 3,5 \\
\hline Total & 724 & 100,0 \\
\hline
\end{tabular}

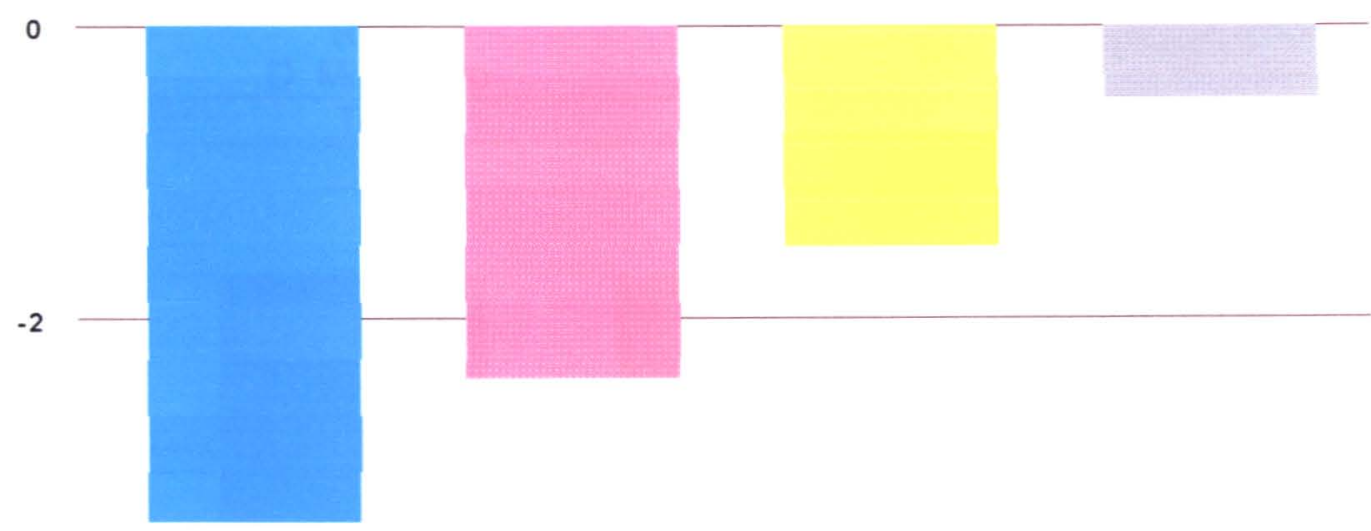

$\begin{array}{ccc}-4 & \text { grave roderado } \\ \text { grau de desnutriçắo } & \text { eutrofico }\end{array}$

FIGURA 04 - Médias dos escores z peso/idade das crianças ao ingressar no ICCN segundo estado nutricional. Mogi das Cruzes, 2002. 
A Figura 4 mostra que o escore $\mathrm{z}$ médio encontrado para as crianças desnutridas graves foi de $-3,40$ (IC95\% -3,54 - -3,24), para os desnutridos moderados $-2,40$ (IC95\% -2,44 - -2,36), para as crianças em risco de desnutrição -1,51 (IC95\% -1,54 - -1,48) e eutróficos apresentaram -0,50 (IC95\% - 0,57--0,42).

Chama a atenção o percentual elevado de desnutridos graves e moderados que, se somados, totalizam $27,7 \%$ da população estudada (escore $\mathrm{z}-<-2,0)$. Ainda é interessante destacar o déficit acentuado de peso para as crianças com desnutrição grave (-3,40 escore $\mathbf{z})$

Os resultados em relação ao índice peso para altura e escore $\mathrm{z}$ das crianças ao ingressar no ICCN podem ser vistos na Tabela 11 e Figura 5:

TABELA 11 - Distribuição em número e percentual de crianças segundo estado nutricional inicial pelo índice peso/altura. Mogi das Cruzes, 2002.

\begin{tabular}{ccc}
\hline Estado Nutricional & $\mathrm{N}$ & $\%$ \\
\hline Eutrofico & 414 & 57,1 \\
Risco & 267 & 37,0 \\
D. Moderado & 43 & 5,9 \\
\hline Total & 724 & 100,0 \\
\hline
\end{tabular}

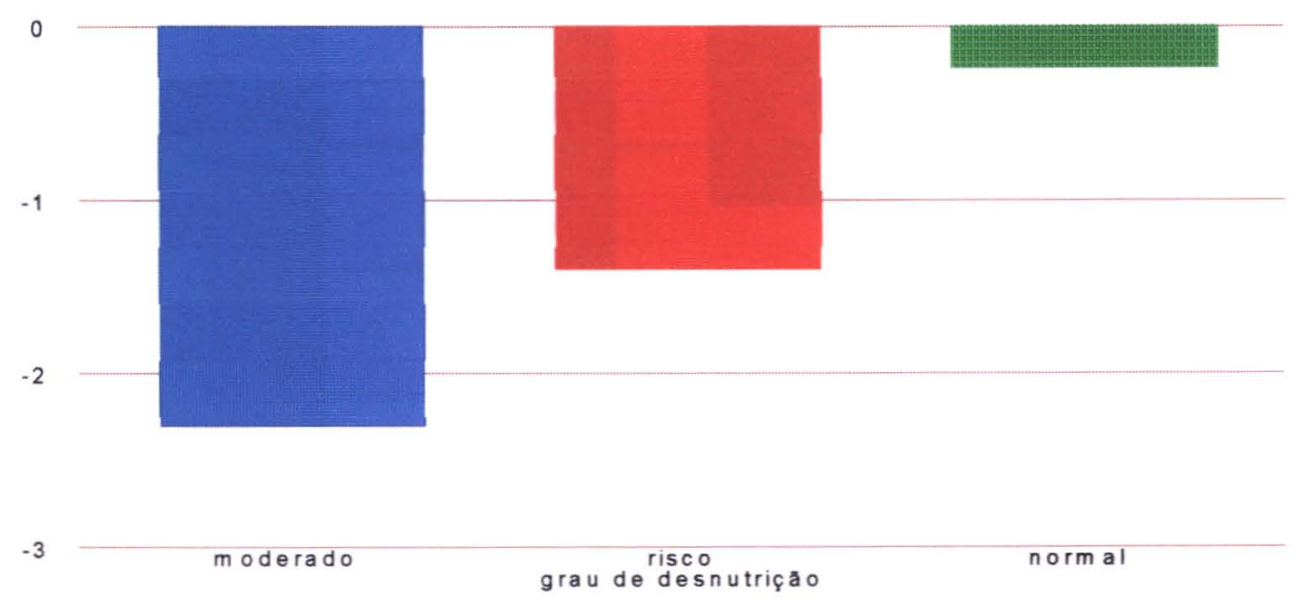

FIGURA 05 - Médias dos escores z peso/altura das crianças ao ingressar no ICCN segundo estado nutricional. Mogi das Cruzes, 2002 
Não são encontradas crianças desnutridas graves pelo índice peso/altura, o escore $\mathrm{z}$ médio encontrado para as crianças com desnutrição moderada foi de $-2,31$ (IC95\% -2,39- -2,22), para as crianças em risco de desnutrição -1,40 (IC95\% -1,43 - -1,37) e eutróficos -0,24 (IC95\% -0,30- $0,18)$.

O percentual de crianças eutróficas segundo este indicador, somado àquele das crianças em risco nutricional, totalizam $94 \%$ da população estudada; este resultado corrobora as pesquisas que têm mostrado a adequação de peso em relação à altura das crianças brasileiras.

$\mathrm{O}$ crescimento linear medido pelo índice antropométrico altura/idade e a média do escore $\mathrm{z}$ pode ser visto na Tabela 12 e Figura 6 :

TABELA 12 - Distribuição em número e percentual de crianças segundo estado nutricional inicial pelo índice altura/idade. Mogi das Cruzes, 2002.

\begin{tabular}{ccc}
\hline Estado Nutricional & $\mathrm{N}$ & $\%$ \\
\hline Eutrófico & 209 & 28,9 \\
Risco & 321 & 44,3 \\
D. Moderado & 150 & 20,7 \\
D. Grave & 44 & 6,1 \\
\hline Total & 724 & 100,0 \\
\hline
\end{tabular}

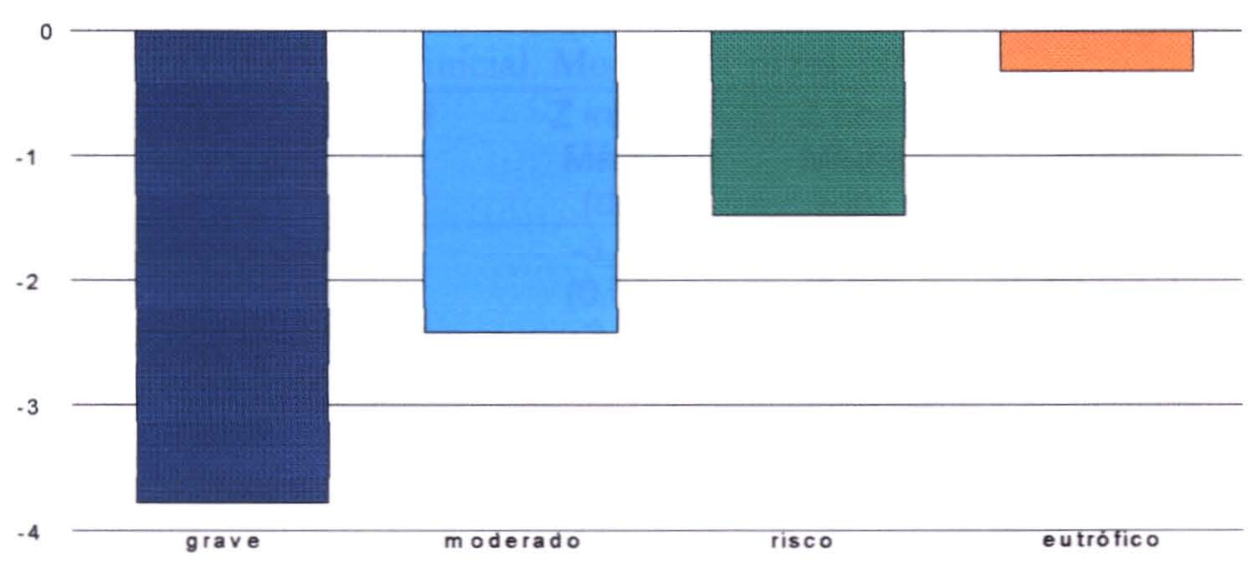

FIGURA 06 - Médias dos escores $\mathrm{z}$ da altura/idade das crianças ao ingressar no ICCN segundo estado nutricional. Mogi das Cruzes, 2002 
A Figura 6 mostra que o escore $\mathrm{z}$ médio encontrado para as crianças desnutridas graves foi de $-3,67$ (IC95\% -3,49 - -3,86), para os desnutridos moderados $-2,46$ (IC95\% $-2,40--2,51$ ), para as crianças em risco de desnutrição -1,48 (IC95\% -1,45 - -1,51) e eutróficos apresentaram -0,38 (IC95\% - 0,30--0.45).

Observa-se um percentual elevado de desnutridos graves $(6,1 \%) \mathrm{e}$ moderados $(20,7 \%)$ que somados, totalizam $26,8 \%$ da população estudada.

Chama atenção também a média do escore $\mathrm{z}$ encontrada para os desnutridos graves $(-3,77)$, o que aponta para um comprometimento importante no crescimento destas crianças.

\subsection{Evolução do Estado Nutricional:}

Como descrito na metodologia, a evolução do estado nutricional das crianças em estudo foi avaliada pelo índice altura para idade.

A evolução nutricional, segundo o estado nutricional inicial e a variação do escore $\mathrm{z}$, pode ser visto na Tabela 13 :

TABELA 13 - Variação do índice altura/idade em 12 meses de programa segundo estado nutricional inicial. Mogi das Cruzes, 2002

\begin{tabular}{cccc}
\hline Estado Nutricional Inicial & $\begin{array}{c}Z \text { inicial } \\
\text { Média }\end{array}$ & $\begin{array}{c}Z \text { final } \\
\text { Média }\end{array}$ & $\begin{array}{c}\text { Variação } \\
\text { Média } \\
(\mathrm{dp})\end{array}$ \\
$\begin{array}{ccc}(\mathrm{d} C \mathrm{C}) \\
\text { Desnutridos Graves }\end{array}$ & $-3,67$ & -2.55 & 1,12 \\
& $(0,60)$ & $(0,72)$ & $(0,80-1,44)$ \\
Desnutridos Moderados & $-2,46$ & $-1,64$ & 0,82 \\
& $(0,28)$ & $(0,66)$ & $(0,67-0,97)$ \\
Risco & $-1,48$ & -0.91 & 0,57 \\
& $(0,27)$ & $(0,63)$ & $(0,47-0,66)$ \\
Eutroficas & $-0,38$ & 0,07 & 0,45 \\
& $(0,54)$ & $(0,73)$ & $(0,30-0,60)$ \\
\hline
\end{tabular}


Os resultados encontrados em relação à evolução nutricional mostram que, a média de ganho de altura foi positiva em todos os grupos de crianças formados a partir do estado nutricional inicial, ou seja, promoveu uma evolução estatural superior ao padrão de referência (escore $z=0,0$ ). Em todos os grupos houve diferenças significantes entre a primeira e a última visita (t pareado, $\quad \mathbf{p}<\mathbf{0 , 0 0 1}$ ). É importante destacar que a evolução no ganho de estatura é diretamente proporcional à gravidade do déficit nutricional, isto é, maior ganho para crianças com maiores déficits.

As Figuras 7, 8, 9 e 10 mostram a tendência da média estimada do escore $\mathrm{z}$ no grupo de crianças desnutridas graves, moderadas, de risco nutricional e eutróficas, respectivamente:

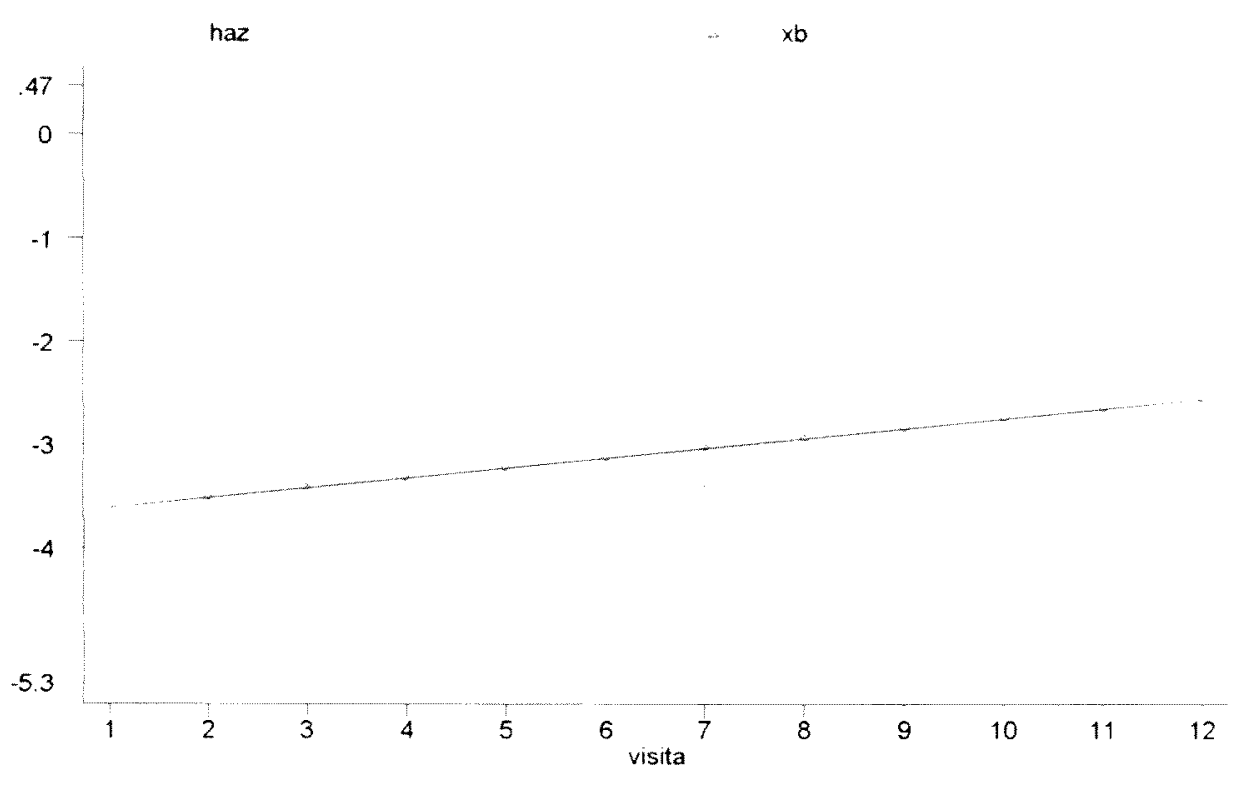

FIGURA 07 - Tendência da média estimada do escore $Z$ segundo visita no grupo de crianças desnutridas graves no início do estudo. Mogi das Cruzes, 2002.

O grupo de crianças desnutridas graves, que no inicio contava com 44 crianças, ao final de doze meses de acompanhamento mantinha 38 crianças no programa (06 abandonaram). $\mathrm{O}$ ganho médio de altura para as crianças 
desnutridas graves foi de 0,10 escore $\mathrm{z}$ por visita para aquelas que permaneceram no programa, o que pode ser visto na Figura 7 .

Os intervalos de variação do escore $\mathrm{z}$ para estas crianças são apresentados na Tabela 14.

TABELA 14 - Distribuição de crianças desnutridas graves segundo intervalos de variação de escore z. Mogi das Cruzes, 2002.

\begin{tabular}{ccc}
\hline Intervalos de escore $\mathrm{z}$ & $\mathrm{N}$ & $\%$ \\
$\geq-0,5-0$ & 3 & 7,9 \\
$>0-<0,5$ & 4 & 10,5 \\
$\geq 0,5$ & 31 & 81,6 \\
\hline
\end{tabular}

Para o conjunto de crianças desnutridas graves $92,1 \%$ obtiveram uma variação superior a 0,0 escore $z$, não havendo ocorrência de variação menor que - 0,5 escore $z$ neste grupo.

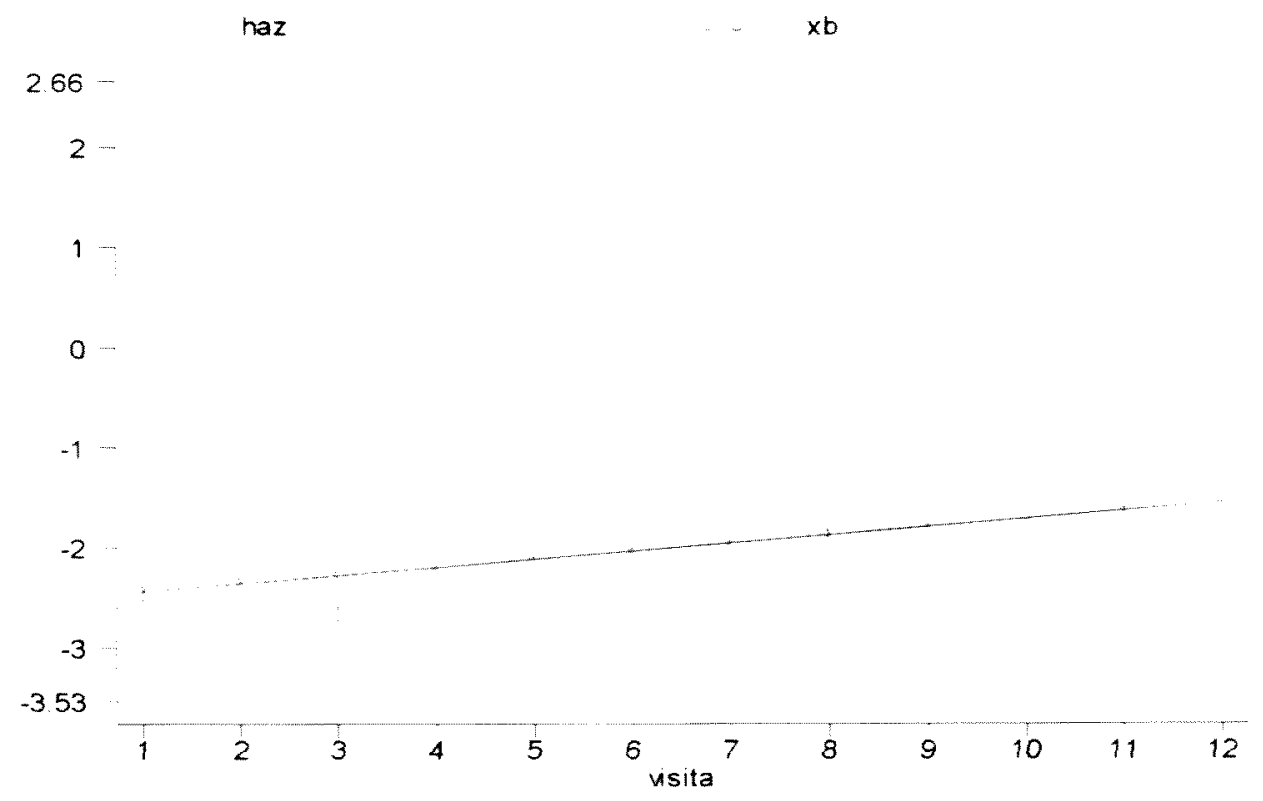

FIGURA 08 - Tendência da média estimada do escore $Z$ segundo visita no grupo de crianças desnutridas moderadas no início do estudo. Mogi das Cruzes, 2002 
O grupo de desnutridos moderados iniciou o programa com 150 crianças. Ao final de 12 meses, do total de crianças que permaneceram no programa (113, em função do abandono de 37 crianças), o ganho médio de altura foi de 0,08 escore $z$ por visita.

Os intervalos de variação do escore $Z$ para estas crianças são apresentados na Tabela 15 .

TABELA 15 - Distribuição de crianças desnutridas moderadas segundo intervalos de variação de escore $z$. Mogi das Cruzes, 2002.

\begin{tabular}{ccc}
\hline Intervalo de escore $\mathrm{z}$ & $\mathrm{N}$ & $\%$ \\
$<-0,5$ & 2 & 1,8 \\
$\geq-0,5-0$ & 7 & 6,2 \\
$>0-<0,5$ & 18 & 15,9 \\
$\geq 0,5$ & 86 & 76,1 \\
\hline
\end{tabular}

Para o conjunto de crianças desnutridas moderadas, à semelhança do ocorrido com os desnutridos graves, $92,0 \%$ obtiveram uma variação superior a 0,0 escore $z$

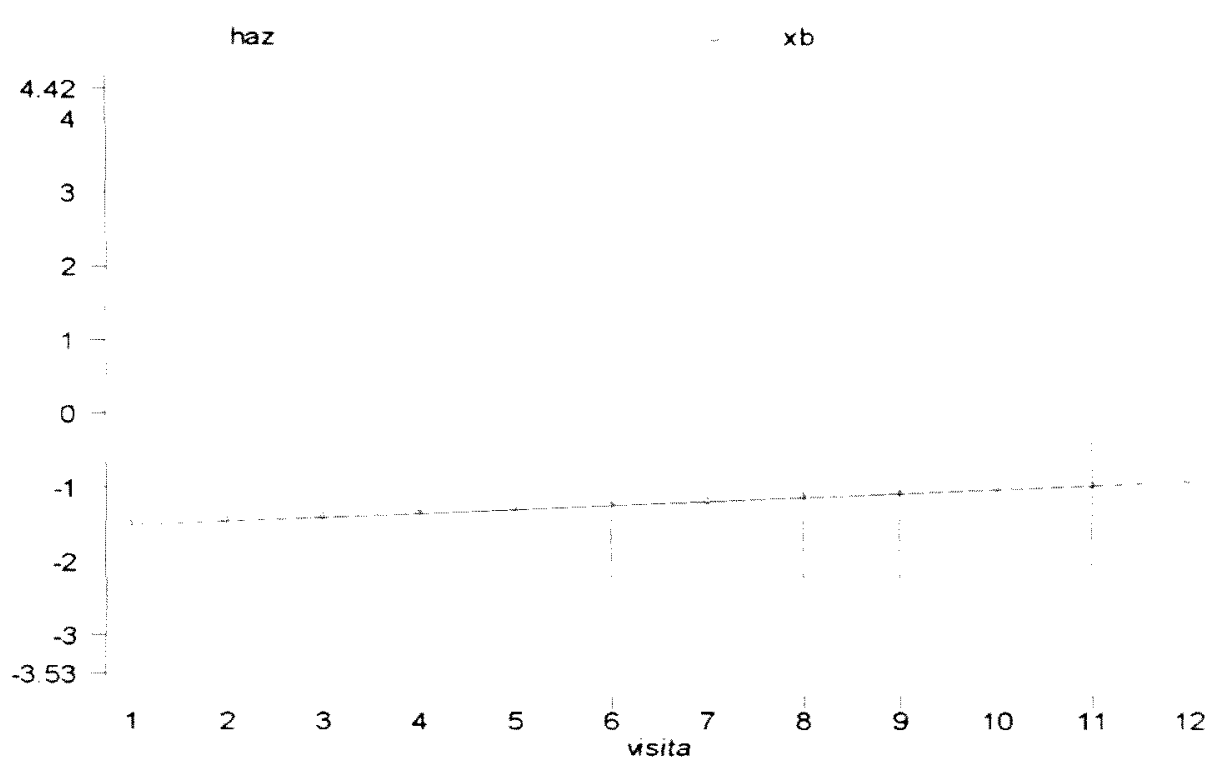

FIGURA 09 - Tendência da média estimada do escore $Z$ segundo visita no grupo de em risco de desnutrição no início do estudo. Mogi das Cruzes, 2002 
As crianças de risco nutricional iniciaram o programa com 321 , ao final de doze meses permaneciam sendo acompanhadas 250 crianças (71 abandonos) apresentando um ganho médio de altura de 0,06 escore $\mathrm{z}$ por visita.

Os intervalos de variação do escore $\mathrm{Z}$ para este grupo são apresentados na Tabela 16 .

TABELA 16 - Distribuição de crianças em risco nutricional segundo intervalos de variação de escore z. Mogi das Cruzes, 2002.

\begin{tabular}{ccc}
\hline Intervalo de escore $\mathrm{z}$ & $\mathrm{N}$ & $\%$ \\
\hline$<-0,5$ & 12 & 4,8 \\
$\geq-0,5-0$ & 31 & 12,4 \\
$>0-<0,5$ & 80 & 32,0 \\
$\geq 0,5$ & 127 & 50,8 \\
\hline
\end{tabular}

Para o conjunto de crianças em risco nutricional, $82,8 \%$ obtiveram uma variação superior a 0,0 escore $\mathrm{z}$

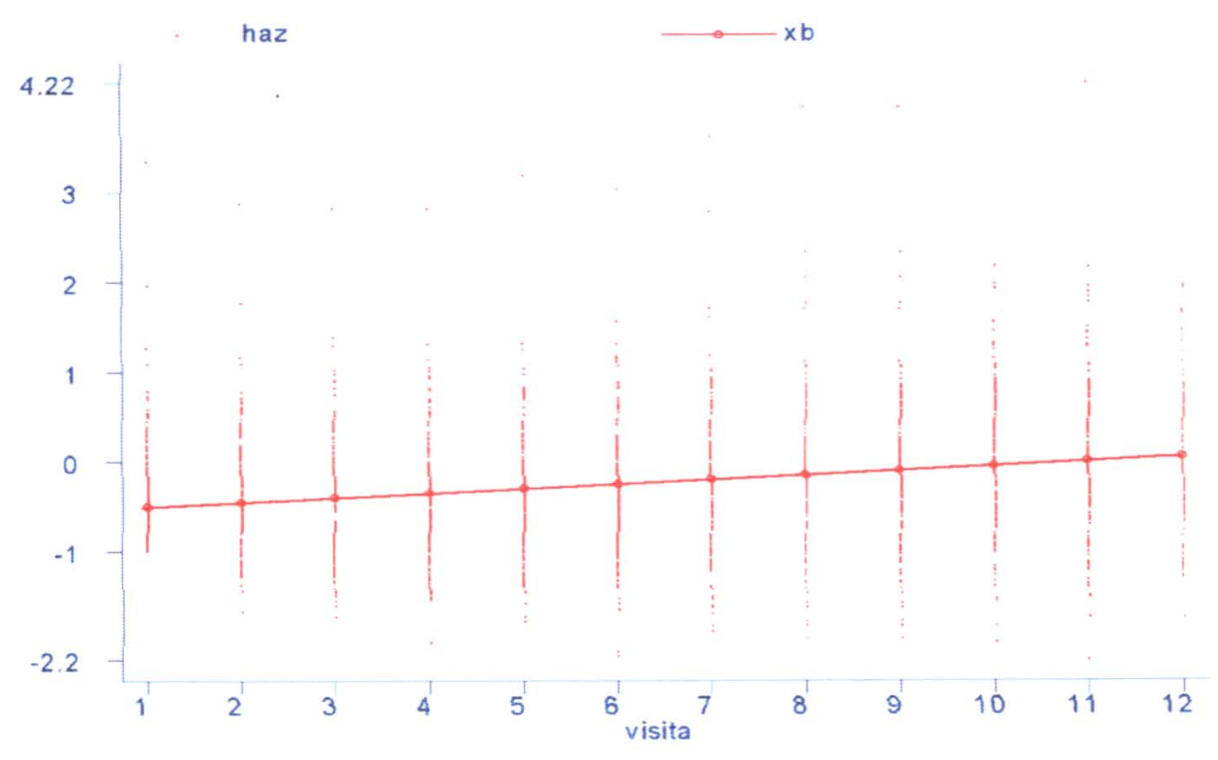

FIGURA 10 - Tendência da média estimada do escore $Z$ segundo visita no grupo de crianças eutróficas no início do estudo. Mogi das Cruzes, 2002. 
Do total de crianças que ingressaram no ICCN na condição de eutrofia (209), após 12 meses mantiveram-se no programa 169 crianças (40 abandonos), sendo que o ganho médio de altura para as estas crianças foi de 0,05 escore $\mathrm{z}$ por visita. Os intervalos de variação do escore $\mathrm{z}$ para este grupo são apresentados na Tabela 17.

TABELA 17 - Distribuição de crianças eutróficas segundo intervalos de variação de escore z. Mogi das Cruzes, 2002.

\begin{tabular}{ccc}
\hline Intervalo de escore $\mathrm{z}$ & $\mathrm{N}$ & $\%$ \\
\hline$<-0,5$ & 19 & 11,2 \\
$\geq-0,5-0$ & 24 & 14,2 \\
$>0-<0,5$ & 39 & 23,1 \\
$\geq 0,5$ & 87 & 51,5 \\
\hline
\end{tabular}

No grupo de crianças eutróficas, $74,6 \%$ apresentaram variação superior a 0,0 escore $z$, no entanto, este percentual é inferior ao obtido pelas crianças de outras categorias nutricionais.

Considerando o número de crianças no início do programa (724) e o número de crianças ao final de 12 meses (570), observou-se um abandono de $21,2 \%$. A Figura 11 permite visualizar conjuntamente a evolução nutricional dos diferentes grupos:

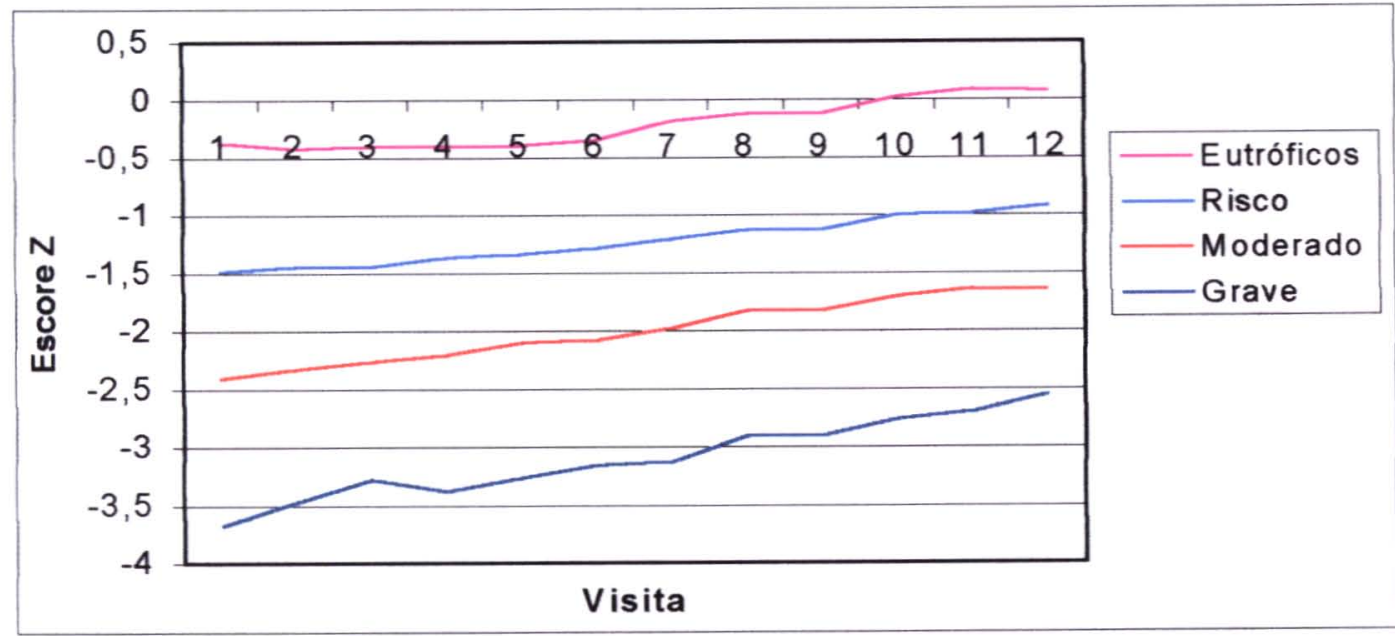

FIGURA 11 - Evolução do escore z segundo visita para os grupos de crianças. Mogi das Cruzes, 2002. 
Verifica-se que até a sexta visita não houve mudança no coeficiente comparado com a primeira visita para as crianças eutróficas. Para as crianças em risco, o coeficiente muda a partir da terceira visita.

Comportamento diferente observa-se para as crianças desnutridas (graves e moderadas) onde as mudanças no coeficiente podem ser observadas desde a segunda visita.

\subsection{Fatores relacionados à recuperação nutricional:}

Em razão do número reduzido de crianças com desnutrição grave (escore $\mathrm{z} \leq-3$ ), elas foram agrupadas às crianças com desnutrição moderada (escore $\mathrm{z}<-2$ e $>-3$ ) para investigar a associação da evolução nutricional com as variáveis independentes selecionadas. A mostra totalizou 194 crianças, que deste momento em diante passam a ser denominadas de desnutridas.

A Tabela 18 condensa as variações médias de escore $\mathrm{z}$ ao longo da exposição ao ICCN, segundo o estado nutricional ao ingressar no programa e as variáveis independentes relacionadas às crianças: 
TABELA 18 - Variação relativa do índice altura/idade (em escore z) em 12 meses de programa segundo variáveis relacionadas à criança e estado nutricional inicial - Análise Univariada. Mogi das Cruzes, 2002.

\begin{tabular}{lccc}
\hline Variáveis/categorias & \multicolumn{4}{c}{$\begin{array}{c}\text { Variação média de escore } z \text { de altura/idade } \\
\text { Eutrófico }\end{array}$} & $\begin{array}{c}\text { Risco } \\
\text { Desnutrido }\end{array}$ \\
\hline Número de visitas: & & & \\
& $0,05(0,05-0,06)$ & $0,06(0,05-0,06)$ & $0,09(0,08-0,09)$
\end{tabular}

Idade ao ingressar no programa (mês):

$$
\begin{array}{cc}
6-12^{\mathrm{a}} & 1,0 \\
12-24 & 0,21 \\
& (0,03-0,40) \\
>24 & -0,06
\end{array}
$$

Peso ao nascer (gramas):

$$
(-0,42-0,30)
$$

$$
\begin{array}{cc}
<2500^{a} & 1,0 \\
2500-2999 & 0,30 \\
\geq 3000 & (-0,02-0,62) \\
& (-0,01-0,57)
\end{array}
$$

Aleitamento Materno:

$$
\begin{gathered}
\text { Não } \\
\text { Sim }
\end{gathered}
$$

Tempo de gestação:

A Termo
Pré-termo

Sexo:

Feminino $^{a}$

Masculino

Pré-natal:

$$
\begin{gathered}
1,0 \\
0,03
\end{gathered}
$$$$
(-0,20-0,26)
$$

$$
\begin{gathered}
1,0 \\
-0,03
\end{gathered}
$$

$$
(-0,28-0,22)
$$

$$
1,0
$$

$-0,17$

$(-0,34-0,00)$

Não ${ }^{2}$

Sim

Internação no periodo:

Não ${ }^{a}$

Sim

Número de irmãos:

$$
\begin{gathered}
0-1^{\mathrm{a}} \\
2-3 \\
>3
\end{gathered}
$$

1,0

0,09

$(-0,24-0,42)$

1,0

$-0,04$

$(-0,25-0,18)$

1,0

$-0,13$

$(-0,31-0,04)$

0,14

$(-0,23-0,51)$

$a=$ categoria de referência

1,0

0,31

$(0,20-0,41)$

0,06

$(-0,20-0,32)$

1,0

0,01

$(-0,13-0,15)$

0,04

$(-0,10-0,18)$

1,0

0,19

$(0,04-0,34)$

1,0

$-0,02$

$(-0,15-0,10)$

1,0

$-0,02$

$(-0,12-0,08)$

1,0

0,04

$(-0,16-0,24)$

1,0

$-0,01$

$(-0,12-0,11)$

1,0

$-0,08$

$(-0,18-0,02)$

$-0,09$

$(-0,32-0,14)$
1,0

0,36

$(0,15-0,56)$

0,42

$(-0,27-1,10)$

1,0

0,15

$(-0,09-0,39)$

0,38

$(0,11-0,64)$

1,0

0,29

$(0,05-0,52)$

1,0

$-0,01$

$(-0,22-0,20)$

1,0

$-0,04$

$(-0,25-0,16)$

1,0

0,11

$(-0,16-0,38)$

1,0

$-0,13$

$(-0,35-0,09)$ 
O "número de visitas", primeira variável descrita na Tabela 18 e nas demais que apresentam a variação em escore $\mathrm{z}$ do índice altura/idade, diz respeito ao comparecimento da criança no programa, o que implicava na tomada de peso e estatura, participação nas atividades educativas e no recebimento do suplemento alimentar.

É importante ressaltar que, nos dados apresentados na Tabela 18, a evolução nutricional, considerando os fatores relacionados à criança, mostra que houve diferença significantemente positiva (limite inferior do intervalo de confiança maior que 0,00 ) para os desnutridos que nasceram com peso igual ou superior a $3000 \mathrm{~g}$ e entre os que receberam aleitamento materno. Inversamente, observa-se uma diferença significantemente negativa (limite superior do intervalo de confiança menor que 0,0 ) para os desnutridos cujo número de irmãos era maior que três.

Ainda é interessante destacar que, além dos desnutridos, para todas as crianças ingressantes com idade entre 12 e 24 meses a evolução nutricional foi positiva, comparando-se com crianças em outros intervalos de idade, inferiores ou superiores.

Para o grupo de crianças em risco nutricional ao ingressar no ICCN, observa-se uma associação positiva, à semelhança das crianças desnutridas, entre o aleitamento materno e a recuperação nutricional.

A Tabela 19 resume os resultados da variação média do escore $\mathrm{z}$ das crianças ao longo de sua permanência no ICCN, segundo características maternas e estado nutricional inicial: 
TABELA 19 - Variação relativa do índice altura/idade (em escore z) em 12 meses de programa segundo variáveis maternas e estado nutricional inicial - Análise Univariada. Mogi das Cruzes, 2002.

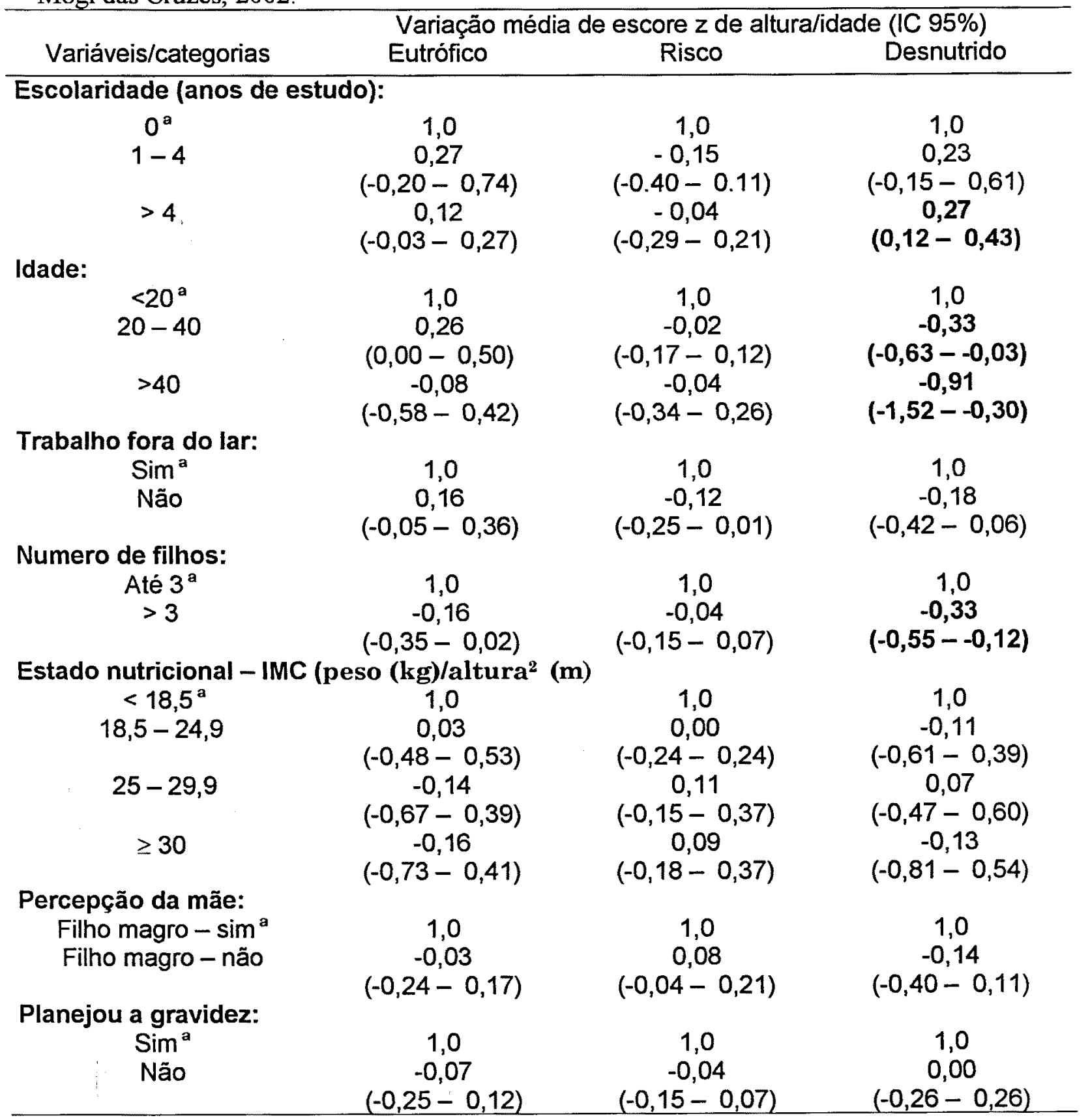


Observa-se na Tabela 19 que apenas a escolaridade materna superior a 4 anos de estudo mostrou-se significantemente associada à melhor evolução nutricional dos desnutridos. Por outro lado, a família possuir mais de três filhos mostrou-se como fator associado à pior recuperação nutricional.

Chama atenção a variação negativa da evolução das crianças desnutridas associadas à idade da mãe. Quanto maior a idade da mãe, pior a evolução da criança.

Além disto, as variações médias do escore $\mathrm{z}$ foram avaliadas segundo as variáveis paternas, renda, densidade familiar e aquisição de emprego de algum membro da família durante o tempo de exposição da criança ao programa; os resultados podem ser vistos nas Tabelas 20 e 21:

TABELA 20 - Variação relativa do índice altura/idade (em escore z) em 12 meses de programa segundo variáveis paternas e estado nutricional inicial - Análise Univariada. Mogi das Cruzes, 2002.

\begin{tabular}{|c|c|c|c|}
\hline \multirow[b]{2}{*}{ Variáveis/categorias } & \multicolumn{3}{|c|}{ Variação média de escore $z$ de altura/idade (IC 95\%) } \\
\hline & Eutrófico & Risco & Desnutrido \\
\hline \multicolumn{4}{|l|}{ Escolaridade: } \\
\hline $0^{\mathrm{a}}$ & 1,0 & 1,0 & 1,0 \\
\hline $1-4$ & $\frac{-0,02}{0,02}$ & $\begin{array}{l}-0,02 \\
-3,199\end{array}$ & $\begin{array}{c}0,31 \\
010\end{array}$ \\
\hline & $(-0,47-0,42)$ & $(-0,23-0,19)$ & $(-0,10-0,72)$ \\
\hline$>4$ & $\begin{array}{c}0,00 \\
(-0,43-0,43)\end{array}$ & $\begin{array}{c}0,01 \\
(-0,18-0,20)\end{array}$ & $\begin{array}{c}0,18 \\
(0,02-0,35)\end{array}$ \\
\hline \multicolumn{4}{|l|}{ Idade: } \\
\hline $\begin{array}{l}<20^{\mathrm{a}} \\
20-40\end{array}$ & $\begin{array}{r}1,0 \\
0,63\end{array}$ & $\begin{array}{c}1,0 \\
-0,10\end{array}$ & $\begin{array}{c}1,0 \\
-0,21\end{array}$ \\
\hline$>40$ & $\begin{array}{c}(-0,55-1,82) \\
-0,17 \\
(-0,44-0,10)\end{array}$ & $\begin{array}{c}(-0,40-0,20) \\
-0,09 \\
(-0,42-0,25)\end{array}$ & $\begin{array}{c}(-0,72-0,30) \\
-0,33 \\
(-0,58--0,08)\end{array}$ \\
\hline Pai mora com a familia: & & & \\
\hline $\begin{array}{l}\text { Não }{ }^{a} \\
\text { Sim }\end{array}$ & $\begin{array}{c}1,0 \\
0,05 \\
(-0,14-0,25)\end{array}$ & $\begin{array}{c}1,0 \\
0,02 \\
(-0,09-0,14)\end{array}$ & $\begin{array}{c}1,0 \\
0,16 \\
(-0,07-0,40)\end{array}$ \\
\hline
\end{tabular}

$\mathrm{a}=$ categoria de referência 
TABELA 21 - Variação média do índice altura/idade (em escore z) em 12 meses de programa segundo renda familiar, número de parentes, emprego no periodo e estado nutricional inicial - Análise Univariada. Mogi das Cruzes, 2002.

\begin{tabular}{|c|c|c|c|}
\hline \multicolumn{4}{|c|}{ Variação média de escore $z$ de altura/idade (IC 95\%) } \\
\hline Variáveis/categorias & Eutrófico & Risco & Desnutrido \\
\hline \multicolumn{4}{|c|}{ Renda familiar (salário mínimo): } \\
\hline$<1^{\mathrm{a}}$ & 1,0 & 1,0 & 1,0 \\
\hline $1-3$ & 0,28 & 0,03 & 0,04 \\
\hline & $(-0,05-0,60)$ & $(-0,08-0,16)$ & $(-0,33-0,41)$ \\
\hline$>3$ & $\begin{array}{c}0,14 \\
(-0,06-0,34)\end{array}$ & $\begin{array}{c}0,16 \\
(0,00-0,32)\end{array}$ & $\begin{array}{c}0,15 \\
(-0,10-0,40)\end{array}$ \\
\hline \multicolumn{4}{|l|}{ Número de parentes: } \\
\hline$<3^{a}$ & 1,0 & 1,0 & 1,0 \\
\hline$\geq 3$ & $-0,13$ & $-0,04$ & $-0,25$ \\
\hline & $(-0,33-0,06)$ & $(-0,17-0,10)$ & $(-0,53-0,02)$ \\
\hline \multicolumn{4}{|c|}{ Trabalho novo no periodo: } \\
\hline $\operatorname{Sim}^{a}$ & 1,0 & 1,0 & 1,0 \\
\hline Não & $\begin{array}{c}0,13 \\
(-0,13-0,39)\end{array}$ & $\begin{array}{c}0,04 \\
(-0,11-0,19)\end{array}$ & $\begin{array}{c}-0,32 \\
(-0,61--0,03)\end{array}$ \\
\hline
\end{tabular}

$a=$ categoria de referência

Pode-se observar, nas Tabelas 20 e 21, a melhor resposta das crianças desnutridas quando o pai apresenta mais de quatro anos de estudo e variação negativa associada a pais com mais idade ( $>40$ anos). Ainda pode ser inferido que a não obtenção de trabalho no período estudado associa-se negativamente à recuperação nutricional da criança, mesmo na presença de suplementação alimentar.

É possivel, a partir das análises univariadas, verificar que estiveram associadas positivamente à melhor recuperação nutricional das crianças desnutridas:

- idade da criança ao ingressar no programa entre 12 e 24 meses;

- peso ao nascer igual ou superior a $3000 \mathrm{~g}$;

- aleitamento materno;

- escolaridades materna e paterna acima de 4 anos de estudo. 
Por outro lado, as variáveis que se associaram negativamente à recuperação nutricional foram:

- ter mais que três irmãos;

- famílias com mais de três filhos;

- pai e/ou mãe possuírem mais idade (>40 anos);

- não obtenção de outra forma de renda (emprego) durante a permanência da criança no programa de suplementação alimentar.

Para as crianças em risco nutricional as variáveis que se mostraram associadas positivamente à melhor recuperação nutricional foram a idade (12-24 meses), o aleitamento materno e renda familiar, esta última com valor limítrofe.

Em relação às crianças eutróficas, a única variável que se mostrou associada de forma positiva a evolução nutricional foi a idade ao ingressar no programa (entre 12 e 24 meses).

Objetivando anular possíveis variações ou contradições nos resultados obtidos em relação aos fatores que se mostraram associados à melhor ou pior recuperação nutricional das crianças estudadas, foram realizadas análises multivariadas para cada categoria do estado nutricional apresentada pelas crianças ao ingressar no ICCN.

Conforme descrito na metodologia, as variáveis com o valor de $p \leq 0,25$, foram selecionadas para a modelagem multivariada. As tabelas 22,23 e 24 mostram as variáveis selecionadas segundo a categoria do estado nutricional inicial das crianças: 
TABELA 22 - Variáveis selecionadas para ajuste no modelo multivariado no grupo de crianças desnutridas. Mogi das Cruzes, 2002.

\begin{tabular}{|c|c|c|}
\hline Variáveis & Escore Z & $\mathbf{p}$ \\
\hline Número de visitas & 0,090 & 0,001 \\
\hline \multicolumn{3}{|l|}{ Idade ao ingressar no ICCN: } \\
\hline $\begin{array}{l}12-24 \text { meses } \\
>24 \text { meses }\end{array}$ & $\begin{array}{l}0,359 \\
0,415\end{array}$ & $\begin{array}{l}0,001 \\
0,236\end{array}$ \\
\hline \multicolumn{3}{|l|}{ Peso ao nascer: } \\
\hline$\geq 2500 \mathrm{e}<3000$ & 0,153 & 0,213 \\
\hline$\geq 3000$ & 0,376 & 0,005 \\
\hline Aleitamento Matemo - Sim & 0,285 & 0,016 \\
\hline $\begin{array}{l}\text { Renda familiar: } \\
1-3 \mathrm{~s} . \mathrm{m} .\end{array}$ & 0,077 & 0,220 \\
\hline $\begin{array}{c}\text { Número de pessoas na família: } \\
>3 \text { pessoas }\end{array}$ & $-0,252$ & 0,074 \\
\hline $\begin{array}{c}\text { Escolaridade da mãe: } \\
\qquad 4 \text { anos }\end{array}$ & 0,271 & 0,001 \\
\hline $\begin{aligned} \text { Escolaridade do pai: } & >4 \text { anos }\end{aligned}$ & 0,184 & 0,029 \\
\hline \multicolumn{3}{|l|}{ Número de Irmãos: } \\
\hline $\begin{array}{c}2 \text { a } 3 \\
>3\end{array}$ & $\begin{array}{l}-0,198 \\
-0,614\end{array}$ & $\begin{array}{l}0,060 \\
0,002\end{array}$ \\
\hline \multicolumn{3}{|l|}{ Idade da mãe: } \\
\hline $\begin{array}{l}20 \text { a } 40 \text { anos } \\
>40 \text { anos }\end{array}$ & $\begin{array}{l}-0,330 \\
-0,914\end{array}$ & $\begin{array}{l}0,003 \\
0,003\end{array}$ \\
\hline Idade do pai (> 40 anos) & $-0,326$ & 0,010 \\
\hline \multicolumn{3}{|l|}{ Numero filhos: } \\
\hline$>3$ filhos & $-0,335$ & 0,002 \\
\hline Mãe com trabalho fora do lar: não & $-0,180$ & 0,145 \\
\hline Pai mora com a familia & 0,164 & 0,178 \\
\hline Trabalho novo no período: não & $-0,319$ & 0,031 \\
\hline
\end{tabular}

Destaca-se, para o grupo de crianças desnutridas, que as variáveis: estado nutricional da mãe, percepção da mãe em relação ao estado nutricional do filho, planejamento da gravidez, tempo de gestação, realização de pré-natal, sexo da criança e internação no período apresentaram o valor de $\mathrm{p}$ maior que 0,25 ; portanto não foram selecionadas para o modelo multivariado. As variáveis selecionadas encontram-se na Tabela 22. 
TABELA 23 - Variáveis selecionadas para ajuste no modelo multivariado no grupo de crianças em risco nutricional. Mogi das Cruzes, 2002.

\begin{tabular}{lcc}
\hline Variáveis & Escore z & $\mathbf{P}$ \\
\hline Número de visitas & 0,060 & $<0,001$ \\
Idade ao ingressar no ICCN & & \\
$12-24$ meses & 0,308 & $<0,001$ \\
Aleitamento Matemo - Sim & 0,194 & 0,012 \\
Renda Familiar: & & \\
$\quad 1$ a $3 \mathrm{sm}$. & 0,036 & 0,550 \\
$\quad>3 \mathrm{sm}$. & 0,157 & 0,053 \\
Número de Irmãos: & & \\
2 - 3 & $-0,081$ & 0,129 \\
Escolaridade da mãe & & \\
$\quad$ 4 anos & 0,053 & 0,241 \\
Mãe com trabalho fora do lar: não & $-0,119$ & 0,070 \\
Percepção da mãe: & 0,080 & 0,192 \\
Filho magro - não & & \\
\hline
\end{tabular}

Para as crianças em risco de desnutrição somente as variáveis relacionadas na Tabela 23 apresentaram $\mathrm{p}<0.25$ e foram para o modelo multivariado. Isto significou a exclusão de todas as demais variáveis descritas a seguir: peso ao nascer, tempo de gestação, sexo da criança, realização de pré-natal, internação no período, idade da mãe, número de filhos, estado nutricional da mãe, gravidez planejada, escolaridade do pai, idade do pai, pai morar junto com a família, número de pessoas da família e trabalho novo no período. 
TABELA 24 - Variáveis selecionadas para ajuste no modelo multivariado no grupo de crianças eutróficas. Mogi das Cruzes, 2002.

\begin{tabular}{|c|c|c|}
\hline Variảveis & Escore Z & $\bar{p}$ \\
\hline Número de visitas & 0,050 & $<0,001$ \\
\hline $\begin{array}{l}\text { Idade ao ingressar no ICCN: } \\
12-24 \text { meses }\end{array}$ & 0,213 & 0.022 \\
\hline Peso ao nascer: & & \\
\hline$\geq 2500-2999$ & 0,299 & 0,069 \\
\hline$\geq 3000$ & 0,279 & 0,063 \\
\hline Número de pessoas na família: & & \\
\hline $\begin{array}{l}\geq 3 \text { pessoas } \\
\text { Escolaridade da mãe: }\end{array}$ & $-0,134$ & 0,179 \\
\hline$>4$ anos & 0,117 & 0,129 \\
\hline Número de filhos & & \\
\hline$>3$ filhos & $-0,165$ & 0,083 \\
\hline Idade do pai: 20 a 40 anos & $-0,171$ & 0,216 \\
\hline Mãe com trabalho fora do lar: sim & 0,157 & 0,133 \\
\hline
\end{tabular}

À semelhança do ocorrido com o grupo de crianças em risco nutricional, para as crianças eutróficas, só permaneceram no modelo, as variáveis relacionadas na Tabela 24 todas as demais foram excluídas, a saber: aleitamento materno, tempo de gestação, sexo da criança, realização de pré-natal, internação no período, número de irmãos, idade da mãe, estado nutricional da mãe, percepção do filho, gravidez planejada, escolaridade do pai, pai morar junto com a família, renda familiar e trabalho novo no período.

Os resultados obtidos, no modelo multivariado, após o ajuste das variáveis descritas anteriormente, são demonstrados por categoria de estado nutricional, conforme podem ser vistos a seguir: 
TABELA 25 - Associação entre fatores relacionados à recuperação de crianças desnutridas - Análise Multivariada. Mogi das Cruzes, 2002.

\begin{tabular}{|c|c|c|c|}
\hline $\begin{array}{l}\text { Variáveis I } \\
\text { Categorias }\end{array}$ & $\begin{array}{l}\text { Variação média não ajustada } \\
\text { de escore z de altura/idade* } \\
\text { (IC) }\end{array}$ & $\begin{array}{l}\text { Variação média ajustada de } \\
\text { escore z de altura/idade* (IC) }\end{array}$ & $p$ \\
\hline \multicolumn{4}{|c|}{ úmero de visitas: } \\
\hline & $0,09(0,08-0,09)$ & $0,07(0,06-0,08)$ & 0,00 \\
\hline \multicolumn{4}{|c|}{ ade da crianças no ingresso no ICCN (meses): } \\
\hline $6-11^{a}$ & 1,0 & 1,0 & - \\
\hline $12-23$ & $0,36(0,15-0,56)$ & $0,40(0,19-0,61)$ & 0,00 \\
\hline$\geq 24$ & $0,42(-0,27-1,10)$ & $0,60(-0,01-1,20)$ & 0,06 \\
\hline \multicolumn{4}{|c|}{ eso ao nascer (g): } \\
\hline$<2500^{\mathrm{a}}$ & 1,0 & 1,0 & - \\
\hline $2500-2999$ & $0,15(-0,09-0,39)$ & $0,05(-0,18-0,28)$ & 0,68 \\
\hline$\geq 3000$ & $0,38(0,11-0,64)$ & $0,30(0,03-0,56)$ & 0,03 \\
\hline \multicolumn{4}{|c|}{ leitamento materno: } \\
\hline Sim & $0,29(0,05-0,52)$ & $0,24(0,01-0,48)$ & 0,05 \\
\hline \multicolumn{4}{|c|}{ úmero de pessoas na familia: } \\
\hline$<3^{\mathrm{a}}$ & 1,0 & 1,0 & - \\
\hline$\geq 3$ & $-0,25(-0,53-0,02)$ & $-0,28(-0,60-0,04)$ & 0,08 \\
\hline \multicolumn{4}{|c|}{ úmero de irmãos: } \\
\hline $0-1^{a}$ & 1,0 & 1,0 & - \\
\hline $2-3$ & $-0,20(-0,40-0,01)$ & $0,10(-0,14-0,34)$ & 0,41 \\
\hline$>3$ & $-0,61(-1,00-0,23)$ & $-0,38(-0,83-0,06)$ & 0,09 \\
\hline \multicolumn{4}{|c|}{ lade da mãe (anos completos): } \\
\hline$<20^{\mathrm{a}}$ & 1,0 & 1,0 & - \\
\hline $20-40$ & $-0,33(-0,63--0,03)$ & $-0,47(-0,80--0,13)$ & 0,00 \\
\hline$>40$ & $-0,91(-1,52--0,30)$ & $-0,51(-1,11-0,08)$ & 0,09 \\
\hline \multicolumn{4}{|c|}{ lãe com trabalho fora do lar: } \\
\hline $\operatorname{Sim}^{\mathrm{a}}$ & 1,0 & 1,0 & - \\
\hline \multicolumn{4}{|c|}{ rabalho novo durante o ICCN: } \\
\hline $\operatorname{Sim}^{a}$ & 1,0 & 1,0 & - \\
\hline \multicolumn{4}{|c|}{ irau da desnutrição: } \\
\hline Moderado ${ }^{a}$ & . çav. & 1,0 & - \\
\hline Grave & $0,10(0,09-0,11)$ & $0,52(0,45-0,59)$ & 0,00 \\
\hline
\end{tabular}

* Os valores foram arredondados para duas casas decimais.

$\mathbf{a}=$ categoria de referência

Após o ajuste das variáveis, ficou retido no modelo como associado à melhor recuperação nutricional das crianças desnutridas o tempo de exposição ao programa (número de visitas). A cada visita a criança ganhou 
0,07 escore $z$ de altura para idade $(p=0,00)$, o que significou em torno de 0,9 escore $\mathrm{z}$ para as crianças que permaneceram doze meses no programa.

Permaneceram também, associados positivamente à recuperação nutricional, a idade da criança ao ingressar no ICCN (12 e 24 meses) o peso de nascimento igual ou superior a $3000 \mathrm{~g}$ e o aleitamento materno, todas com $p<0,05$, exceto para aleitamento que apresentou valor limítrofe para $p=0,05$, mas o limite inferior do intervalo de confiança do escore médio ajustado não incluiu o zero.

As crianças cujas mães não trabalhavam fora evoluíram pior comparadas às crianças cujas mães trabalhavam. É interessante observar, que após o ajuste das possíveis variáveis de confusão, a ausência de trabalho materno aumentou em $35,6 \%$ sua associação negativa com a recuperação nutricional, isto ocorreu quando foi incluído no modelo a variável gravidade da desnutrição. Esta associação pode ser verificada no anexo 4.

A faixa etária da mãe - 20 a 40 anos - que estava associada na análise univariada com a pior recuperação nutricional da criança, aumentou em $41,2 \%$ sua associação negativa na análise multivariada (anexo 4).

Julgou-se importante ainda avaliar a recuperação nutricional das crianças segundo o grau de desnutrição apresentado no início do ICCN (graves e moderados), cujos resultados mostram que foi significantemente superior a recuperação de crianças que ingressaram no programa com maiores déficits nutricionais (escore z 0,52 e $\mathrm{p}=0,00$ ).

A inclusão dos desnutridos graves no modelo reduziu a força da associação do ganho de altura por visita (de 0,09 para 0,07 ) e do peso ao nascer $\geq 3000 \mathrm{~g}$. (de 0,38 para 0,30 ).

Estes resultados mostram que para a criança desnutrida a freqüência ao programa de suplementação alimentar foi favorável à recuperação nutricional independentemente dos outros fatores avaliados neste estudo. 
Analisando-se a associação entre o peso ao nascer e a desnutrição inicial, observou-se que $64,1 \%$ dos desnutridos graves nasceram com peso menor que 2500g (Anexo 4). Ainda que tenha sido impactado pelo ajuste multivariado o peso ao nascer se manteve associado de forma significante com a melhora nutricional da criança exposta ao ICCN.

A seguir cumpre destacar aquelas variáveis que se mostravam inicialmente associadas à evolução nutricional $(p<0,05)$ e, após os ajustes, não permaneceram no modelo. São elas: a idade do pai, o número de irmãos e o número de filhos (Anexo 4).

Com efeito, a escolaridade da mãe foi deslocada do modelo multivariado pela idade da mãe e pelo peso de nascimento da criança, como pode ser visto nas Tabelas 26 e 27:

TABELA 26 - Distribuição (\%) de crianças desnutridas segundo escolaridade e idade da mãe. Mogi das Cruzes, 2002.

\begin{tabular}{ccccc}
\hline Escolaridade da mãe & \multicolumn{5}{c}{ Idade da mãe (anos completos) } \\
(anos de estudo) & $<20$ & $20-40$ & $>40$ & Total \\
& $\%$ & $\%$ & \multicolumn{1}{c}{$\%$} & \multicolumn{1}{c}{$\%$} \\
\hline 0 & - & 8,7 & 33,3 & 8,5 \\
$1-4$ & 22,7 & 37,6 & 66,7 & 36,7 \\
$>4$ & 77,3 & 53,7 & - & 54,8 \\
\hline Total & 100,0 & 100,0 & 100,0 & 100,0 \\
\hline
\end{tabular}

É possível verificar que, entre as mães que apresentavam maior escolaridade, $77,3 \%$ tinham menos de 20 anos.

TABELA 27 - Distribuição (\%) de crianças desnutridas segundo escolaridade da mãe e peso ao nascer. Mogi das Cruzes, 2002.

\begin{tabular}{ccccc}
\hline Escolaridade da mãe & \multicolumn{5}{c}{ Peso ao Nascer } \\
(anos de estudo) & $<2500$ & $2500-2999$ & $>3000$ & Total \\
& $\%$ & $\%$ & $\%$ & $\%$ \\
\hline 0 & 13,9 & 3,8 & 5,1 & 8,5 \\
$1-4$ & 34,7 & 39,6 & 28,2 & 34,8 \\
$>4$ & 51,4 & 56,6 & 66,7 & 56,7 \\
\hline Total & 100,0 & 100,0 & 100,0 & 100,0 \\
\hline
\end{tabular}


Da mesma forma, entre as mães com maior escolaridade, é maior a freqüência do peso ao nascer adequado (66,7\%).

As variáveis que não se mostravam associadas à evolução nutricional das crianças no modelo univariado $(p>0,05)$ e que também não se mostraram associadas, após os ajustes no modelo multivariado, foram: idade ao ingressar maior que 24 meses, peso ao nascer - 2500 a $2999 \mathrm{~g}$-, renda familiar, número de pessoas da família, a criança possuir 2 ou 3 irmãos e o pai morar com a famíla.

A Tabela 28 mostra a variação dos coeficientes do escore $\mathrm{z}$ para as crianças em risco nutricional nas análises univariada e multivariada.

TABELA 28 - Associação entre fatores relacionados à recuperação nutricional de crianças em risco de desnutrição - Análise Multivariada. Mogi das Cruzes, 2002.

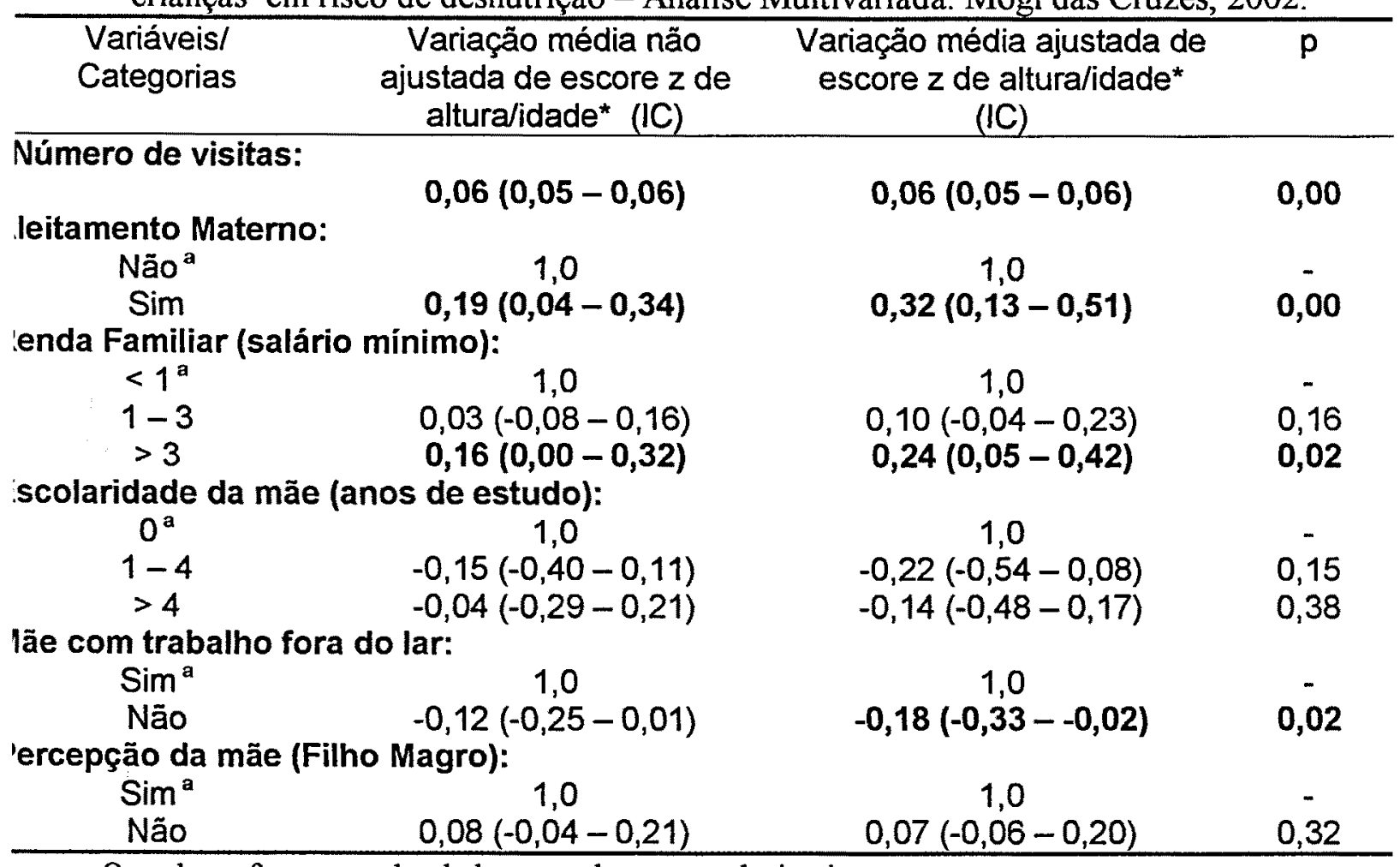

- Os valores foram arredondados para duas casas decimais.

$a=$ categoria de referência

Para o grupo de crianças em risco nutricional, após o ajuste das possíveis variáveis de confusão, ficou retido no modelo como associado à 
melhora nutricional o aleitamento materno, a renda familiar e o tempo de exposição ao programa (número de visitas), este último, mostrando-se como fator independente para a evolução estatural, uma vez que não sofreu variação.

A renda familiar acima de 3 salários mínimos aumentou sua associação positiva com a melhora nutricional em $50 \%$ com a introdução das variáveis "trabalho novo" e "escolaridade materna" (anexo 4).

Manteve-se associado negativamente à recuperação nutricional a ausência de trabalho materno, que na verdade ganhou maior força de associação após o ajuste no modelo multivariado. As demais variáveis selecionadas para ajuste no modelo multivariado, a saber: a idade ao ingressar no ICCN e o número de irmãos não ficaram retidas no modelo após os ajustes. A Tabela 29 mostra a variação dos coeficientes do escore z para as crianças eutróficas nas análises univariada e multivariada.

TABELA 29 - Associação entre fatores relacionados à evolução nutricional de crianças eutróficas - Análise Multivariada. Mogi das Cruzes, 2002.

\begin{tabular}{|c|c|c|c|}
\hline $\begin{array}{l}\text { Variáveis/ } \\
\text { Categorias }\end{array}$ & $\begin{array}{l}\text { Variação média não } \\
\text { ajustada de escore z de } \\
\text { altura/idade } \\
\text { (IC) }\end{array}$ & $\begin{array}{l}\text { Variação média ajustada } \\
\text { de escore } z \text { de } \\
\text { altura/idade }{ }^{*} \text { (IC) }\end{array}$ & $P$ \\
\hline Número de visita & $0,05(0,05-0,06)$ & $0,04(0,04-0,05)$ & 0,00 \\
\hline \multicolumn{4}{|c|}{ Idade da crianças no ingresso no ICCN (meses): } \\
\hline $6-11^{\mathrm{a}}$ & 1,0 & 1,0 & - \\
\hline $12-24$ & $0,21(0,03-0,40)$ & $0,28(0,05-0,51)$ & 0,02 \\
\hline$\geq 24$ & $-0,06(-0,42-0,30)$ & $0,35(-0,15-0,84)$ & 0,17 \\
\hline \multicolumn{4}{|c|}{ Peso ao nascer $(\mathrm{g})$ : } \\
\hline$<2500^{\mathrm{a}}$ & 1,0 & 1,0 & - \\
\hline $2500-2999$ & $0,30(-0,02-0,62)$ & $0,20(-0,17-0,57)$ & 0,30 \\
\hline$\geq 3000$ & $-0,28(-0,01-0,57)$ & $0,24(-0,09-0,57)$ & 0,16 \\
\hline \multicolumn{4}{|c|}{ Número de pessoas na família: } \\
\hline$<3^{a}$ & 1,0 & 1,0 & - \\
\hline$\geq 3$ & $-0,13(-0,06-0,34)$ & $-0,17(-0,40-0,06)$ & 0,15 \\
\hline \multicolumn{4}{|c|}{ Escolaridade da mãe (anos de estudo): } \\
\hline $0^{a}$ & 1,0 & 1,0 & - \\
\hline$>4$ & $0,12(-0,03-0,27)$ & $0,37(-0,22-0,97)$ & 0,22 \\
\hline
\end{tabular}

\footnotetext{
* Os valores foram arredondados para duas casas decimais.
}

$a=$ categoria de comparação 
Para as crianças que ingressaram eutróficas no ICCN, o tempo de exposição ao programa (número de visitas) se mostrou associado ao maior ganho de altura para idade, independentemente de outros fatores.

Outra variável que se mostrou associada de forma positiva ao ganho de altura foi a idade da criança entre 12 e 24 meses, que aumentou em $31,2 \%$ seu efeito quando foi ajustado o peso ao nascer. Analisando-se esta associação, verificou-se que $66,4 \%$ da crianças com idade entre 12 e 24 meses haviam nascido com peso igual ou maior que $3000 \mathrm{~g}$ (Anexo 4).

Não mostraram associação nos modelos uni e multivariados o peso ao nascer, o número de pessoas na família e a escolaridade materna.

As demais variáveis testadas, a saber: número de filhos, idade do pai e trabalho materno fora do lar não ficaram retidas no modelo após os ajustes.

A fim de avaliar a adequação do modelo utilizado para a análise da evolução nutricional das crianças, realizou-se a avaliação dos resíduos para as crianças desnutridas, de risco nutricional e eutróficas, o que pode ser visto nas Figuras 12, 13, 14, 15, 16 e 17, respectivamente: 


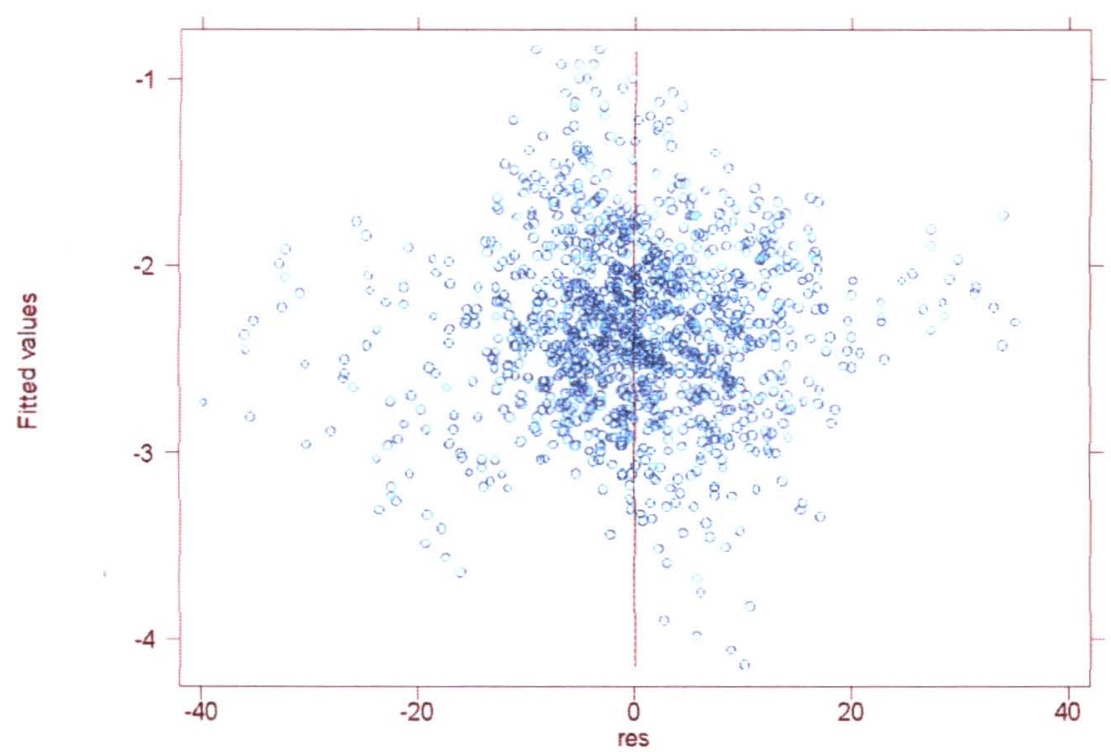

FIGURA 12 - Valores ajustados no modelo para crianças desnutridas versus resíduo. Mogi das Cruzes, 2002.

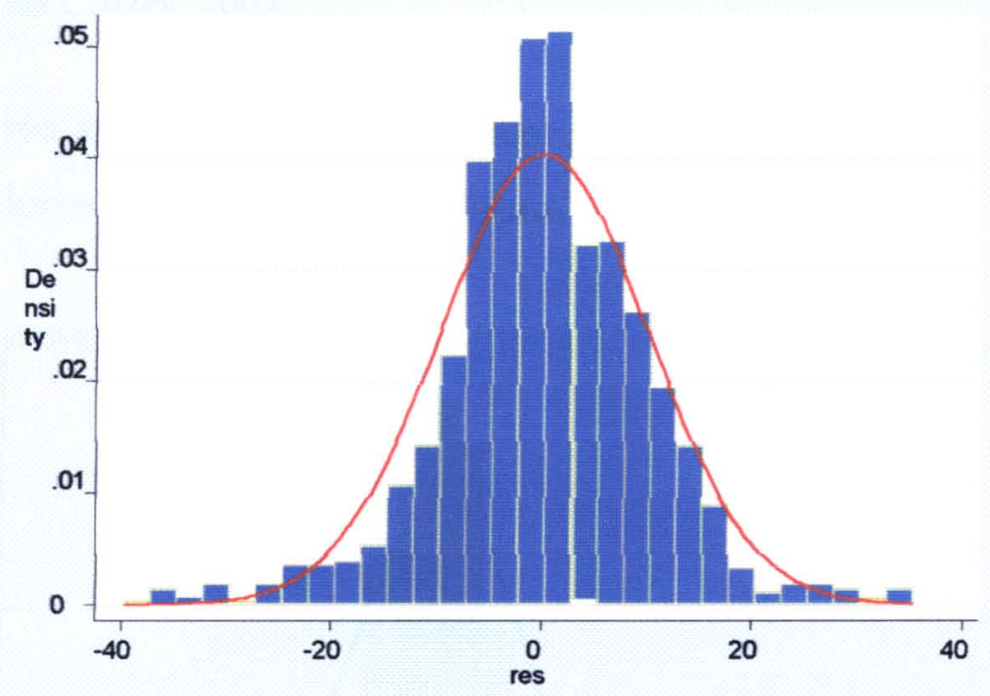

FIGURA 13- Distribuição do resíduo do modelo para crianças desnutridas. Mogi das Cruzes, 2002.

A avaliação dos resíduos do modelo para as crianças desnutridas (Figuras 12 e 13) mostra que o modelo está bem ajustado. 


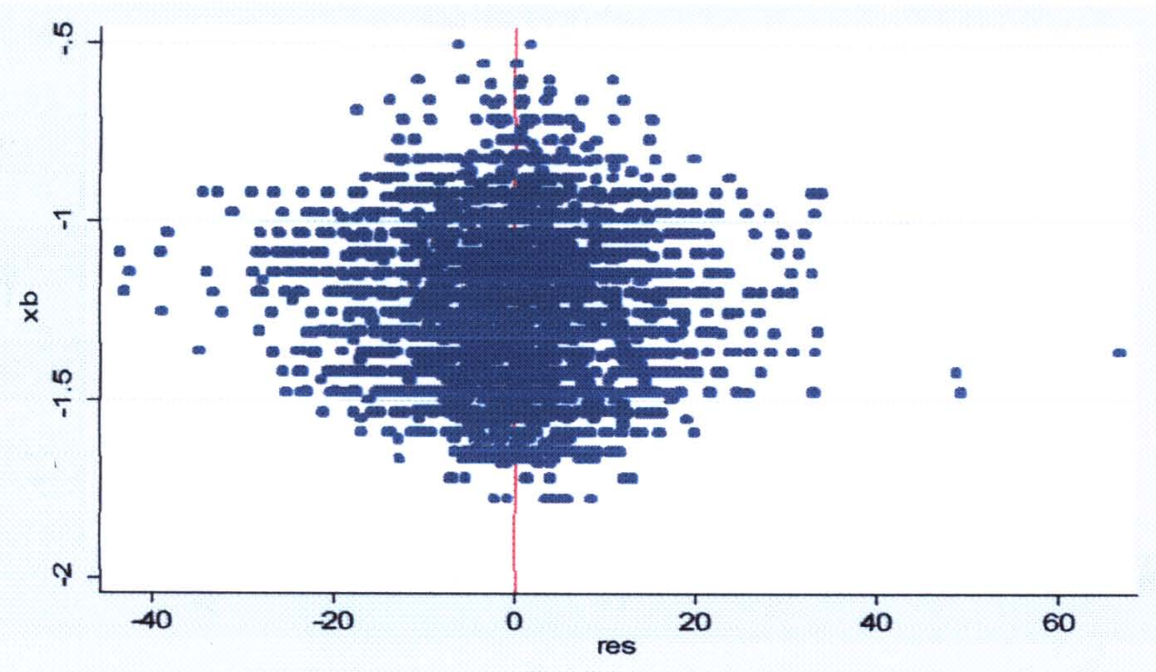

FIGURA 14 - Valores ajustados no modelo para crianças em risco versus resíduo. Mogi das Cruzes, 2002.

Os valores ajustados x resíduo mostram uma distribuição homogênea, com alguns valores outliers que não afetam a distribuição.

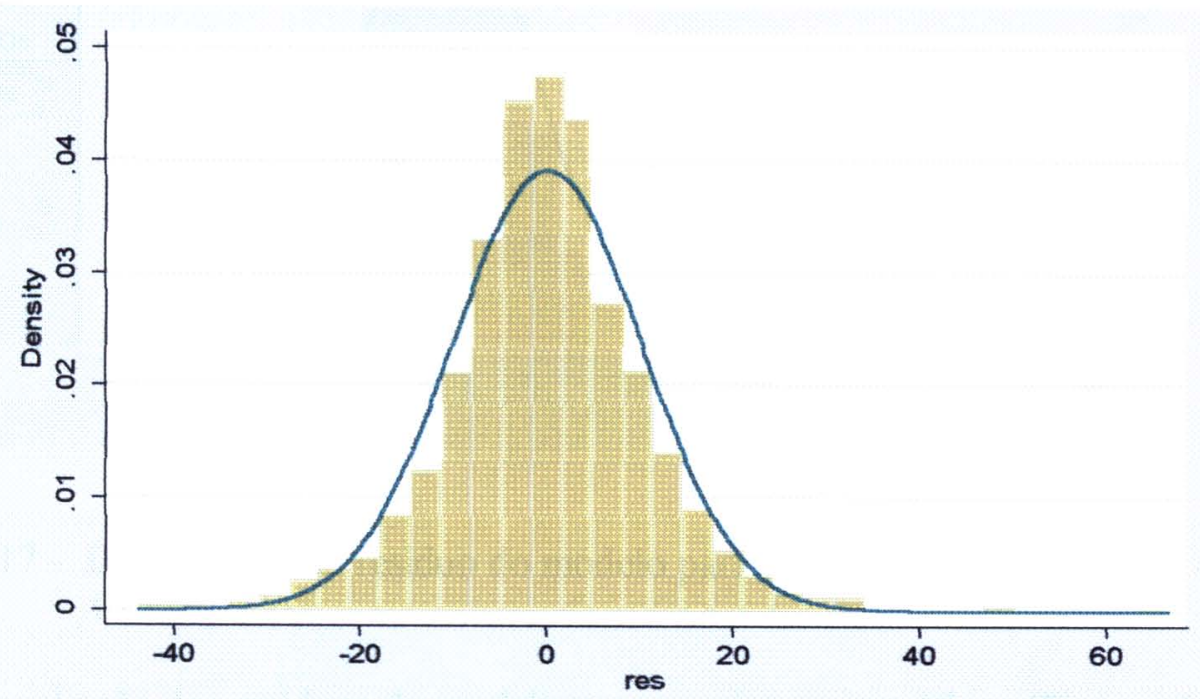

FIGURA 15 - Distribuição do resíduo do modelo para crianças em risco nutricional.

Mogi das Cruzes, 2002.

O resíduo tem uma distribuição próxima da normal, mostrando um bom ajustamento. 


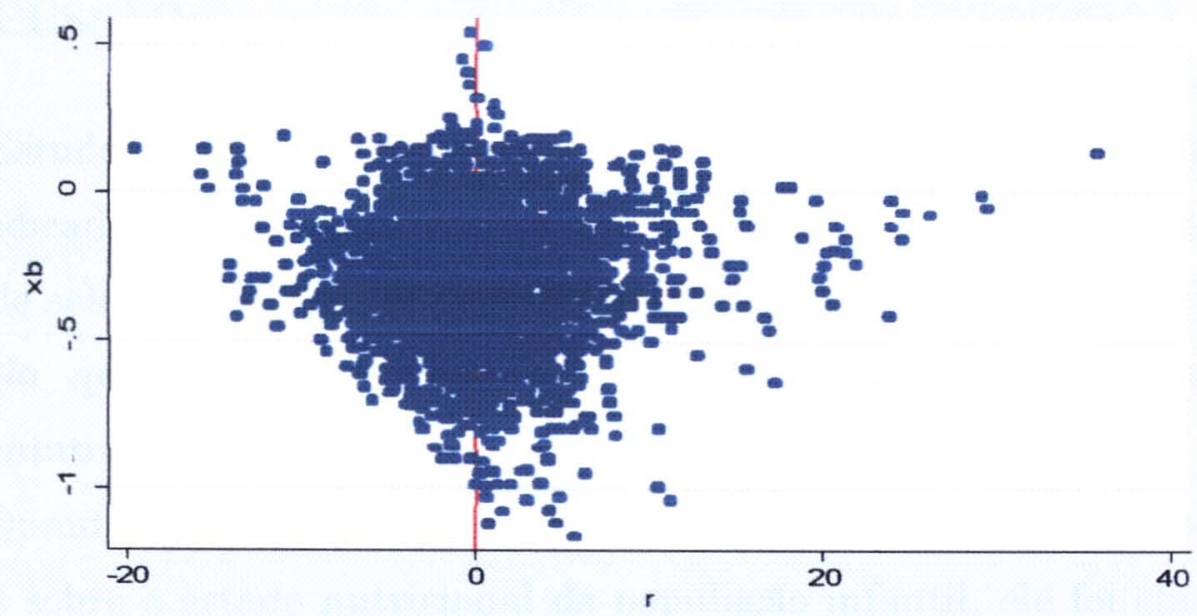

FIGURA 16 - Valores ajustados no modelo para crianças eutróficas versus resíduo Mogi das Cruzes, 2002.

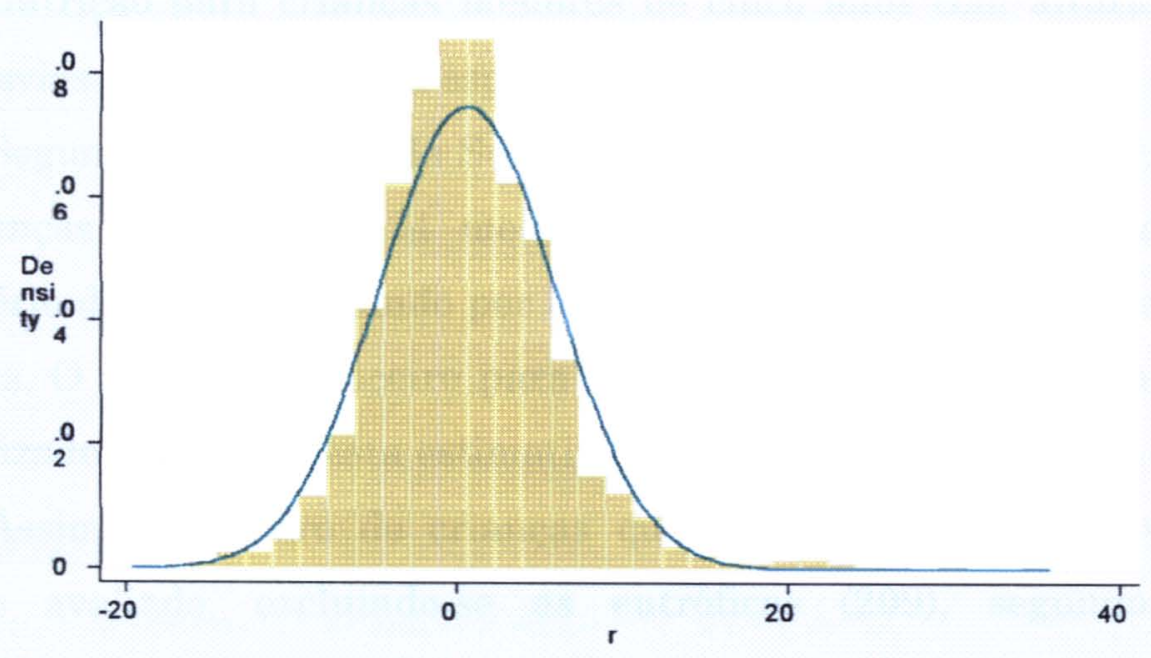

FIGURA 17 - Distribuição do resíduo do modelo para crianças eutróficas. Mogi das Cruzes, 2002.

A avaliação dos resíduos do modelo para as crianças eutróficas (Figuras 16 e 17), mostra que o modelo está bem ajustado. 


\section{DISCUSSÃO:}

Estudos epidemiológicos observacionais devem discutir a validade de seus indicadores, em nosso caso a recuperação nutricional, e os possíveis vieses de seleção, de aferição e confundimento eventualmente presentes.

No que diz respeito ao viés de seleção, é oportuno avaliar a representatividade da amostra e as perdas seletivas no seguimento.

Quanto à seleção da amostra, embora o município não disponha de estudos sobre o estado nutricional da população infantil, ele foi classificado como de baixo risco para desnutrição pelo NUPENS - Núcleo de Pesquisas Epidemiológicas em Nutrição e Saúde da Universidade de São Paulo (BENÍCIO e MONTEIRO, 1997), ou seja, estimou-se em 5,21\% a prevalência de desnutrição para crianças menores de cinco anos com altura inferior a dois desvios-padrão da média esperada para idade e sexo.

Segundo informação da Secretaria da Saúde do Município ${ }^{4}$, o número de crianças menores de 24 meses em risco nutricional estimados pelo Ministério da Saúde, tomando por base os dados do NUPENS, seria de $\mathbf{5 5 0}$ crianças. $O$ repasse financeiro para a compra da suplementação alimentar foi realizado com base nesta estimativa.

Assim, o número de crianças que ingressaram no ICCN (724) no período avaliado, excluindo-se as eutróficas (209), segundo o índice altura/idade, totalizaram 515 o que sugere uma boa cobertura da rede básica de saúde, garantindo o acesso ao programa de suplementação alimentar à população mais carente do município.

Vale ressaltar ainda que Mogi das Cruzes dispõe de 20 Unidades Básicas de Saúde, localizadas de forma estratégica para facilitar o acesso a todos os seus munícipes.

\footnotetext{
${ }^{4}$ Secretaria Municipal da Saúde de Mogi das Cruzes - SP, comunicação pessoal.
} 
Em relação à perda seletiva de seguimento, esta parece não ter ocorrido, uma vez que, ao avaliar o número de crianças que ingressaram no ICCN nas diferentes categorias de estado nutricional, o percentual de abandono mostrou-se semelhante, conforme descrito a seguir:

QUADRO 06 - Distribuição de crianças segundo percentual de abandono e estado nutricional ao ingressar no ICCN. Mogi das Cruzes, 2003.

\begin{tabular}{|l|c|c|c|}
\hline $\begin{array}{c}\text { Estado nutricional } \\
\text { Inicial }\end{array}$ & Início do ICCN & $\begin{array}{c}\text { Término do } \\
\text { ICCN }\end{array}$ & $\%$ de abandono \\
\hline Eutróficos & 209 & 169 & 19,1 \\
\hline Risco Nutricional & 321 & 250 & 22,1 \\
\hline Desnutridos & 194 & 151 & $22,1^{*}$ \\
\hline
\end{tabular}

${ }^{*}$ Desnutridos Graves: $13,6 \%$ e Desnutridos Moderados: $24,6 \%$

Foi realizado também uma análise das principais características apresentadas pelo conjunto de crianças e suas famílias que iniciaram o acompanhamento no programa e comparadas àquelas que abandonaram antes de completar doze meses, o que pode ser visto no anexo 3 .

Os resultados indicam que as perdas ocorridas durante o período de seguimento não super ou subestimaram os resultados obtidos em relação à evolução nutricional, uma vez que as crianças que deixaram o programa (perdas) se assemelham, em relação às variáveis estudadas, às crianças que permaneceram no estudo, exceto em relação à perda de crianças cujos pais apresentavam menor escolaridade ( $1-4$ anos), a qual foi maior entre as que não permaneceram no estudo.

Segundo CRIQUI (1983), vieses de aferição são também denominados vieses de informação e uma estratégia para minimizar a ocorrência deste viés é a utilização de critérios diagnósticos bem definidos.

$\mathrm{O}$ índice escolhido, altura para idade, é recomendado pela OMS para avaliar o estado nutricional de pré-escolares em estudos populacionais (WHO, 1986). Ainda, é interessante destacar que, por ser um índice mais estável, o ganho em estatura pode representar um alcance efetivo da 
intervenção, uma vez que o peso pode estar sujeitos a maiores flutuações, além de estar sujeito à perda após o término da suplementação alimentar, caso a criança não receba os substratos de nutrientes suficientes para atender sua necessidade nutricional e de crescimento, porém o ganho estatural, uma vez adquirido não sofre redução.

Vários estudos que se propõem a avaliar o estado nutricional de crianças inscritas em programas de suplementação alimentar utilizam o índice peso para idade, uma vez que é de mais fácil mensuração e, invariavelmente, estes estudos trabalham com dados coletados na rotina dos serviços de saúde (prontuários), sendo muito comum não se encontrar consistência na medida de estatura, uma vez que esta exige cuidados técnicos para sua tomada.

No caso deste estudo, quando a Secretaria da Saúde planejava a implementação do ICCN no município, decidiu-se centralizar a entrega do suplemento alimentar em um único local, em razão de que as 20 UBS não dispunham de estrutura para manter o suplemento em local apropriado (espaço e ambiente), além de não dispor de recursos humanos suficientes para treinamento das auxiliares de enfermagem que seriam as responsáveis pela tomada das medidas antropométricas. Desta forma, decidiu-se centralizar a entrega e a Universidade de Mogi das Cruzes (UMC) foi convidada, sendo indicada a autora deste estudo como responsável, para o acompanhamento das crianças e orientação aos seus responsáveis.

Antes do início do programa, estagiárias do $4^{\circ}$ ano do Curso de Nutrição da UMC foram treinadas quanto aos critérios para a tomada de peso e estatura, com supervisão direta no decorrer do programa. Adicionalmente procedeu-se a conferência, por amostragem, das medidas de peso e estatura aferidas das crianças, o que permitiu maior confiabilidade dos resultados. Assim foi possível controlar possíveis erros de medida. 
Outra importante vantagem na utilização deste índice, para análise da evolução nutricional das crianças, diz respeito ao fato de não ter sido este o critério utilizado para admissão no programa, uma vez que a criança foi inscrita segundo o índice peso para idade, eliminando a desvantagem do grupo estudado estar posicionado nos extremos da distribuição, não necessitando assim a correção do "efeito de regressão à média" (ERM), indicado em estudos de avaliação de impacto de programas de intervenção nutricional sem grupo controle (CASTRO 1999).

Ainda, no grupo dos vieses de aferição, encontra-se o viés de memória. Em estudos como este há sempre a questão da confiabilidade das informaçōes coletadas, principalmente no que diz respeito àquelas retrospectivas. Para minimizar as questōes relacionadas a este viés, a informação do peso de nascimento, foi confirmada com a Declaração de Nascido Vivo. Buscou-se também garantir maior confiabilidade nas informações prospectivas levantadas ao longo e ao final do estudo. Todas as mães eram informadas, no momento da inscrição no ICCN, que a criança permaneceria pelo período mínimo de 12 meses no programa e que esta permanência não dependeria de qualquer outro fator (recuperação nutricional, melhoria da renda familiar, aquisição de emprego por algum membro a família....).

Para avaliar a ocorrência do viés de confundimento há que se diferenciar o controle dos fatores de confusão para o estudo do impacto do programa que se referem a mudanças em condições econômicas e outras que poderiam ter ocorrido ao longo do tempo, do controle das variáveis de confusão que influenciam o impacto do programa, tais como: escolaridade paterna e materna, paridade e condições ambientais citadas por RIVERA e col. (1991).

Na primeira situação (fator de confusão), a exemplo do ocorrido com o estudo de CASTRO (1999), o confundimento decorrente de uma possível 
influência sazonal sobre a evolução nutricional das crianças atendidas no ICCN parece não ter ocorrido, uma vez que a admissão dos mesmos se deu ao longo de todos os meses do ano e a evolução foi acompanhada mês a mês durante doze meses.

Em relação a mudanças econômicas que poderiam influenciar a evolução nutricional, procurou-se identificá-las perguntando, ao final de 12 meses ao responsável pela criança, se durante o período de exposição ao ICCN alguém da família havia conseguido emprego e, portanto, aumentado a renda familiar. Ainda, foi verificado ao longo do acompanhamento, portanto durante o tempo de exposição ao programa, a ocorrência de internação da criança.

Na segunda situação (variáveis de confusão), buscou-se neste estudo o ajuste das variáveis citadas por RIVERA (1991) além da densidade familiar, idade da mãe e do pai, trabalho materno e aleitamento materno. Estas variáveis, anteriores à intervenção nutricional, possuem o poder de influenciar a recuperação nutricional das crianças, positiva ou negativamente, pois podem alterar a postura materna e paterna no trato com a criança (idade e escolaridade), reduzir o acesso à alimentação pela diluição intrafamiliar (densidade familiar, número de irmãos), expor a criança à condições agressivas à sua saúde (falta de água, esgoto, coleta de lixo), de tal maneira que os resultados do programa podem ser modificados independentemente das ações desenvolvidas.

No entanto é necessário destacar que existem outros fatores que contribuem para a desnutrição da criança, os quais têm sido estudados recentemente, como violência contra a mulher e cuidados infantis inadequados, particularmente no que diz respeito ao estado de saúde física e mental da mãe (UNITED NATIONS UNIVERSITY 2001; CARVALHAES e BENÍCIO 2002). Estes fatores não foram avaliados neste estudo em razão da 
falta de serviços de apoio no município que pudessem prestar a assistência necessária, caso fossem detectados.

É oportuno, neste momento, discutir as opções metodológicas para análise dos dados. A opção pelo modelo de painel possibilitou visualizar os momentos em que ocorreram alterações no estado nutricional das crianças com base em todas as medidas coletadas, o que não é possível conhecer com os estudos que avaliam a evolução nutricional tomando como referência o peso inicial e final. $O$ estudo de painel assemelha-se a um desenho de estudos transversais repetidos, onde é possível observar o que está ocorrendo a cada tomada de medida. A aplicabilidade desta técnica pode servir na avaliação dos serviços que trabalham com programas de suplementação alimentar, pois pode predizer o tempo esperado para que as crianças apresentem respostas às ações de intervenção desenvolvidas.

Um problema encontrado em estudos com amostras repetidas é a autocorrelação existente entre os dados, uma vez que são realizadas medidas das mesmas crianças (no caso do ICCN). Os efeitos de auto-correlação podem ser controlados através do uso do modelo de regressão logística múltipla com o emprego de equações de estimativas generalizadas (GEE). Sinteticamente, a técnica GEE é vantajosa para estudos longitudinais e com medidas repetidas, situação comum em estudos de suplementação nutricional

É pertinente ainda discutir a opção metodológica feita para este estudo separando as crianças pelas categorias do estado nutricional inicial. Esta opção foi feita com objetivo de verificar se existiam diferenças na evolução nutricional para cada categoria. A outra alternativa seria considerar a efetividade global do programa, incluindo todas as crianças independentemente da sua categoria inicial. Em Mogi das Cruzes, aproximadamente $30 \%$ das crianças incluídas no ICCN eram eutróficas. Como este grupo mostrou menor variação de escore $\mathrm{z}$ (Tabela $\mathrm{xx}$ ) é possível que uma análise global subestimasse o impacto. Por outro lado, a opção feita 
permitiu identificar uma melhor resposta dos desnutridos, em especial dos graves.

Se por um lado a estratificação diminuiu o poder estatístico em identificar os possíveis fatores associados à evolução nutricional, uma vez que algumas variáveis podem não ter se mostrado associadas em razão do número reduzido de crianças, por outro lado foi possível ganhar poder explicativo para identificar fatores diferenciados em relação à recuperação nutricional nos grupos estudados.

Uma alternativa promissora para ganhar poder estatístico, sem perder a capacidade de discriminar os diferentes grupos, seria analisar o conjunto, onde o diagnóstico nutricional inicial seria uma variável explanatória a ser modelada.

Futuramente serão realizadas explorações adicionais dos dados, a fim de verificar a evolução nutricional para o conjunto de crianças e os fatores a ela associados, assim como pretende-se avaliar a evolução nutricional através do índice peso para idade, uma vez que se espera menor tempo de resposta para a recuperação nutricional neste índice.

Considerando a validade deste estudo em razão da pouca presença de vieses (de seleção, aferição e confundimento) e da adequação da técnica estatística empregada, passamos a considerar os resultados obtidos.

\subsection{Características da População:}

Em relação às características da população, a comparação dos resultados obtidos na pesquisa Origem/Destino, realizado no município de Mogi das Cruzes, no mês de agosto/96 pela Emplasa, permite evidenciar a situação de desvantagem social das crianças do presente estudo. Por exemplo, a freqüência de chefe de família não alfabetizado no município era de $4,7 \%$ contra $7,7 \%$ da população em estudo. Em relação à residência, 
enquanto $71,5 \%$ dos mogianos moravam em casas próprias, somente $45 \%$ das famílias estudadas eram proprietárias.

Em relação à renda familiar enquanto $28,9 \%$ do total de famílias residentes no município recebiam até três salários mínimos, este percentual chegou a $82,3 \%$ das famílias atendidas pelo ICCN.

Ao se avaliar a oferta de água tratada no município, $87 \%$ dos domicílios tinham o serviço disponível e 78,9\% contavam com rede de esgoto enquanto na população estudada $14 \%$ não possuíam água tratada e $27 \%$ não dispunham de rede de esgoto, o que pode influenciar não somente a qualidade de vida da população, como também predispor as crianças a maior risco de desnutrição.

As condições ambientais de uma população estão estreitamente relacionadas com as suas condições de saúde e bem-estar. Crianças de famílias com abastecimento de água e saneamento adequados estão mais protegidas, especialmente das doenças de veiculação hídrica, da desnutrição e da mortalidade infantil.

BENICIO e col. (2000), através de um estudo que avaliou a evolução da desnutrição, da pobreza e do acesso a serviços públicos em dezesseis estados do país, evidenciou a relação entre melhor desempenho em disponibilidade de serviços públicos e maior redução na prevalência da desnutrição infantil.

O Município não dispõe de dados que mostrem o percentual de mulheres que trabalham fora de casa, no entanto, a freqüência encontrada neste estudo (20\%) é inferior ao encontrado por CARVALHAES e BENÍCIO (2002) estudando 300 crianças de 12 a 23 meses em Botucatu, cidade de porte médio da região Centro-Sul do Estado de São Paulo, classificada à semelhança de Mogi das Cruzes, como de baixo risco para desnutrição, onde $28 \%$ e $33,5 \%$ das mães de crianças desnutridas e eutróficas, respectivamente, exerciam atividade fora do lar. Este resultado pode ser decorrente do baixo 
nível de escolaridade apresentado pelas mães das crianças estudadas, onde $38,6 \%$ apresentavam até 4 anos de estudo e somente $15,4 \%$ haviam completado o ensino fundamental, o que potencialmente limita o acesso ao mercado de trabalho.

\subsection{Características das crianças:}

A distribuição das crianças em relação à faixa etária no momento de inscrição no ICCN mostra que aproximadamente $70 \%$ apresentavam entre 12 e 24 meses. A literatura tem mostrado que quanto mais precoce ocorrer a intervenção nutricional, melhores respostas podem ser obtidas.

As crianças aqui estudadas apresentaram piores condições de nascimento quando comparadas às crianças nascidas no ano de $2000 \mathrm{em}$ Mogi das Cruzes, cuja prevalência de baixo peso ao nascer (BPN) foi de 9,63\% (SEADE, 2000) comparada a $23,7 \%$ neste estudo.

No Brasil, segundo o relatório da Situação Mundial da Infância, a prevalência de baixo peso ao nascer é de $11 \%$ (UNICEF, 1998). Para a cidade de São Paulo, um estudo sobre a tendência secular do peso ao nascer, conduzido por MONTEIRO e col. (2000), mostrou uma prevalência de 8,9\% para o mesmo ano. Um trabalho realizado por LUCENA e col. (1998), revisando os artigos publicados no período de 1990 a 1996 sobre esta temática, desenvolvida em diferentes áreas populacionais no Brasil, mostrou maior incidência de BPN na região Norte e Nordeste (12\%) em relação à região Sul e Sudeste (10\%).

Há que se considerar que este resultado seria esperado por se tratar de um grupo de crianças selecionadas por estarem desnutridas ou em risco de desnutrição, uma vez que a literatura tem mostrado que quanto menor o peso ao nascer, maior é o risco de desnutrição nos primeiros anos de vida (PUCCINI 1988; FITZHARDING e INWOOD 1989). 
A distribuição do peso ao nascer entre as crianças estudadas (média de 2850 g. com $23,7 \%$ de crianças com peso de nascimento $<2.500 \mathrm{~g}$ ) é inferior àquela esperada quando são ótimas as condições do crescimento fetal (média de $3.400-3.500 \mathrm{~g}$ com cerca de $4-5 \%$ de pesos $<2.500 \mathrm{~g}$ ) (MONTEIRO 2000).

Ainda, é interessante considerar que este percentual elevado de BPN poderia refletir também falhas no pré-natal, que tem como objetivo, entre outros, assegurar a evolução normal da gravidez, preparar a mãe para o parto, puerpério e lactação normais, além de identificar o mais rápido possível as situações de risco, para que seja possível prevenir as complicações mais freqüentes da gravidez (FAÚNDES e col. 1987).

Segundo LUCENA e col. (1998), a condição da criança com baixo peso ao nascer reflete a qualidade de atenção dos serviços assistenciais de saúde, que se destinam a evitar essa condição. MONTEIRO e col. (2000) referem que são conhecidas as relações entre falta ou deficiência de assistência prénatal e o retardo do crescimento intra-uterino, prematuridade e, por extensão, a morbimortalidade infantil.

O Ministério da Saúde recomenda o início da assistência pré-natal ainda no primeiro trimestre da gestação e um número mínimo de cinco consultas (MINISTÉRIO DA SAUDE 2000b). Quando investigada a realização do pré-natal, entre as mães das crianças estudadas, 90,8\% (N 658) responderam afirmativamente, sendo que $66,4 \%$ iniciaram no primeiro trimestre e $62,6 \%$ realizaram no mínimo 6 consultas. Estes resultados apontam para falhas na deteç̧ão e prevenção de eventos negativos para a saúde da gestante e da criança.

Destaca-se ainda, em relação aos serviços de saúde do município, que aproximadamente $63,0 \%$ das mães não planejaram a gravidez, o que, mais uma vez, pode refletir deficiência nos serviços prestados pelas Unidades Básicas de Saúde (UBS), uma vez que, o planejamento familiar deve fazer parte dos programas de atenção primária à saúde. Ainda, este quadro 
poderia explicar a média de 3,0 filhos apresentada pelas famílias estudadas, superior ao observado para as mulheres brasileiras, de 2,5 filhos (PNDS, 1996).

\subsection{Estado nutricional das crianças ao ingressar no ICCN:}

As prevalências de déficit para esta população (< - 2 escore z) de estatura para idade, peso para idade e de peso para estatura, foram $26,8 \%$, $27,7 \%$ e 5,9\%, respectivamente. Embora o índice P/I não discrimine a natureza da desnutrição, a prevalência do déficit de $\mathrm{P} / \mathrm{I}$, próxima da prevalência do déficit de $\mathrm{A} / \mathrm{I}$, aliada à prevalência do déficit $\mathrm{P} / \mathrm{A}$ sugere que a maioria do déficit de $\mathrm{P} / \mathrm{I}$ encontrado é, provavelmente, decorrente do comprometimento do crescimento linear. Forte correlação entre déficit de peso/idade e altura/idade foi identificada em publicação de VICTORA e col. (1998).

O estado nutricional das crianças, avaliado pelo índice peso/idade, mostrou maior prevalência de crianças em risco nutricional $(53,3 \%)$ seguido de crianças desnutridas (27,7\%).

Em relação ao peso para a estatura, evidencia-se a inexistência de desnutrição grave e um percentual próximo ao esperado em populações saudáveis $(5,9 \%)$ de desnutridos moderados ( $<-2$ escore $z)$, o que corrobora os achados da literatura. Segundo MONTEIRO (1996), a freqüência de valores baixos da relação peso para estatura (<- 2 escore $z$ ) é muito reduzida e confirma a irrelevância desta forma de desnutrição no país (3,0\% - PNDS, 1996) e a limitada utilidade deste indicador na avaliação do estado nutricional das crianças brasileiras.

Em outros estudos realizados com populações latino-americanas de baixo nível socioeconômico foram encontradas prevalências inexpressivas de déficit de peso para estatura. Esta característica nutricional também tem 
sido encontrada em estudos realizados em alguns estados e regiões brasileiras (POST e col. 2000).

Considerando o índice altura para idade, observa-se na população estudada um percentual elevado de desnutridos graves $(6,1 \%)$ e moderados $(20,7 \%)$ somados, totalizam $26,8 \%$ de crianças (<- 2 escore $z$ ).

Além do comprometimento de estatura, várias conseqüências funcionais adversas estão associadas com a desnutrição em idade precoce, entre os quais: prejuízo da função imune, aumento das taxas e severidade das infecções, elevado risco de morte, além do prejuízo da função cognitiva e do rendimento escolar (CHANDRA 1988; BROWN e BÉGIN 1993; HUFFMAN e MARTIN 1994).

\subsection{Evolução nutricional das crianças:}

Os resultados em relação à resposta das crianças indicaram que, ao longo do tempo de exposição ao ICCN, a condição nutricional estava significativamente melhor para todas as categorias avaliadas, sendo o impacto do programa maior quanto mais intensa a deficiência nutricional apresentada inicialmente. Observaram-se ganhos, em altura, de 1,12 escore z para os desnutridos graves, 0,82 para os desnutridos moderados, 0,57 para as crianças em risco nutricional e 0,45 para os eutróficos. Estes resultados são coincidentes com pesquisas que mostram que as melhores respostas aos programas de suplementação alimentar são apresentadas pelas crianças com maiores déficits nutricionais (CHAVES e col. 1989; SANTOS 1990; LEI e SZARFARC 1992; PUCCINI e col. 1996; GOULART 1998; GUTIERREZ e col. 1998; CASTRO 1999 ).

Ainda é interessante destacar que a recuperação nutricional ocorreu em diferentes momentos segundo as categorias de estado nutricional inicial. 
Sendo mais rápida a resposta das crianças desnutridas quando comparadas às crianças em risco nutricional.

Segundo MONTE (1999), citado por SOARES e PARENTE (2001), para crianças em tratamento ambulatorial e no domicílio, como foi o caso das crianças estudadas, o Departamento de Nutrição da Sociedade Brasileira de Pediatria preconiza recuperação nutricional entre dois e três meses, desde que se consiga repassar efetiva orientação às mães e dar-lhes apoio e supervisão direta. Em nosso estudo a recuperação nutricional teve início no segundo mês para os desnutridos graves e moderados conforme a Figura 10. Resultados semelhantes foram encontrados por PERRA e COSTELLO (1995) e RIVERA e col. (1991), avaliando o índice peso para idade e TADDEI e col. (2000), avaliando os três índices; tais mudanças ocorreram entre o terceiro e o quarto mês nos estudos conduzidos por estes autores.

Em relação às crianças desnutridas a freqüência ao programa de suplementação alimentar esteve associado de forma independente à evolução nutricional, uma vez que o coeficiente de ganho em altura não sofreu redução mesmo após a introdução de outras variáveis no modelo estatístico empregado.

Resultados semelhantes foram encontrados por AITCHISON e col. (2000), estudando o efeito de um programa de suplementação alimentar no crescimento de 133 crianças desnutridas de 12 a 18 meses na Indonésia, onde após análise multivariada, constataram efeito positivo no crescimento de crianças suplementadas quando comparadas às não suplementadas.

LUTTER e col. (1990), em um estudo de intervenção com grupo controle, conduzido na Colômbia com suplementação alimentar de leite e óleo para crianças entre zero e 36 meses de idade, verificaram associação independente do crescimento linear para as crianças suplementadas, sendo a melhor resposta apresentada pelas crianças mais jovens em dois momentos 
diferentes: entre 9 a 12 meses (período de pico de diarréias), seguido do período entre 3 a 6 meses ( caracterizado pelo desmame).

OBATOLU (2003) em um estudo controvertido do ponto de vista ético, conduzido com 90 crianças de quatro a dezoito meses de idade, sendo 60 desnutridas de mesmo estrato socio-econômico (30 com suplementação e 30 sem suplementação) e 30 eutróficas (sem suplementação) na Nigéria, verificou que, ao final da intervenção nutricional, as crianças suplementadas atingiram a mesma média de peso das crianças eutróficas, enquanto as desnutridas não suplementadas permaneceram com a desvantagem de peso inicialmente diagnosticada ( $<$ Percentil 3), mostrando que a suplementação alimentar melhora o estado nutricional de crianças com comprometimento de crescimento.

GRANTHAM-McGREGOR e col. (1996), ao realizar um estudo, com grupo controle, na Jamaica com 127 crianças de 9 a 24 meses com desnutrição crônica, evidenciaram através de análise de regressão múltipla, que ao final de dois anos de intervenção, a suplementação alimentar havia produzido aceleração do crescimento, medido através do ganho de comprimento.

A despeito de procedimentos controvertidos do ponto de vista ético, a exemplo de desnutridos não receberem intervenção nutricional e serem usados apenas para estudo, os programas de suplementação alimentar realizados em diferentes partes do mundo parecem convergir para uma resposta positiva deste tipo de intervenção na recuperação de crianças que apresentam déficits nutricionais e que, quanto maior o comprometimento, melhores são as respostas. 
5.5. Variáveis associadas à evolução nutricional das crianças:

Foram identificadas como variáveis associadas positivamente à recuperação nutricional das crianças desnutridas: a idade da criança ao ingressar no programa (12 a 24 meses), o melhor peso de nascimento ( $\geq 3000$ g) e a oferta do aleitamento materno.

Consistentes com a literatura estão os achados em relação a melhor recuperação das crianças na idade entre 12 e 24 meses (LERNER e col. 1988; CHAVES e col. 1989; LEI e SZARFARC 1992; CARVALHO e col. 1992, RIVERA e HABICHT 1996, RIVERA e HABICHT 2002).

Segundo SCHROEDER e col. (1995), poucas publicações têm analisado a resposta da suplementação para uma idade específica. Adicionalmente, refere que o entendimento mais preciso das idades nas quais as crianças obtêm maior beneficio da suplementação nutricional pode auxiliar na melhoria da efetividade de tais programas. Em estudo conduzido com 1208 crianças de áreas rurais na Guatemala, o autor observou que no primeiro ano de vida a suplementação foi associada com crescimento adicional em peso e altura, com respostas menos significantes no segundo ano e entre o segundo e terceiro ano a suplementação só teve efeito no comprimento.

Em relação ao peso ao nascer, embora muitos estudos tenham evidenciado sua relação direta com o estado nutricional futuro da criança, existe escassez de publicações que tenham avaliado sua influência na recuperação nutricional de crianças atendidas em programas de suplementação alimentar.

SANTOS (1990) refere a importância de incluir o peso ao nascer em estudos de impacto de intervenções nutricionais na infância como uma possível variável interveniente no processo de recuperação nutricional. No entanto, ao buscar esta associação no estudo conduzido com 439 crianças atendidas em programa de suplementação alimentar em São Paulo, não 
conseguiu identificar esta influência em razão de limitações no tamanho amostral e nas informações dos prontuários do serviço.

CASTRO (1999), acompanhando 748 crianças atendidas em programa de recuperação nutricional no Rio de Janeiro, encontrou evolução semelhante entre crianças nascidas com baixo peso, comparadas àquelas que nasceram com peso igual ou superior a 2500 gramas. No entanto não foram avaliadas separadamente as crianças que nasceram com peso adequado $(\geq$ $3000 \mathrm{~g})$.

Neste estudo, avaliando as crianças nas três categorias de nascimento (baixo peso, peso insuficiente e peso adequado), somente foi encontrado efeito significante nas crianças nascidas com 3000 gramas ou mais.

Em relação ao aleitamento materno, vários estudos indicam que as crianças amamentadas têm menor risco de desnutrição. AGUILON e col. (1982), analisando a relação entre as características familiares e o estado nutricional de crianças pré-escolares, identificaram que, entre as crianças eutróficas, $69,8 \%$ foram amamentadas, enquanto apenas $28 \%$ das crianças desnutridas severas receberam aleitamento materno.

No entanto, tem sido pouco explorada a influência do aleitamento materno na recuperação de crianças atendidas em programas de suplementação alimentar.

O achado neste estudo, que mostra a associação positiva do aleitamento materno na evolução nutricional das crianças desnutridas e em risco nutricional é mais dificil de explicar, uma vez que, avaliou-se a oferta do aleitamento materno no passado e não a presença do aleitamento no período de intervenção. Tal achado sugere que há algo diferente nestas crianças, hipoteticamente talvez a criança seja diferente pelo estabelecimento de um vínculo afetivo mãe-filho, ainda o aleitamento materno pode produzir um impacto duradouro na condição nutricional e de saúde da crianças que lhe garante melhor resposta à recuperação. 
Este resultado mostra, que o aleitamento materno é uma variável que deve ser explorada em estudos que se propõe a avaliar impacto de programas de suplementação alimentar, além de outras variáveis relacionadas ao estado de saúde da criança (parasitoses, infecções...).

Ainda no grupo de desnutridos, as crianças cujas mães não trabalhavam fora evoluíram pior comparadas às crianças cujas mães trabalhavam fora. $O$ trabalho materno tem despertado interesse dos pesquisadores no sentido de avaliar o quanto ele poderia influenciar na determinação do estado nutricional infantil, quer seja de forma positiva, quando ele permite um maior acesso a bens e serviços, quer seja de forma negativa, quando a criança é privada de uma maior cuidado pela ausência da mãe.

Estudos têm evidenciado que freqüentemente as mães de crianças desnutridas não desenvolvem atividades remuneradas; por outro lado, quando as mulheres trabalham fora de casa, elas substancialmente melhoram a renda familiar o que se reflete no melhor estado nutricional das crianças (AGUILLON e col. 1982; OBATOLU 2003).

Um estudo realizado em Pelotas, RS, constatou que crianças de famílias cujas mães não trabalhavam fora apresentaram um aumento de $70 \%$ no risco de déficit nutricional (OLINTO e col. 1993).

CARDOSO (1995), analisando os resultados da PNSN (1989), constatou que o trabalho materno acima de $\mathbf{3 0}$ horas semanais atuou como fator de proteção à desnutrição de pré-escolares no Nordeste e no Sul rural.

Estudos complicados por LESLIE (1988), citado por CARVALHAES e BENÍCIO (2002), não encontraram evidências conclusivas da associação entre trabalho materno e pior estado nutricional infantil. Outros pesquisadores afirmam que, dependendo da renda gerada, do tipo de trabalho, da adequação do cuidado substituto e da idade da criança, além da consideração da autonomia materna para direcionar os recursos gerados por 
seu trabalho, o efeito sobre o estado nutricional da criança poderá variar de risco à proteção.

Pouco se tem investigado sobre a influência do trabalho materno na recuperação nutricional de crianças em programas de suplementação alimentar. No entanto, os resultados deste estudo apontam, consistentemente com a associação entre o não trabalho e o estabelecimento da desnutrição, para uma pior recuperação da criança na ausência do trabalho materno. Um possível explicação pode ser a menor disponibilidade de recursos para o cuidado da criança, antes e após o recebimento do suplemento alimentar, sugerindo que o impacto do não trabalho materno dificulta a recuperação nutricional. Este resultado aponta para os limites de atuação da área da saúde no controle da desnutrição, remetendo à necessidade de mudanças nas políticas públicas que atuam na estrutura da sociedade, por exemplo, aumentando a oferta de trabalho para mulheres que têm crianças desnutridas.

Para as crianças em risco nutricional, destacou-se como significativamente associadas à recuperação nutricional, a freqüência ao programa de suplementação alimentar, o aleitamento materno, e a renda familiar acima de três salários mínimos e de forma negativa a ausência de trabalho materno.

Da mesma forma, para as crianças eutróficas a participação no programa permaneceu associado à evolução nutricional, sendo que para estas crianças esteve associado, também, de forma positiva ingressar no ICCN entre 12 e 24 meses. No entanto, é importante destacar que as crianças eutróficas tiveram uma resposta inferior às crianças com comprometimento nutricional, tendência observada em outros estudos realizados com clientela de programas de suplementação alimentar que incluíram crianças com déficits nutricionais leves ou inexistentes (SOARES e PARENTE, 2001; RIVERA e col. 2002). 
A partir da análise destes resultados, verifica-se que permaneceu para todas as crianças, como fator associado à melhora nutricional, independente de outros fatores, a freqüência ao programa, o que implicava no recebimento da suplementação alimentar e participação nas atividades educativas. É possível supor que o ICCN, tal como foi implantado no município, ou seja, direcionando ações de educação nutricional e não apenas a distribuição de alimentos, tenha contribuído para 0 alcance dos resultados obtidos.

Historicamente os programas de suplementação alimentar são desenvolvidos na rede básica de saúde, onde outras ações preventivas são desenvolvidas, tais como: imunizações, consultas periódicas, entre outras.

Quando a suplementação alimentar é vista como uma mera distribuição de alimentos, sem que seja desenvolvido junto à população beneficiária um trabalho educativo, os resultados por vezes são inexpressivos (GUERRI e col. 1985, BEVILACQUA e col. 1990; CARVALHO e col.1992; MONTE e col.1998). Por outro lado, a suplementação alimentar, quando acompanhada de outras ações de saúde e educação, tem se mostrado efetiva quanto à recuperação da desnutrição (LEI e col. 1993; PERRA e COSTELLO 1995; PAKNAWIN-MOCK e col. 2000).

No caso do ICCN em Mogi das Cruzes, embora o programa de suplementação alimentar não tenha sido implantando nas UBS, quando a mãe comparecia ao local de distribuição do suplemento recebia orientação alimentar e nutricional, aprendia a acompanhar a evolução do peso no "cartão da criança", o que lhe dava maior autonomia para procurar assistência médica ao perceber falhas no crescimento de seu filho, sendo orientada a comparecer à UBS regularmente para vacinação e consultas periódicas, o que era verificado periodicamente.

Talvez este diferencial explique parte da recuperação obtida pelas crianças deste estudo. É interessante destacar que um estudo conduzido no norte do Vietnã com 238 crianças desnutridas de 6 a 24 meses, tendo como 
intervenção a educação nutricional, em um programa eticamente questionável, encontrou associação significante na não deterioração do crescimento infantil nas famílias que receberam as ações educativas, comparadas às crianças das famílias controle, o que levou os autores a concluírem que a educação nutricional é um fator importante para o desenvolvimento infantil e que os programas de intervenção que buscam melhorar as condições nutricionais de crianças produzem melhores resultados se focarem crianças menores de 24 meses e portadoras de maiores déficits nutricionais (SCHROEDER e col. 2002).

BANAPURMATH e col. (1999), estudando 100 crianças que saíram da condição de desnutrição grave após terem passado por programa de suplementação e educação nutricional, atribuíram a recuperação, obtida inicialmente no peso e depois na altura, não somente à suplementação alimentar, mas também à atenção da família voltada para a criança que por percebê-la mais "frágil", provavelmente dedicou-lhe maior atenção e melhor alimentação.

Finalmente, cabe tecer algumas considerações sobre as variáveis que não se mostraram associadas à recuperação nutricional das crianças estudadas. Começando pela renda familiar, há que se observar que esta variável ao ser analisada no modelo univariado não se mostrou associada à condição nutricional de nenhuma categoria de criança. No entanto, como apresentou um $\mathrm{p}<0,25$, foi incluída nas análises multivariadas. No caso das crianças desnutridas acabou sendo retirada com a inclusão da escolaridade materna. Para as crianças em risco nutricional, após o controle das variáveis de confusão, a renda familiar acima de 3 salários mínimos mostrou-se associada à melhor recuperação nutricional.

A renda tem sido relacionada com as condições de saúde e de nutrição das crianças que, por sua vez, está relacionada com a educação da mãe e o trabalho materno. Neste estudo a renda não mostrou associação na 
recuperação de crianças desnutridas, provavelmente em razão de se tratar de uma população homogênea, onde $85,2 \%$ das famílias destas crianças recebiam até 3 salários mínimos; destas, aproximadamente $34 \%$ viviam com menos de um salário. Resultados semelhantes foram encontrados no estudo de OBATOLU (2003), onde as famílias das crianças desnutridas tinham baixa renda, o que foi associado à não ocupação materna e sua baixa escolaridade.

Outras variáveis que não se mostraram associadas à evolução nutricional das crianças foram: a família possuir mais de três filhos e a criança possuir mais de três irmãos. Embora inicialmente estas variáveis tivessem mostrado uma associação negativa à recuperação das crianças suplementadas, após o controle das variáveis de confusão, perderam sua associação.

Por fim cabe ressaltar que a não aquisição de trabalho novo por algum membro da família, que no modelo univariado apresentava-se associado de forma negativa à evolução das crianças desnutridas, após ajuste apresentouse como uma variável limítrofe (IC $-0,41-0,02)$ o que pode ser decorrente do número reduzido de crianças nesta análise. É possível que caso o número de sujeitos fosse maior, esta associação permaneceria a exemplo do que ocorreu com a ausência de trabalho materno, limitando as possibilidades destas famílias em adquirir bens e serviços necessários para suprir as necessidades básicas da família e, por consegüinte, das crianças.

\subsection{Adequação do programa:}

A Portaria que estabelecia os critérios para inscrição no ICCN determinava que as crianças deveriam ser inscritas na faixa etária de 6 a 23 meses quando o peso para idade apresentava-se abaixo da linha inferior do Percentil 10. 
Na população estudada, 4,0\% (Tabela 1) encontrava-se acima do limite da idade; este fato pode ser decorrente do trâmite estabelecido para inscrição no programa. De início, a criança deveria ser examinada pelo pediatra na UBS que, ao verificar se a mesma se enquadrava nos critérios propostos pelo Ministério da Saúde, fazia o encaminhamento para a Secretaria da Saúde do Município (anexo 5) que procedia ao cadastro da criança no sistema. A partir de então, a mãe deveria aguardar um telegrama informando o local e o dia que deveria levar a criança para o início do acompanhamento (anexo 6), com demora média de 30 a 40 dias.

Ao se verificar o tempo médio excedendo o limite de idade estabelecido, constatou-se o valor de $\mathbf{2 8 , 5}$ dias, o que de fato aponta para a demora no tempo transcorrido entre o encaminhamento e a inscrição no programa. Ressalta-se que os dias excedentes não apresentaram distribuição normal tendo a sua mediana em 22,5 dias (p25: 13,5; p75: 37,5; mínimo 3 e máximo 96 dias).

Em relação ao estado nutricional, é importante destacar que, pelo critério recomendado pelo Ministério da Saúde (indice peso/idade abaixo do Percentil 10), 31,5\% das crianças seriam classificadas como eutróficas ao entrar no programa, o que pode ter ocorrido em razão de:

- Falhas na obtenção do peso da criança nas UBS;

- Tomada de peso das crianças em instrumentos não aferidos (balanças);

- Erro na localização do peso da criança na Curva de Crescimento (falta de treinamento de pessoal);

- Inscrição realizada por solicitação da mãe ou avaliação do pediatra considerando questões sociais e não o critério antropométrico.

A inclusão de crianças eutróficas, portanto fora dos critérios estabelecidos para inscrição em programas de suplementação alimentar, 
leva a algumas dificuldades: a primeira diz respeito à avaliação de impacto, uma vez que não se espera que estas crianças venham a ter uma velocidade de crescimento maior à que vinham apresentando, pois encontravam-se dentro do padrão esperado, o que pode comprometer a avaliação do programa; outra dificuldade diz respeito aos recursos, sempre escassos, que acabam sendo diluídos em razão de uma demanda aumentada. Ainda, freqüentemente, a equipe de saúde torna-se insuficiente para atender essa demanda, o que acaba por prejudicar o atendimento à criança que realmente necessita de atenção diferenciada.

Destaca-se na análise do programa que a distribuição da suplementação alimentar não sofreu descontinuidade, o que é comum observar em programas deste tipo, exceto no mês de julho de 2000 , quando houve atraso na entrega do leite pelo fornecedor que havia ganho a concorrência pública recentemente. Este fato, sem dúvida, contribuiu para o baixo índice de abandonos observado na população estudada.

Observa-se, através da renda das famílias beneficiadas pelo ICCN, comparada com a população do município, que o programa conseguiu captar aquelas mais vulneráveis do ponto de vista socioeconômico.

Finalmente, é importante destacar que, em decisão inédita, o Conselho de Saúde do município optou por manter o programa com recursos próprios, após a decisão do Ministério da Saúde (MS) em substituir o ICCN pelo programa Bolsa Alimentação, em fins de 2001.

No início de 2001, o município recebeu uma auditoria do MS que tinha como objetivo avaliar o funcionamento do ICCN e, caso não fosse observada qualquer irregularidade, o mesmo poderia se cadastrar para o programa Bolsa Alimentação. Após uma semana de auditoria, o Secretário da Saúde recebeu um parecer favorável em relação às atividades desenvolvidas no ICCN e a aprovação para o cadastramento no novo programa que estava sendo implantado em nível nacional. 
Apesar de iniciar o processo para cadastrar as famílias neste novo programa, foi decidido pela continuidade do ICCN, conforme citado anteriormente, com recursos do próprio município. Esta decisão, segundo as autoridades de saúde, foi tomada em razão do custo-benefício que o programa apresentava, ou seja, as respostas obtidas na evolução nutricional das crianças, somadas à aprovação da população beneficiada em relação às atividades desenvolvidas, justificava a continuidade do mesmo. 


\section{CONCLUSÃO:}

A partir dos resultados obtidos é possível concluir que:

As crianças beneficiárias do ICCN no município de Mogi das Cruzes apresentaram melhora do estado nutricional, avaliado através da variação média do escore $\mathrm{z}$ ao longo de 12 meses em 1,12 (desnutridos graves), 0,82 (desnutridos moderados), 0,57 (risco) e 0,45 (eutróficos).

Estes dados mostram que os melhores resultados são obtidos pelas crianças com maiores déficits nutricionais, corroborando estudos que têm avaliado os programas de suplementação alimentar desenvolvidos em diferentes partes do mundo.

De forma positiva esteve associado também à recuperação das crianças o melhor peso de nascimento ( $\geq 3000 \mathrm{~g})$, o aleitamento materno e a idade das crianças ao ingressar no programa (12 a 24 meses). Especial atenção deve ser dada, portanto, à assistência pré-natal no que diz respeito ao estímulo ao aleitamento materno, acompanhamento da evolução nutricional da gestante e a inclusão de crianças em programas de suplementação alimentar na faixa etária onde a possibilidade de resposta é maior.

A renda familiar (> 3 salários mínimos) mostrou-se associada à melhor recuperação para o grupo das crianças em risco nutricional, o que não foi possível observar no grupo de crianças desnutridas provavelmente em razão da homogeneidade das famílias em relação ao baixo poder aquisitivo apresentado.

Foi possivel também verificar, através das análises utilizadas, que a ausência de trabalho materno esteve associada à pior recuperação das crianças e a não aquisição de trabalho por algum membro da família, no período de exposição da criança ao programa, fica como uma possível 
associação à pior recuperação nutricional e deve ser estudada em amostras maiores, pois aqui apresentou valor limítrofe. 


\section{CONSIDERAÇÕES FINAIS:}

\section{- Em relação ao município:}

Em razão dos resultados insatisfatórios obtidos, no que diz respeito a oferta do aleitamento materno na população estudada, e o seu possível efeito não só na proteção da desnutrição como também na sua associação com recuperação nutricional, ratifica-se a necessidade de se realizar ampla campanha de estímulo ao aleitamento materno junto à população e uma mobilização por parte dos profissionais da saúde no sentido de promover o aleitamento materno junto à população assistida pela rede de saúde.

As informações encontradas indicaram como fatores de risco para a pior recuperação nutricional das crianças, a ausência do trabalho materno e, possivelmente, a falta de trabalho de outros membros da família, o que pode estar condicionado à baixa escolaridade apresentada pela população estudada, e coloca a necessidade de aumentar a oferta de emprego e educação, principalmente para as famílias mais vulneráveis com crianças desnutridas e/ou em risco nutricional. Logo, ações como as implementadas neste programa devem ser associadas à melhoria do quadro socioeconômico para que sejam eficazes e perenes, gerando independência e auto-suficiência na manutenção de uma melhor qualidade de vida dos munícipes.

\section{- Em relação do programa de suplementação alimentar:}

Segundo MONTEIRO (2000), ao analisar criticamente as intervenções nutricionais implantadas no país a partir de 1993, o governo federal retomou os programas de suplementação alimentar, tentando corrigir as deficiências observadas no passado, tais como: o não cumprimento de metas de cobertura, o não direcionamento da atividade para os estratos pobres e biologicamente 
mais vulneráveis da população, a irregularidade na provisão dos alimentos e a pouca associação com a prestação de cuidados básicos de saúde. Deste esforço surgiu a concepção de programas que estimulam a participação ativa dos governos municipais, a compra descentralizada dos alimentos, o envolvimento das comunidades (por intermédio dos Conselhos de Saúde), a vinculação obrigatória com as ações básicas de saúde e a seleção criteriosa de beneficiários restrita aos grupos biologicamente mais vulneráveis da população.

A experiência do ICCN, tal como foi implantado em Mogi das Cruzes, parece ter atendido a estas determinações, o que resultou efetivamente na melhora nutricional da população assistida.

Apesar do resultados positivos na recuperação nutricional das crianças, foram identificados fatores que mostram a necessidade da ampliação das atividades de caráter emergencial e transitório, tais como são classificados os programas de suplementação alimentar, para mudanças na organização social, política e econômica do país.

Temos assistido neste ano de governo novo, um movimento voltado para o combate à fome a partir da mobilização nacional da sociedade, das organizações governamentais e não governamentais no sentido de prover alimentação adequada a todos os cidadãos, garantindo assim a Segurança Alimentar, definida pela FAO, 1983, como sendo a capacidade de "... assegurar que todas as pessoas, todo o tempo, tenham o acesso físico e econômico aos alimentos básicos que necessitam" .

O movimento parece legítimo, no entanto carece de maiores definições para enfrentar o problema nutricional no país. Um avanço que merece destaque no Projeto Fome Zero do governo federal é a ênfase na educação alimentar, cabendo ao poder público estabelecer campanhas e educação para o consumo, tendo como objetivos a promoção de práticas alimentares saudáveis e o incentivo à dieta balanceada, entre outros, o que, segundo os 
resultados obtidos neste estudo, contribuem efetivamente para o alcance de melhores resultados, quando somados a ações emergenciais de combate à fome e carências nutricionais. 


\section{REFERÊNCIAS BIBLIOGRÁFICAS:}

Aguillon DB. Caedo MM, Araold JC, Engel RW. The relationship of family characteristics to the nutritional status of pre-school children. Food Nutr Bull 1982; 4 (4):5-16.

Aitchison TC, Durnin JVGA, Beckett C, Pollitt E. Effects of an energy and micronutrient supplement on growth and activity, correcting for nonsupplemental sources of energy input in undernourished children in Indonesia. Eur J Clin Nutr 2000; 54 (2): S69-S73.

Almeida CAN, Ricco RG, Ciampo LAD, Nogueira MPC, Rico RC. Determinação da influência da escolaridade dos pais no estado nutricional de crianças. Pediatria Moderna 1999; XXXV (9): 707-12.

Assis AMO, Barreto ML. Condições de vida, saúde e nutrição na infância em Salvador. Brasília; INAN, Salvador: UFBA/Escola de Nutrição/Instituto de Saúde Coletiva, 2000.

Banapurmath CR, Prasad SM, Banapurmath S, Kesaree N. Follow-up study of survivors of severe protein energy malnutrition. Indian Pediatrics 1999; 36: 139-143.

Beaton G H., Ghassemi H. Supplementary feeding programs for young children in developing countries. Am J Clin Nutr 1982; 35: 864-916.

Behar M. Análisis crítico de los programas de nutrición aplicada en América Latina. Rev Nutr PUCCAMP 1991; 4 (1/2): 9-24. 
Bellamy C. Situação Mundial da Infância 1998. Unicef, Brasília.

Benício MHD'A, Monteiro CA, Pontieri MJ, Gandra YR, Lima FD. Avaliação antropométrica da eficácia da suplementação alimentar dos centros de educação de alimentação do pré-escolar. Rev Saúde Pública. 1981; 15 Supl.1: 40-7.

Benício MHD'A, Monteiro, CA. Desnutrição infantil nos municípios brasileiros: risco de ocorrência. São Paulo: Núcleo de Pesquisas Epidemiológicas em Nutrição e Saúde da Universidade de São Paulo NUPENS/USP; Brasília, DF: UNICEF, 1997.

Benicio MHD`A; Monteiro CA; Rosa TEC. Evolução da desnutrição, da pobreza e do acesso a serviços públicos em dezesseis estados. In: Monteiro CA. Velhos e novos males da saúde no Brasil: a evolução do país e de suas doenças. $2^{\text {a }}$ ed. São Paulo: Hucitec; 2000. p. 142-150.

Bevilacqua AB, Marcondes TM, Pripas S, Pedrazzani ES, Ubeda EML. Avaliação do Programa de Suplementação Alimentar no Município de São Carlos. Rev. Esc. Enf. 1990; 24 (1):101-110.

Brasilia (2000). Incentivo ao Combate às Carências Nutricionais. Manual de Orientação. pg 25.

Brasil. Ministério da Saúde. Secretaria de Políticas de Saúde. Departamento de Atenção Básica. Saúde da criança: acompanhamento do crescimento $e$ desenvolvimento infantil. Brasília: Ministério da Saúde 2002. (Série Cadernos de Atenção Básica; n.II). 
Brown KH; Bégin F. Malnutrition among wealings of developing countries: still a problem begging for solutions. J Ped Gastr Nutr 1993; 17 (2): 132-138.

Campana AP, Nóbrega FJ, Moraes S, Yida M. Status socio-econômico e deficiência intelectual em escolares. J Ped 1977; 43: 17-25.

Cardoso MAA. Cuidado infantil e desnutrição de pré-escolares: Regiões Nordeste e Sul do Brasil. São Paulo, 1995. [Tese de Doutorado - Faculdade de Saúde Pública da USP].

Carvalhaes MABL, Benício MHD’A. Capacidade materna de cuidar e desnutrição infantil. Rev. Saúde Pública 2002; 36 (2): 188-197.

Carvalho NM, Giugliani ERJ, Seffrin CF, Hartmann RM. Seguimento de crianças com desnutrição moderada ou grave em população periférica (Brasil). Rev. Saúde Pública 1992; 26 (4): 223-8.

Castro IRR. Efetividade da suplementação alimentar na recuperação nutricional de crianças: avaliação do programa "Leite é saúde" no município do Rio de Janeiro. São Paulo; 1999. [Tese de Doutorado - Faculdade de Saúde Pública da USP].

Castro IRR. Efetividade da suplementação alimentar na recuperação nutricional de crianças: avaliação do programa "Leite é saúde" no município do Rio de Janeiro. NUPENS, USP, São Paulo, 2000.

Chandra RK. Nutrition and immunity. Trop Geogr Med 1988; 40 (3): 46-51. 
Chaves SP, Stefanini MLR, Lei DLM, Lerner BR. Evolução do estado nutricional de desnutridos matriculados em programas de intervenção. Rev Nutr PUCCAMP 1989; 2 (2): 161-77.

Chen LC, Chowdhury A, Huffman SL. Anthropometric assessment of energy protein malnutrition and subsequent risk of mortality among preschool aged children. Am J Clin Nutr 1980; 33: 1836-45.

Criqui MH. Response bias and risk ratio in epidemilogic studies. $A m J$ Epidemiol 1983; 109:394-9.

Dean AG, Dean JA, Coulombier D, Brendel KA, Smith DC, Burton AH et al. Epi Info, Version 6: a word processing, database, and statistics program for epidemiology on microcomputers. Atlanta (Ge): Centers for Disease Control and Prevention, 1994.

Engstrom EM. Sisvan: instrumento para o combate aos distúrbios nutricionais em serviços de saúde: o diagnóstico nutricional. 2.ed. Rio de Janeiro: FIOCRUZ, 2002.

Faúndes A, Pinotti JA, Cecatti JG. Atendimento pré-natal: assistência obstétrica primária: quais as necessidade no Brasil. J Bras Med 1987; 3:3854.

Ferreira HS. Desnutrição: magnitude, significado social e possibilidade de prevenção. Maceió: EDUFAL, 2000. 218p.

Ferro-Luzzi A, Sette S, Franklin M, James WPT. A simplified approach of assessing adult chronic energy deficiency. Eur J Clin Nutr 1992; 46: 173-86. 
Fisberg M, Pedromônico MR, Braga JAP, Ferreira AMA, Pini C, Campos SCC et al. Comparação do desempenho de pré-escolares, mediante teste de desenvolvimento de Denver antes e após intervenção nutricional. Rev.Ass Med Brasil 1997; 43 (2): 99-104.

Fitzharding PM, Inwood S. Long-term growth in small-for-date children. Acta Paediatr Scand 1989; 349:27-33.

[FNUAP] Fundação das Nações Unidas para a População. $A$ situação $d a$ população mundial. New York 1994.

Ghassemi H. Supplementary feeding in programmes ind developing countries: lessons of the eighties. Asia Pacific J Clin Nutr 1992; 1: 131-152.

Gopalan S. Malnutrition: Causes, Consequences, and Solutions. Nutrition 2000; 16: 556-58.

Goulart RMM. Evolução do estado nutricional de crianças submetidas a programa de suplementação alimentar e ações educativas à família no município de Itaquaquecetuba - SP. São Paulo; 1998 [Dissertação de Mestrado - Faculdade de Saúde Pública da USP.

Grantham-McGregor SM, Wlaker SP, Himes JH, Powell CA. Stunting and Mental Development in Children. Nutr Res 1996; 16 (11/12):1821-1828.

Greenland S. Modeling and variable selection in epidemiologic analysis. Am J Public Health 1989; 79: 340-49. 
Guerri M, Andrews N, Fox K, Jutsum P, Hill DS. A supplementary feeding programme for the management of severe and moderate malnutrition outside hospital. J Trop Pediatrics 1985; 31: 101- 108.

Gutierrrez MR, Bettiol H, Barbieri MA. Avaliação de um programa de suplementação alimentar. Rev Panam Salud Publ/Pan Am J Public Health 1998; 4(1): 32-40.

Habicht JP, Victora CG, Vaughan J P. Evaluation designs for adequacy, plausibility and probability of public health programme performance and impact. Int $J$ Epidemiol 1999; 28: 10-18.

Hanley JA, Negassa A, Edwardes MD de B, Forrester JE. Statistical analysis of correlated data using generalized estimating equations: an orientation. Am J Epidemiol 2003; 157:364-375.

Horton NJ, LIPSITZ SR. Review of software to fit generalized estimating equation regression models. Am Stat Assoc 1999; 53:160-9.

Hosmer DW, Lemeshow S. Applied logistic regression. USA, John Wiley \& Sons, 1989.

Huffman SL; Martin L. Child nutrition, birth spacing, and child mortality. Ann New York Acad Sci 1994; 709: 236-248.

Jonsson U. The causes of hunger. In: Food Nutr Bull 1981; 3 (2). 
Kalil AC, Lei DLM, Lerner BR, Ramos RG. Evolução do estado nutricional de pré-escolares matriculados em atividade de suplementação alimentar na Grande São Paulo. Alimentação 1981; 56: 38-47.

Kelsey J, Whittemore AS, Evans A, Thompson WD. Methods in observational epidemiology. Oxford University Press 1996; 2a ed., New York.

Keller W, Fimore CM. Prevalence of protein energy malnutrition. World Hlth Stats 1983; 36:129-166.

Klebanoff MA, Yip R. Influence of maternal birth weight on rate of fetal growth and duration of gestation. J. Pediatr1987; 111: 287-92.

Kramer MS. Determinats of low birth weight: methodological assessment and meta-analysis. Bull World Health Organ 1987; 65: 663-737.

Leavel H \& Clark EG. Medicina Preventiva. São Paulo: Megraw-Hill; 1976.

Lei DLM. Estudo antropométrico da evolução do estado nutricional de crianças desnutridas beneficiárias de um programa de suplementação alimentar. São Paulo; 1986 [Dissertação de Mestrado - Faculdade de Saúde Pública da USP].

Lei DLM, Monteiro CA, Lerner BR, Chaves SP. Medindo o impacto de programas de recuperação nutricional de pré-escolares: teste de uma metodologia. Rev Saúde Pública 1989; 23 (3):230-5. 
Lei DLM, Szarfarc SC. Intervenção Nutricional a desnutridos: evolução antropométrica após um ano de programa. Rev Bras Cresc Des Hum 1992; II (2): 101-113.

Lei DLM, Chaves SP, Lerner BR, Arruda SC, Stefanini MLR. Estudo em escolares de Barueri (SP): estatura, rendimento escolar e suplementação alimentar: Parte II. Perfil de crescimento de crianças suplementadas. Rev Nutr PUCCAMP 1993; 6 (1): 29-51.

Lei DLM, Freitas IC, Chaves SP, et al. Retardo do Crescimento e condições sociais em escolares de Osasco, São Paulo, Brasil. Cad Saúde Pública 1997; 13 (2): 277-283.

Lei DLM, Chaves SP, Saldiva SRDM, et al. Curso de atualização em vigilância do crescimento: Manual de Orientação Técnica. São Paulo: SISVAN, 2002.

Lerner BR, Lei DLM, Mondini L, Chaves SP, Stefanini MLR. Perfil de crescimento de crianças matriculadas em programa de suplementação alimentar. Rev Saúde Pública 1988; 22 (5): 436-40.

Lerner BR, Chaves SP, Lei DLM, Mondini L, Stefanini MLR. Perfil de crescimento de crianças matriculadas em programa de suplementação alimentar: II. Evolução do estado nutricional de desnutridos. Rev Nutr PUCCAMP 1991; 4 (1/2):93-109.

Liang KY, Zegger SL. Longitudinal data analysis using generalized linear models. Biometrika $1986 ; 73: 13-22$. 
Lopes AC, Sustovich DR, Chacon JP. Influência da desnutrição sobre os mecanismos de defesa do organismo contra a infecção. $F$ Méd 1988; 96 (5):267-270.

Lucena L, Lima RT, Marino WT. O baixo peso ao nascer ainda é um problema de saúde pública no Brasil?. Rev Paul Pediatria 1998; 16 (1): 15-27.

Lutter CK, Mora JO, Habicht JP, Rasmussen KM, Robson DS, Herrera G. Age-specific responsiveness of weight na length to nutritional supplementation. Am J Clin Nutr 1990; 51:359-64.

Martorell R, Mendoza F, Castilho R. Poverty and stature in children. In: Waterlow, J.C. Linear growth retardation in less developed countries. New York: Raven Press, 1988 (Nestle Nutrition Workshop Serie, 14:57-74).

Maulen-Radovan I, Villagómez S, Soler E, Villicana R, Hernandez-Ronquillo L, Rosado JL. Impacto nutricio del consumo de una leche entera adicionada com vitaminas y minerales en ninos. Salud Pública Méx 1999; 41 (5): 389396.

Ministério da Saúde. Incentivo ao combate às carência nutricionais. Manual de Orientação. Brasília, 2000a.

Ministério da Saúde. Assistência pré-natal: manual técnico. $3^{\mathrm{a}}$ ed. Brasília: $2000 \mathrm{~b}$.

Ministério da Saúde. Saúde da criança: acompannhamento do crescimento e desenvolvimento infantil. Brasília: 2002. 
Ministério da Saúde. Organização Pan Americana da Saúde. Guia alimentar para crianças menores de dois anos. Brasília, 2002. 152p.

Mondini L, Monteiro C A. Relevância epidemiológica da desnutrição e da obesidade em distintas classes sociais: métodos de estudo e aplicação à população brasileira. Rev Bras Epidemiol 1998; 1 (1): 28-39.

Monte CMG, Ashworth A, As MLB, Diniz RLP. Effectiveness of nutrition centers in Ceará state, northeastern Brazil. Rev Pan Salud Pública 1998; 4 (6): 375-382.

Monteiro CA, Meyer M. Estudo das condições de saúde das crianças do município de São Paulo, SP (BRASIL) 1984-1985: VIII - Cobertura e impacto da suplementação alimentar. Rev Saúde Pública 1988; 22 (2): 132-9.

Monteiro CA. Evolução da Nutrição Infantil nos anos 90. In: Monteiro CA. Velhos e novos males da saúde no Brasil: a evolução dos país e suas doenças. $2^{2}$ ed. rev. e aumentada, São Paulo: Hucitec; 2000. p375-392.

Monteiro CA, Conde WL. Tendência secular da desnutrição e da obesidade na infância na cidade de São Paulo (1974-1996). Rev Saúde Pública 2000; 34 (6): $52-61$.

Monteiro CA, França Júnior I, Conde WL. Evolução da assistência maternoinfantil na cidade de São Paulo (1984-1996). Rev Saúde Pública 2000a; 34(6): 19-25.

Monteiro CA, Benício MHD'A, Ortiz LP. Tendência secular do peso ao nascer na cidade de São Paulo (1976-1998). Rev Saúde Pública 2000b; 34 (6): 26-40. 
Monteiro CA; Benício MHD'A; Iunes RF; Gouveia NC; Cardoso MAA. Evolução da Desnutrição Infantil. In: Monteiro CA. Velhos e novos males da saúde no Brasil: a evolução dos país e suas doenças. $2^{2}$ ed. rev. e aumentada, São Paulo: Hucitec; 2000c. p93-114.

National Center for Health Statistics. NCHS Growth curves for children birth-18 years United States. Washington, D.C.: U.S. Printing Office; 1977. (Vital and Health Statistics Series 11, no.165, DHEW Pub. no. 78-1650).

Nóbrega, FJ. Desnutrição intra-uterina e pós-natal. $2^{a}$ ed. São Paulo: Panamed; 1986.

Nóbrega FJ. Evolução a longo prazo do desnutrido grave. Ped Mod 1997; XXXIII (4): 143-166.

Obatolu VA. Growth pattern of infants fed with a mixture of extruded malted maize and cowpea. Nutr Africa 2003; 19:174-178.

Olinto MTA; Victora CG; Barros FC; Tomasi E. Determinantes da desnutrição infantil em uma população de baixa renda: um modelo de análise hierarquizado. Cad. Saúde Pública 1993; 9 (1): 14-27.

Omran AR; Solis JA. Planificación de la familia en las Américas. In: Lopes G et al. Salud Reprod Ámericas. 1992.

Onis M; Monteiro CA; Akré J; Clungston G. The worldwide magnitude of protein-energy malnutrition: an overview from the WHO Global Database On Child Growth. Bull World Health Organ. 1993; 71:703-12. 
Onis M, Frongillo EA, Blossner M. Is malnutrition declining? An analysis of changes in levels of child malnutrition since 1980. Bull World Health Organ. 2000;78(10):1222-33.

Onis M. Medición del estado nutricional en relación com la mortalidad. Bol Org Mund Salud 2001; 4: 120-123.

Organización Mundial de la Salud. Medición del cambio del estado nutricional. Ginebra, 1983.

Paknawin-Mock J, Jarvis L, Jahari AB, Husaini MA, Pollitt E. Communitylevel determinants of child growth in an Indonesian tea plantation. Eur $J$ Clin Nutr 2000; 54 (2): S28-S42.

Peliano AMM. Os programas de alimentação e nutrição para mães e crianças no Brasil. Perfil estatístico de crianças e mães no Brasil: aspectos de saúde e nutrição de crianças no Brasil 1989. Rio de Janeiro: IBGE, 1992, p.111-121.

Pelletier DL, Frongillo JR, Schroeder DG, Habicht JP. The effects of malnutrition on child mortality in developing countries. Bull WHO 1995; 73 (4):443-48.

Perra A, Costello AM Efficacy of outreach nutrition rehabilitation centers in reducing mortality and improving nutritional aoutcome of severely malnourished children in Guinea Bissau. Eur J Clin Nutr 1995; 49: 353-359.

[PNDS] - Pesquisa Nacional sobre Demografia e Saúde. Rio de Janeiro: BENFAM, 1996. cap.9, p.125-138. 
[PNSN] - Pesquisa Nacional sobre Saúde e Nutrição. Perfil de crescimento da população brasileira de 0 a 25 anos. Brasília, Instituto Nacional de Alimentação e Nutrição - INAN, 1990.

Pollitt E, Watkins W, Husaini MA. Three-month nutritional suplementation in Indonesian infants and toddlers benefits memory function 8 y later. $A m J$ Clin Nutr 1997; 66: 1357-63.

Pollitt E. Developmental sequel from early nutritional deficiencies: conclusive and probability judgements. Am Soc Nutr Sci 2000: 350S-353S.

Post CLA, Victora CG, Barros AJD. Entendendo a baixa prevalência de déficit de peso para estatura em crianças brasileira de baixo nível sócioeconômico: correlação entre índices antropométricos. Cad Saúde Pública 2000 ; 16 (1): 73-82.

Post CLA, Victora CG, Barros AJD. Baixa prevalência de déficit de peso para estatura: comparação de crianças brasileiras com e sem déficit estatural. Rev Saúde Pública. [periódico on line]. 1999: 33 (6). Disponível em $<$ URL:http//www.scielo.br/ rsp> [2003 fev 09].

Puccini RF. Avaliação do programa de recuperação de desnutridos no município de Embú (1984-1986). São Paulo; 1988. [Tese de Doutorado Escola Paulista de Medicina.

Puccini RF, Goihman S, Nóbrega FJ. Avaliação do programa de recuperação de desnutridos do município de Embú, na região metropolitana de São Paulo. $J$ Pediatr 1996; 72 (2): 72-79. 
Rivera JA, Habicht JP, Robson DS. Effect of supplementary feeding on recovery from mild to moderate wasting in preschool children. Am $J$ Clin $1991 ; 54: 62-68$.

Rivera JA, Habicht JP. The recovery of Guatemalan children with mild to moderate wasting: factors enhancing the impact of supplementary feeding. Am J Public Health 1996; 86: 1430-1434.

Rivera JA, Habicht JP. Effect of supplmentary feeding on the prevention of mild-to-moderate wasting in conditions of endemic malnutrition in Guatemala. Bull WHO 2002; 80 (12): 926-932.

Santos Filho E. Avaliação operacional das atividades de recuperação nutricional em duas unidades básicas de saúde do município de Santos. São Paulo; 1991. [Dissertação de Mestrado - Faculdade de Saúde Pública da USP).

Santos H. Recuperação nutricional como atividade do programa de assistência integral à saúde da criança: avaliação de aspectos operacionais e de impacto nutricional em uma unidade de saúde da Secretaria de Estado da Saúde de São Paulo; 1990. [Dissertação de Mestrado - Faculdade de Saúde Pública da USP].

Sawaya AL Desnutrição urbana no Brasil em um período de transição. São Paulo: Cortez; 1997.

Schilling PR. Supplementary feeding programs: a critical analysis. Rev Saúde Pública 1990; 24 (5): 412-9. 
Schroeder DG, Martorell R, Rivera JA, Ruel MT, Habicht JP. Age differences in the impact of nutritional supplementation on growth. $J$ Nutr 1995; 125:151S-9S.

Schroeder DG, Pachón H, Dearden KA, Ha TT, Lang TT, Marsh DR. An integrated child nutrition intervention improved growth of younger, more malnourished children in northern Viet Nam. Food and Nutr Bull 2002; 23 (4): 50-57.

SEADE - Sistema Estadual de Análise de Dados [site da Internet\}. Disponível em <URL: http://www.seade.gov.br/cgi-bin/pcvv98/opcao_pcv_01.ksh>. [2003 Ago $16]$.

Seoane N, Latham MC. Nutritional anthropometry in the identification of malnutrition in childhood. $J$ Trop Pediat Oxford 1971; 17 (3): 98-103.

Shank RE. Nutrição em medicina preventiva, in: Leavell HG, Clark G. Medicina preventiva. São Paulo, McGraw Hill do Brasil, 1978.

Sigulem DM. Contribuição ao estudo da desnutrição energético protéica em crianças de 6 a 60 meses no Município de São Paulo. São Paulo; 1981. (Dissertação de Mestrado - Escola Paulista de Medicina).

Silva AC. De Vargas a Itamar: políticas e programas de alimentação e nutrição. [Apresentado no Seminário Pobreza, Fome e Desnutrição no Brasil; 1994 dez 02; São Paulo, Brasil]. 
Sit CS, Yeung DL. Growth of infants and children in China. Indian Pediatrics 1999; 36: 464-75.

Soares BT, Parente WG. Desnutrição e resultados de reabilitação em Fortaleza. Rev Nutr Campinas 2001; 14 (2):103-110.

Stata Corp.' (2003). Stata statistical software: realease 8.1. College Station, TX, Stata Corporation.

Stein Z, Susser M, Saenger G, Marolla F. Nutrition and mental performance. Prenatal exposure to the dutch family of 1944-45 seems not relate to performance at age 19. Science 1972; 78: 708-13.

Taddei JAA. Avaliação antropométrica do impacto nutricional de um programa de suplementação alimentar. São Paulo; 1987. [Tese de Doutorado. Faculdade de Saúde Pública da USP).

Taddei JAA, Cannon MJ, Warner L, Souza P, Vitalle S, Palma D, Nóbrega F. Nutritional gains of underprivileged children attending a day care center in S.Paulo City, Brazil: a nine month follow-up study. Rev Bras Epidemiol 2000; 3 (1-3): 29-37.

Tomkins AM. Protein energy malnutrition and risk of infection. Proc Nutr Soc 1986; 45: 289-304.

Tomkins AM. Malnutrition, morbidity and mortality in children and their mothers. Proc Nutr Soc 2000; 59: 135-46. 
Tonial SR, Silva AAM. Saúde, Nutrição e Mortalidade Infantil no Maranhão. São Luís: UFMA: Secretaria de Estado da Saúde: Unicef, 1997.

Tontisirin K, Bhattacharjee L. O ônus global da desnutrição e da infecção na infância. Nutrição, Imunidade e Infeçcão na Infância. Nestlé Nutr. Workshop Serie - Programa Pediátrico 2001; 45:1-3.

[UNICEF] - Fundo das Nações Unidas para a Infância. Situação mundial da infância Brasileira, 1987.

[UNICEF] - Fundo das Nações Unidas para a Infância. Estratégia para melhorar a nutrição de crianças e mulheres nos países em desenvolvimento. New York, 1990.

[UNICEF] - Fundo das Nações Unidas para a Infância. A infância Brasileira nos anos 90. Brasília, 1998.

[UNICEF] - Fundo das Nações Unidas para a Infância. Situação Mundial da Infância 1998. Brasília, 2000.

[UNICEF] - United Nations Children's Found. The state of the world's children 2003. www.unicef.org/sowc03/tables/table2.htm> [2003 Ago 09].

UNITED NATIONS UNIVERSITY. Context and supporting policies. Food Nutr Bull 2001; 22 (3):40-51.

Valente FLS. Fome e desnutrição: determinantes sociais. $2^{a}$ ed. São Paulo: Cortez; 1989. 
Vasconcelos ACCP. Situação de saúde e nutrição das crianças do programa de vigilância do recém-nascido de risco no município de Santos. São Paulo; 1996. [Dissertação de Mestrado - Faculdade de Saúde Pública da USP].

Vega-Franco L. Hitos conceptuales en la historia de la desnutrición proteicoenergetica. Salud Publica Mexico 1999; 41:328-33.

Victora CG, Vaughan JP, Kirkwood BR, Martines JC, Barcelos LB. Risk factors for malnutrition in Brazilian children: The role of social and environmental variables. Bull WHO 1986; 64 (2): 299-309.

Victora CG, Gigante DP, Barros AJD, Monteiro CA, Onis M. Estimativa da prevalência de déficit de altura/idade a partir da prevalência de déficit de peso/idade em crianças brasileiras. Rev Saúde Pública 1998; 32 (4): 321-7.

Walka H; Pollitt E. A preliminary test of a developmental model for the study of undernourished children in Indonesia. Eur J Clin Nutr 2000; 54 (2): S21-S27.

Waterlow JC. Protein Energy Malnutricion. London: Edward Arnold, 1992.

Winick M, Meyer KK, Harris RC. Malnutrition and enviromental enrichment by early adoption. Science (Washington, DC) 1975; 190:1173-5.

World Health Organization Working Group. Use and interpretation of anthropometric indicators of nutricional status. Bull WHO 1986; 64: 929-41. 
World Health Organization Working Group. An evaluation of infant growth: the use and interpretation of anthropometric in infants. Bull WHO 1995; 73 : 165-74.

World Health Organization. Global database on child growth and malnutrition. Program of Nutrition Family and Reproductive Health. Geneva; 1997. 


\section{ANEXOS}

ANEXO 1 - Formulário aplicado às mães

ANEXO 2 - Termo de Consentimento

ANEXO 3 - Características de crianças que iniciaram e que abandonaram o ICCN.

ANEXO 4 - Variáveis associadas às mudanças nas variações médias dos escores z nos modelos multivariados

ANEXO 5 - Encaminhamento para o ICNN

ANEXO 6 - Telegrama enviado às mães

ANEXO 7 - Listagem dos programas de computador: EPINFO, ACCESS, STATA. 
ANEXO 1 - FORMULÁRIO APLICADO ÀS MÃES 


\section{Programa de combate a carências nutricionais \\ Secretaria da Saúde de Mogi das Cruzes}

UBS:

Pront. N. $^{\circ}$

Data:

\section{IDENTIFICAÇÃO}

Nome da criança:

Naturalidade:

Peso ao nascer:

Data Nascimento :

Sexo:Feminino ( ) Masculino ( )

Comprimento: $\mathrm{cm}$

Nome da mãe:

Idade da mãe: (anos) Idade dos filhos:

Peso Atual: $\mathrm{kg}$

Trabalha fora do lar? ( )sim ( ) não

Altura:

Horário:

Em caso afirmativo, com quem fica a criança?

Nome do Pai:

Mora com vocês? ( ) Sim ( ) Não

Idade: anos

Em caso negativo, ele ajuda financeiramente:

( ) Sim

( ) Não

Constituicão Familiar (pessoas que moram na casa)

\begin{tabular}{|l|l|l|l|l|l|}
\hline Nome & Sexo & Idade & Parentesco & Ocupação & Renda \\
\hline & & & & & \\
\hline & & & & & \\
\hline & & & & & \\
\hline & & & & & \\
\hline & & & & & \\
\hline & & & & & \\
\hline & & & & & \\
\hline & & & & & \\
\hline
\end{tabular}

*Parentesco: em relação à criança

\section{Renda Familiar :}
( ) sem renda
( ) De 1 à 3 s.m.
( ) De 5 à 10 s.m.
( ) $<1$ s.m.
( ) De 3 à 5 s.m.
( ) $>10$ s.m.

Escolaridade Materna : anos de estudo

Escolaridade Paterna : anos de estudo 
Condições de Habitação/Saneamento :

Casa: ( ) Própria ( ) Alugada ( ) Coletiva ( ) Cedida

Tijolo ( ) Madeira ( )

Água Encanada : ( ) Sim ( ) Não

Poço: ( ) Sim ( ) Não

Esgoto: ( ) Sim ( ) Não

Coleta de Lixo: ( ) Sim ( ) Não

História Obstétrica:

Tempo de gestação:

Início do pré-natal: (meses) Pré-natal: ( ) SIM ( ) NÃO

Local:

Intercorrências na gestação:

Hipertensão( ) Diabetes ( ) Infecção ( ) Edema ( )

Outras

Tipo de Parto

Espontâneo ( ) Induzido ( ) Cesárea ( ) Fórceps ( )

\section{Condições de Saúde:}

Principais doenças que a criança teve:

Já tomou suplementos/vitaminas? ( ) Sim ( ) Não

Qual?

Com qual idade?

Dose: Por quanto tempo?

Teve ou tem verminose? ( ) Sim( ) Não

Se sim, como foi o tratamento?

Qual água a criança toma?

Hábito Intestinal:

Dia ( ) $n^{\circ}$ de vezes Semana ( ) $n^{\circ}$ de vezes

Consistência das fezes :

ressecadas ( ) normais ( ) amolecidas ( )

\section{Hábitos :}

Chupeta ( ) sim não ( ) higienização

Dedo ( ) sim não( )

Outros

2. NUTRIÇÃO

Recebeu aleitamento materno? ( ) Sim ( ) Não

Exclusivo: (dias) ou (meses)

Quando introduziu mamadeira?

Tipo de leite : Pó integral

Fórmula modificada

Fluido:

Adição de farinha :

()

)

tipo B ( ) tipo C ( )

adição de açúcar 
Motivo para introdução da mamadeira :
( ) leite fraco/insuficiente
( ) orientação de terceiros
( ) criança chorava muito
( ) não tinha leite
( ) trabalho
( ) nova gestação
( ) outros

Modo de preparo da mamadeira

Quando foram introduzidos outros alimentos:

Suco de frutas

Papa de frutas meses

Papa salgada meses

Carnes meses

Feijão meses

Vegetais verde escuros meses meses

Hábito Alimentar Atual:

\begin{tabular}{|l|l|l|}
\hline Refeicão/hora & Alimento & Quantidade \\
\hline & & \\
\hline & & \\
\hline & & \\
\hline & & \\
\hline & & \\
\hline & & \\
\hline & & \\
\hline & & \\
\hline & & \\
\hline & & \\
\hline
\end{tabular}

A gravidez desta criança foi planejada/desejada? (Perguntar a senhora queria ficar grávida? )
( ) SIM
( ) NÃO

A senhora considerada seu filho magro?
( ) SIM
( ) NÃO
( ) NÃO SOUBE RESPONDER*

* para as mães que apresentam dúvida para o julgamento 


\begin{tabular}{|c|c|c|c|c|}
\hline Data & $\begin{array}{l}\text { Idade } \\
\text { (meses) }\end{array}$ & $\begin{array}{l}\text { Peso } \\
\text { (kg) }\end{array}$ & $\begin{array}{l}\text { Estatura } \\
(\mathrm{cm})\end{array}$ & Intercorrências no mês \\
\hline & & & & \\
\hline & & & & \\
\hline & & & & \\
\hline & & & & \\
\hline & & & & \\
\hline & & & & \\
\hline & & & & \\
\hline & & & & \\
\hline & & & & \\
\hline & & & & \\
\hline & & & & \\
\hline & & & & \\
\hline & & & & \\
\hline & & & & \\
\hline & & & & \\
\hline & & & & \\
\hline
\end{tabular}

NO MOMENTO DA ALTA, PERGUNTAR PARA O RESPONSÁVEL:

Alguém na família/casa conseguiu emprego durante o período de permanência da criança no ICCN?
( ) SIM
( ) NÃO 


\section{ANEXO 2 -TERMO DE CONSENTIMENTO}


UNIVERSIDADE DE SÃO PAULO - FACULDADE DE SAÚDE PÚBLICA DEPARTAMENTO DE SAÚDE MATERNO-INFANTIL

\section{TERMO DE CONSENTIMENTO}

\section{Titulo da Pesquisa: Evolução do estado nutricional de crianças atendidas pelo ICCN no municipio de Mogi das Cruzes}

A pesquisa que vamos realizar, faz parte da tese de doutoramento da aluna Rita Maria Monteiro Goulart de Pós-Graduação da Faculdade de Saúde Pública da Universidade de São Paulo. Para tanto, estamos solicitando a sua colaboração a fim de responder a algumas perguntas a respeito das características socio-econômicasculturais de sua família alem de sua permissão para a tomada de peso e estatura do seu filho inscrito no Programa de Incentivo ao Combate às Carências Nutricionais (ICCN) neste município.

Esta pesquisa é muito importante e vai nos ajudar a avaliar as açōes desenvolvidas e a partir dos resultados obtidos, será possível redirecionar as atividades caso haja necessidade.

Asseguramos que sua participação é livre e voluntária, sendo que, em qualquer momento do levantamento dos dados, o $\mathrm{Sr}$ (a). poderá desistir e que esta participação não implica em quaisquer riscos e desconfortos.

Comprometemo-nos ainda, a não divulgar seu nome e nem seus dados pessoais. Prometemos, também, que ao longo da coleta de dados, o $\mathrm{Sr}$ (a). será informado sobre o peso e a estatura apresentado por seu filho.

Com o compromisso de acompanhar todo o processo da entrevista e da coleta dos dados antropométricos, colocamo-nos à disposição para esclarecimentos, seja do modo como vamos trabalhar, seja do conteúdo dos objetivos da pesquisa. Esta pesquisa não implica em despesas da parte do entrevistado.

Desde já agradecemos a sua valiosa colaboração.

$$
\text { Mogi das Cruzes, }
$$

RG 13.143.161 
ANEXO 3 - CARACTERÍSTICAS DE CRIANÇAS QUE INICIARAM E QUE ABANDONARAM O ICCN. 
Distribuição das características de crianças que iniciaram e que abandonaram o ICCN. Mogi das Cruzes, 2002.

\begin{tabular}{|c|c|c|c|c|}
\hline \multirow[t]{2}{*}{ Variáveis } & \multicolumn{2}{|c|}{ Crianças que abandonaram } & \multicolumn{2}{|c|}{ Crianças que iniciaram } \\
\hline & $\mathrm{N}$ & $\%$ & $\mathrm{~N}$ & \\
\hline \multicolumn{5}{|l|}{ Faixa Idade (mês) } \\
\hline $6-12$ & 17 & 12,1 & 202 & 27,9 \\
\hline $12-24$ & 113 & $\mathbf{8 0 , 7}$ & 482 & 66,6 \\
\hline$>24$ & 10 & 7,2 & 40 & 5,5 \\
\hline \multicolumn{5}{|l|}{ Peso ao nascer (g) } \\
\hline$<2500$ & 21 & 15,0 & 70 & 12,4 \\
\hline $2500-2999$ & 48 & 34,3 & 187 & 33,0 \\
\hline$\geq 3000$ & 61 & 43,6 & 271 & 47,9 \\
\hline S/Informação & 10 & 7,1 & 38 & 6,7 \\
\hline \multicolumn{5}{|l|}{ Aleitamento Materno } \\
\hline Sim & 120 & 85,7 & 605 & 83,5 \\
\hline Não & 20 & 14,3 & 119 & 16,5 \\
\hline \multicolumn{5}{|l|}{ Renda Familiar (s.m.) } \\
\hline$<1$ & 40 & 28,6 & 197 & 27,2 \\
\hline $1-3$ & 74 & 52,8 & 367 & 50,7 \\
\hline$>3$ & 25 & 17,8 & 121 & 16,7 \\
\hline S/informação & 1 & 0,8 & 39 & 5,4 \\
\hline \multicolumn{5}{|l|}{ Escolaridade da mãe } \\
\hline Sem escolaridade & 11 & 7,8 & 37 & 5,1 \\
\hline $1-4$ anos & 53 & 37,9 & 235 & 32,4 \\
\hline$>4$ anos & 75 & 53,6 & 433 & 59,8 \\
\hline S/informação & 1 & 0,7 & 19 & 2,7 \\
\hline \multicolumn{5}{|l|}{ Escolaridade do pai } \\
\hline Sem escolaridade & 9 & 6,4 & 48 & 7,7 \\
\hline $1-4$ & 74 & 52,8 & 181 & 28,8 \\
\hline$>4$ & 46 & 32,8 & 398 & 63,5 \\
\hline S/informação & 11 & 7,8 & 110 & 15,5 \\
\hline \multicolumn{5}{|c|}{ Trabalho da mãe fora do lar } \\
\hline Não & 108 & 77,1 & 579 & 80,0 \\
\hline Sim & 32 & 22,9 & 145 & 20,0 \\
\hline \multicolumn{5}{|l|}{ Idade Materna (anos) } \\
\hline$<20$ & 19 & 13,5 & 98 & 13,5 \\
\hline $20-40$ & 113 & 81,5 & 604 & 83,1 \\
\hline$>40$ & 7 & 5,0 & 22 & 3,4 \\
\hline \multicolumn{5}{|l|}{ Número de irmãos } \\
\hline 0 a 1 & 72 & 51,4 & 402 & 55,5 \\
\hline $2-3$ & 59 & 42,1 & 280 & 38,7 \\
\hline$>3$ & 9 & 6,5 & 42 & 5,8 \\
\hline
\end{tabular}


ANEXO 4 - VARIÁVEIS ASSOCIADAS ÀS MUDANÇAS NAS VARIAÇÕES

MÉDIAS DOS ESCORES Z NOS MODELOS MULTIVARIADOS 


\section{CRIANÇAS DESNUTRIDAS}

- DESNUTRIÇÃO GRAVE E TRABALHO MATERNO

Distribuição (\%) de crianças desnutridas segundo trabalho materno e desnutrição grave.

\begin{tabular}{cc}
\hline $\begin{array}{c}\text { Trabalho da mãe } \\
\text { fora do lar }\end{array}$ & $\begin{array}{c}\text { Desnutrição Grave } \\
\%\end{array}$ \\
\hline Não & $\mathbf{7 4 , 4}$ \\
Sim & 25,6 \\
\hline
\end{tabular}

O percentual de desnutrição grave é cerca de três vezes superior entre os filhos de mães que não trabalham fora.

- FAIXA ETARIA DA MÃE E TRABALHO NOVO

Distribuição (\%) de crianças desnutridas segundo faixa etária materna e trabalho novo.

\begin{tabular}{cc}
\hline Faixa etária materna (anos) & $\begin{array}{c}\text { Trabalho novo - NÅO } \\
\%\end{array}$ \\
\hline$<20$ & 9,4 \\
$20-40$ & 87,5 \\
$>40$ & 3,1 \\
\hline
\end{tabular}

Do conjunto das famílias que não conseguiram trabalho durante o periodo de exposição da criança ao ICCN, a maior concentração está na faixa etária materna de 20 a 40 anos $(87,5 \%)$. 


\section{- PESO AO NASCER E DESNUTRIÇÃO GRAVE}

Distribuição (\%) de crianças desnutridas segundo peso ao nascer e desnutrição grave.

\begin{tabular}{cc}
\hline Peso ao nascer $(\mathrm{g})$ & Desnutrição grave - SIM \\
\hline & $\%$ \\
\hline$<2500$ & 64,1 \\
$2500-2999$ & 28,2 \\
$\geq 3000$ & 7,7 \\
\hline
\end{tabular}

A concentração de crianças desnutridas graves foi maior entre aquelas que nasceram com menos de $2500 \mathrm{~g}$.

\section{- IDADE DO PAI E IDADE DA CRIANÇA}

Distribuição (\%) de crianças desnutridas segundo idade do pai e faixa etária ao ingressar no ICCN. Mogi das Cruzes, 2002.

\begin{tabular}{cccc}
\hline Idade do Pai & \multicolumn{4}{c}{ Faixa etária da criança } \\
(anos completos) & $6-11$ & $12-24$ & $>24$ \\
& $\%$ & $\%$ & $\%$ \\
\hline$<20$ & 3,1 & 4,9 & - \\
$20-40$ & 78,1 & 85,3 & 100 \\
$>40$ & 18,8 & 9,8 & - \\
\hline
\end{tabular}

Observa-se que, pra a idade do pai acima de 40 anos, a concentração de crianças menores de 12 meses é o dobro da concentração na faixa de 12-24 meses.

\section{- TRABALHO NOVO E NUMERO DE IRMÃOS}

Distribuição (\%) de crianças desnutridas segundo trabalho novo e número de irmãos. Mogi das Cruzes, 2002.

\begin{tabular}{cc}
\hline Trabalho novo & Número de irmãos $>3(\%)$ \\
\hline Não & 33,3 \\
Sim & 66,7 \\
\hline
\end{tabular}


Observa-se uma concentração $2 / 3$ maior de aquisição de trabalho novo entre famílias cujas crianças tinham mais de três irmãos.

\section{- NUMERO DE IRMÃOS E DESNUTRIÇÃO GRAVE}

Distribuição (\%) de crianças desnutridas segundo número de irmãos e desnutrição grave. Mogi das Cruzes, 2002.

\begin{tabular}{cc}
\hline Número de irmãos & $\begin{array}{c}\text { Desnutrição grave } \\
\text { SIM (\%) }\end{array}$ \\
\hline $0-1$ & 20,5 \\
$2-3$ & 23,8 \\
$>3$ & 42,8 \\
\hline
\end{tabular}

Observa-se que existe o dobro de desnutridos graves entre famílias cujo número de irmãos é maior que três.

\section{CRIANÇAS RISCO NUTRICIONAL}

- RENDA FAMILIAR E TRABALHO NOVO

Distribuição (\%) de crianças em risco nutricional segundo renda familiar e trabalho novo no período. Mogi das Cruzes, 2002.

\begin{tabular}{ccc}
\hline Renda & \multicolumn{2}{c}{ Trabalho Novo } \\
Familiar (sm) & SIM (\%) & NÄO (\%) \\
\hline$<1$ & 61,4 & 38,6 \\
$1-3$ & 75,9 & 24,1 \\
$>3$ & 76,7 & 23,3 \\
\hline
\end{tabular}

Destaca-se que, das famílias com mais de 3 salários mínimos, 76,7\% obtiveram trabalho novo durante o seguimento do estudo. 
- RENDA FAMILIAR E ESCOLARIDADE

Distribuição (\%) de crianças em risco nutricional segundo renda familiar e escolaridadematerna. Mogi das Cruzes, 2002.

\begin{tabular}{lccc}
\hline Renda & \multicolumn{3}{c}{ Escolaridade } \\
Familiar (sm) & 0 & $1-4$ & $>4$ \\
\hline$<1$ & 6,4 & 37,1 & 56,5 \\
$1-3$ & 2,8 & 33,3 & 68,9 \\
$>3$ & 6,0 & 18,0 & 76,0 \\
\hline
\end{tabular}

Observa-se que das famílias com mais de 3 salários mínimos, $76,0 \%$ das mães tinham melhor escolaridade ( $>4$ anos de estudo).

\section{CRIANÇAS EUTROFICAS}

- PESO AO NASCER E IDADE AO INGRESSAR NO ICCN

Distribuição (\%) de crianças eutróficas segundo peso ao nascer e idade ao ingressar no ICCN. Mogi das Cruzes, 2002.

\begin{tabular}{lccc}
\hline $\begin{array}{l}\text { ldade da criança } \\
\text { no ingresso }\end{array}$ & \multicolumn{3}{c}{ Peso ao nascer $(\mathrm{g})$} \\
(meses & $<2500$ & $2500-2999 \geq 3000$ \\
\hline $6-11$ & 21,0 & 31,4 & 28,8 \\
$12-24$ & 63,0 & 62,8 & 66,4 \\
$>24$ & 16,0 & 5,8 & 4,8 \\
\hline
\end{tabular}

As crianças com idade entre 12 e 24 meses apresentaram maior concentração de peso ao nascer na faixa igual ou acima de $3000 \mathrm{~g}$. 
ANEXO 5 - ENCAMINHAMENTO PARA ICNN 
PREFEITIRA MUNTCWAL DE MOGI DAS CRLZES

SECRETARLA NUTCTPAL DE SAIDE

PROGRAMA DE COMPATE AS CARGMOAE MUTRIOIONAS

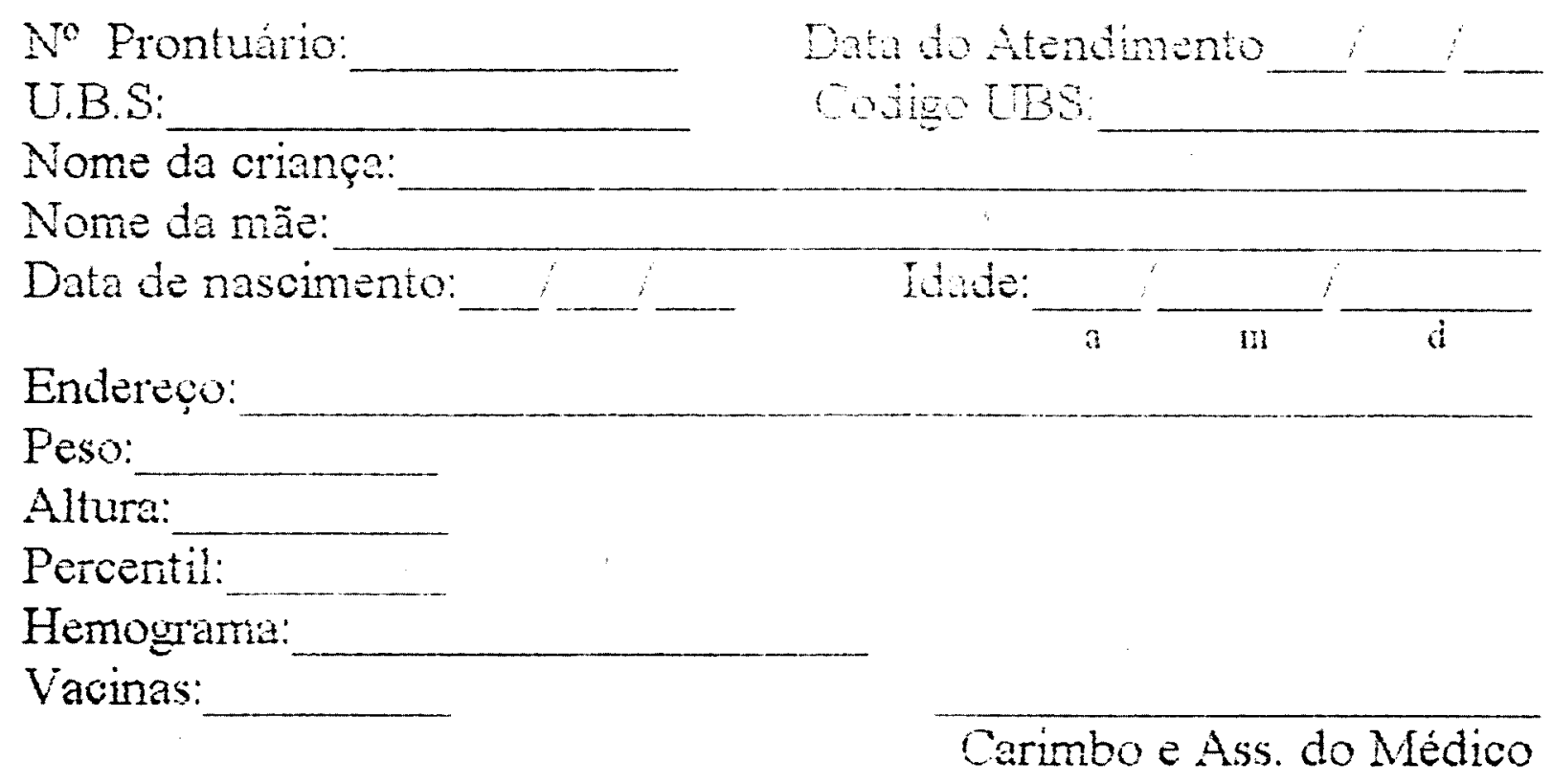


ANEXO 6 - TELEGRAMA ENCAMINHADO ÀS MÃES 
Comunicamos que seu filho foi beneficiado com o "Programa Carências Nutricionais" (leite integral e óleo de soja).

Comparecer com seu filho no Prédio do "CIP" - Av. Prefeito Carlos Ferreira Lopes, n. ${ }^{\circ}$ 540, Mogilar, no período de 15 a 25 de Julho de 1999, das $14 \mathrm{~h} 00$ às $17 \mathrm{~h} 00$.

Procurar a Auxiliar de Enfermagem Marisa.

O atendimento desta convocação, significa SAÚdE para seu fillo.

S.M.S.P.S., 13 de Julho de 1999.

A Coordenação do Programa 


\section{ANEXO 7 - LISTAGENS DOS PROGRAMAS DE COMPUTADOR:}

EPI-INFO, ACCESS, STATA. 


\section{PROGRAMAS TIPO PGM PARA RODAR NO EPINFO V 6.0}

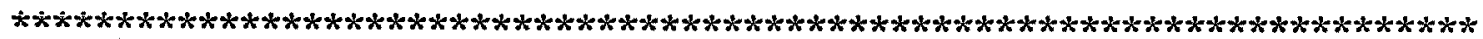
* PROGRAMA DE VERIFICAÇÃO DO ARQUIVO DE DOUTORADO V.1 * * AUTOR: PROF. DR. ELIAS E. GOULART 06/06/2002*

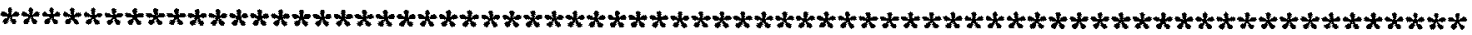

* Tomadas de valores para estudo da situação nutricional na entrada no

* Programa

* Variáveis: FXETARIA, SEXO, PESONASC, TEMPOGESTA, PRENATAL, * ESCOLAMAE, IDADE(MAE), RENDAFAM, NOFILHOS,

* NOPESSOASCASA, PAIMORA, TRABMAE, NOIRMAOS, ESGOTO, AGUA,

* LIXO, TIPOCASA, CONSTRUCAO, POCO, ESTADOMAE, ESTADO

* NUTRICIONAL INICIAL.

READ D: $\backslash E P I 6 \backslash D O U T O R \backslash M E D I D A S 2 . R E C$

RELATE PRONTUARIO D: \EPI6 \DOUTOR \CRI2.REC

$* * * * * * * * * * * * * * * * * * * * * * * * * * * * * * * * * * * * * * * * * * * * * * *$

$* * * * * * * *$ Categorias de Variaveis

$* * * *$

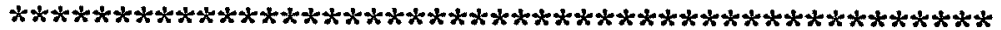

DEFINE IDADEDIAS \#\#\#

DEFINE IDADEMES \#\#.\#

DEFINE FXETARIA \#

DEFINE FXPESO \#

DEFINE TERMO \#

LET IDADEDIAS=D01-DATANASC

LET IDADEMES=IDADEDIAS/30.4

LET FXETARIA $=0$

IF IDADEMES $<1$ THEN FXETARIA $=1$

IF IDADEMES $>=1$ AND IDADEMES $<2$ THEN FXETARIA $=2$

IF IDADEMES $>=2$ AND IDADEMES $<4$ THEN FXETARIA $=3$

IF IDADEMES $>=4$ AND IDADEMES $<6$ THEN FXETARIA $=4$

IF IDADEMES $>=6$ AND IDADEMES $<12$ THEN FXETARIA $=5$

IF IDADEMES $>=12$ AND IDADEMES $<24$ THEN FXETARIA $=6$

IF IDADEMES $>=24$ THEN FXETARIA=7

IF PESONASC $<2.500$ THEN FXPESO $=1$ 
IF PESONASC $>=2.500$ AND PESONASC $<3.000$ THEN FXPESO $=2$ IF PESONASC $>=3.000$ THEN FXPESO $=3$

DEFINE DM01 \#\#.\#
DEFINE DM02 \#\#.\#
DEFINE DM03 \#\#.\#
DEFINE DM04 \#\#.\#
DEFINE DM05 \#\#.\#
DEFINE DM06 \#\#.\#
DEFINE DM07 \#.\#
DEFINE DM08 \#\#.\#
DEFINE DM09 \#.\#
DEFINE DM010 \#\#.\#
DEFINE DM011 \#.\#
DEFINE DM012 \#\#.\#

LET DM01 $=($ D01-DATANASC $) / 30.4$ LET DM02 $=($ D02-DATANASC $) / 30.4$ LET DM03 $=($ D03-DATANASC $) / 30.4$ LET DM04 $=($ D04-DATANASC $) / 30.4$ LET DM0 $5=($ D05-DATANASC $) / 30.4$ LET DM06 $=($ D06-DATANASC $) / 30.4$ LET DM07=(D07-DATANASC $) / 30.4$ LET DM08 $=($ D08-DATANASC $) / 30.4$ LET DM09=(D09-DATANASC $) / 30.4$ LET DM10 $=($ D $10-D A T A N A S C) / 30.4$ LET DM11 $=($ D $11-D A T A N A S C) / 30.4$ LET DM12 $=($ D $12-D A T A N A S C) / 30.4$

ERASE D: $\backslash$ EPI6 $\backslash$ DOUTOR $\backslash$ MED12.REC ROUTE D: $\backslash E P I 6 \backslash D O U T O R \backslash M E D 12 . R E C$ WRITE RECFILE PRONTUARIO SEXO DATANASC PESONASC FXPESO FXETARIA DM01 P01 E01 DM02 P02 E02 DM03 P03 E03 DM04 P04 E04 DM05 P05 E05 DM06 P06 E06 DM07 P07 E07 DM08 P08 E08 DM09 P09 E09 DM10 P10 E10 DM11 P11 E11 DM12 P12 E12

ERASE D: $\backslash E P I 6 \backslash D O U T O R \backslash M E D 1318 . R E C$ ROUTE D: $\backslash E P I 6 \backslash D O U T O R \backslash M E D 1318 . R E C$ WRITE RECFILE PRONTUARIO SEXO DATANASC PESONASC FXPESO FXETARIA D13 P13 E13 D14 P14 E14 D15 P15 *E15 D16 P16 E16 D17 P17 E17 D18 P18 E18 


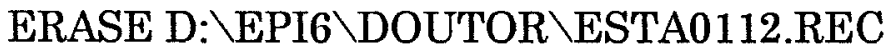

ROUTE D: $\backslash E P I 6 \backslash D O U T O R \backslash E S T A 0112 . R E C$

WRITE RECFILE PRONTUARIO WAZ1 HAZ1 WHZ1 WAZ2 HAZ2 WHZ2

WAZ3 HAZ3 WHZ3 WAZ4 HAZ4 WHZ4 WAZ5 HAZ5 *WHZ5 WAZ6 HAZ6 WHZ6 WAZ7 HAZ7 WHZ7 WAZ8 HAZ8 WHZ8 WAZ9 HAZ9 WHZ9 WAZ10 HAZ10 WHZ10 WAZ11 HAZ11 *WHZ11 WAZ12 HAZ12 WHZ12

ERASE D: $\backslash E P I 6 \backslash D O U T O R \backslash E S T A 1318 . R E C$

ROUTE' D: $\backslash E P I 6 \backslash D O U T O R \backslash E S T A 1318 . R E C$

WRITE RECFILE PRONTUARIO WAZ13 HAZ13 WHZ13 WAZ14 HAZ14 WHZ15 WAZ16 HAZ16 WHZ16 WAZ17 HAZ17 WHZ17 *WAZ18 HAZ18 WHZ18

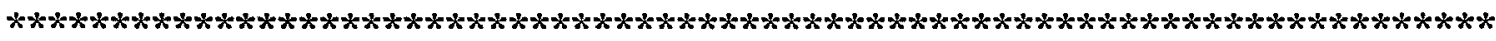
$* *$

* LE ARQUIVO DE TRABALHO CRIANCAS.REC

* 1. Determina o estado nutricional na mae e população familiar

* 2. Estuda a amamentação

* 3 . Determina categorias de variaveis

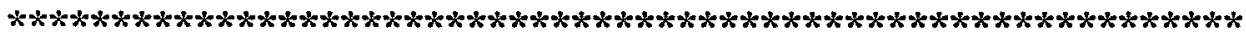

******* ESTADO MAE E POPULACAO FAMILIAR *********

$* * * * * * * * * * * * * * * * * * * * * * * * * * * * * * * * * * * * * * * * * * * * * * * * * * * * * * * * * * * * *)$

DEFINE IMC \#\#.\#\#

DEFINE SEXOMAE

DEFINE MAEMES \#\#.\#

DEFINE ESTADOMAE \#

DEFINE PARENTES \#

DEFINE IRMAOS \#

DEFINE PAICASA \#

LET SEXOMAE $=" F "$

LET MAEMES $=$ IDADE $* 12$

$\mathrm{IMC}=\mathrm{PESOMAE} /\left((\mathrm{ALTURAMAE} / 100)^{\wedge} 2\right)$

IF IMC $<=17.99$ THEN ESTADOMAE $=1$

IF IMC $>18$ AND IMC $<=24.99$ THEN ESTADOMAE $=2$

IF IMC $>25$ AND IMC $<=29.99$ THEN ESTADOMAE $=3$

IF IMC $>30$ AND IMC $<=34.99$ THEN ESTADOMAE $=4$ 
IF IMC $>35$ AND IMC $<=39.99$ THEN ESTADOMAE $=5$

IF IMC $>=40$ THEN ESTADOMAE $=6$

IF PESOMAE $=$. OR ALTURAMAE $=$. THEN ESTADOMAE $=0$

LE'T PARENTES $=0$

LE'T IRMAOS $=0$

LET PAICASA $=0$

IF PARENTE1 $>$. THEN PARENTES=PARENTES+1

IF PARENTE2 $>$. THEN PARENTES=PARENTES +1

IF PARENTE3 $>$. THEN PARENTES=PARENTES +1

IF PARENTE4 $<$. THEN PARENTES=PARENTES +1

IF PARENTE5 $<$. THEN PARENTES=PARENTES+1

IF PARENTE1="I" THEN IRMAOS=IRMAOS+1

IF PARENTE2="I" THEN IRMAOS=IRMAOS+1

IF PARENTE3="I" THEN IRMAOS=IRMAOS+1

IF PARENTE4="I" THEN IRMAOS=IRMAOS+1

IF PARENTE5="I" THEN IRMAOS=IRMAOS+1

IF (PARENTE1="P" OR PARENTE2="P" OR PARENTE3="P" OR PARENTE4="P" \

OR PARENTE5="P") THEN PAICASA=1

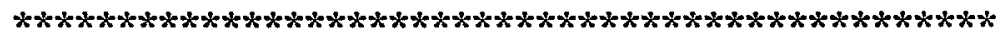

******** Estuda o Aleitamento $* * * * * * * *$

$* * * * * * * * * * * * * * * * * * * * * * * * * * * * * * * * * * * * * * * * * * * * * * *$

define ame \#

define amp \#

define amc\#\#

define aa \#\#

* variaveis para DETERMINAR aqueles periodos

if aleitamate $=" y "$ then ame=exclusivo

if aleitamate $=" n$ " or aleitamate $=$. then aa $=1$ else $\mathbf{a a}=0$

if aleitamate $=" y "$ and (mamadeira-suco) $>0$ then amp=mamadeira-suco else amp $=0$

if aleitamate $=" y "$ and mamadeira $<>$. then amc=mamadeira 


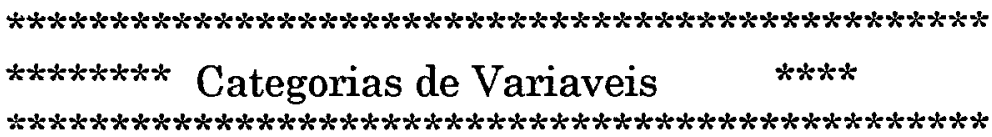

DEFINE FXESCMAE \#

DEFINE FXESCPAI \#

DEFINE FXETARIA \#

DEFINE FXETAMAE \#

IF ESCOLAMAE $=0$ THEN FXESCMAE $=0$

IF ESCOLAMAE $>=1$ AND ESCOLAMAE $<=4$ THEN FXESCMAE $=1$

IF ESCOLAMAE $>=5$ AND ESCOLAMAE $<=8$ THEN FXESCMAE $=2$

IF ESCOLAMAE $>=9$ AND ESCOLAMAE $<=11$ THEN FXESCMAE $=3$

IF ESCOLAMAE $>=12$ THEN FXESCMAE $=4$

IF ESCOLAPAI $=0$ THEN FXESCPAI $=0$

IF ESCOLAPAI $>=1$ AND ESCOLAPAI $<=4$ THEN FXESCPAI $=1$

IF ESCOLAPAI $>=5$ AND ESCOLAPAI $<=8$ THEN FXESCPAI $=2$

IF ESCOLAPAI $>=9$ AND ESCOLAPAI $<=11$ THEN FXESCPAI $=3$

IF ESCOLAPAI $>=12$ THEN FXESCPAI $=4$

IF IDADE $<14$ THEN FXETAMAE $=1$

IF IDADE $>=14$ AND IDADE $<=18$ THEN FXETAMAE $=2$

IF IDADE $>=19$ AND IDADE $<=24$ THEN FXETAMAE $=3$

IF IDADE $>=25$ AND IDADE $<=29$ THEN FXETAMAE $=4$

IF IDADE $>=30$ AND IDADE $<=39$ THEN FXETAMAE $=5$

IF IDADE $>=40$ THEN FXETAMAE $=6$

IF TEMPOGESTA $<9$ THEN TERMO $=1$

IF TEMPOGESTA $=9$ THEN TERMO $=2$

IF TEMPOGESTA $>9$ THEN TERMO $=3$

ERASE D: $\backslash E P I 6 \backslash D O U T O R \backslash I N F O C R I . R E C$ ROUTE D: $\backslash E P I 6 \backslash D O U T O R \backslash I N F O C R I . R E C$

WRITE RECFILE PRONTUARIO CRIANCA SEXO DATANASC PESONASC TAMANHO FXPESO FXETARIA IDADEDIAS IDADEMES PRENATAL INICIOPRE CONSULTAS INTERCOR INTERNACAO TEMPOINT ALEITAMATE AA AMC AME AMP PARTO DOENCAS VERMINOSE TERMO

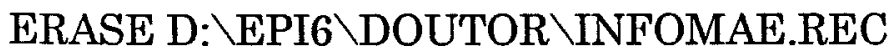
ROUTE D: $\backslash E P I 6 \backslash D O U T O R \backslash I N F O M A E . R E C$ 
WRITE RECFILE PRONTUARIO IMC ESTADOMAE IRMAOS PAICASA PARENTES ESCOLAMAE ESCOLAPAI FXESCMAE FXESCPAI IDADE FXETAMAE NOFILHOS TRABFORA IDADEPAI PAIMORA PAIAJUDA RENDAFAM TIPOCASA CONSTRUCAO AGUA POCO ESGOTO LIXO FILHOMAGRO PLANOFILHO SALARIO TRABNOVO 


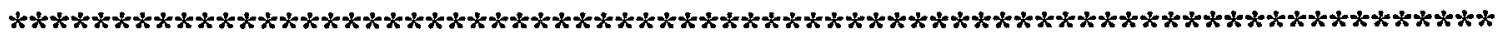

* PROGRAMA DE COPIA DOS VALORES DOS ESTADOS NUTRICIONAI* * AUTOR: PROF. DR. ELIAS E. GOULART 03/07/2002*

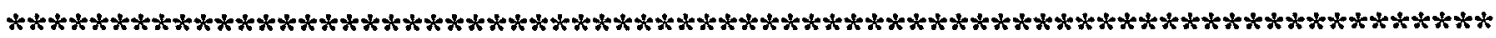

* O ESTADO NUTRICIONAL É GERADO PARA CADA DATA E

* COLOCADO EM WAZ, WHZ E HAZ PELO EPINUT.

* ESTA????.REC CONTEM OS ESCORES Z EM CADA DATA

* DEVE-SE RODAR O EPINUT PARA CADA DATA E RODAR DEPOIS ESTE

* PROGRAMA ALTERANDO-SE O NUMERO CORRESPONDENTE A CADA

* DATA EM WAZ? , WHZ? , HAZ?

READ D: \EPI6 \DOUTOR \ESTA11.REC

RELATE PRONTUARIO D: $\backslash E P I 6 \backslash D O U T O R \backslash M E D 0112 . R E C$

LET WAZ12=WAZ

LET HAZ12=HAZ

LET WHZ12=WHZ

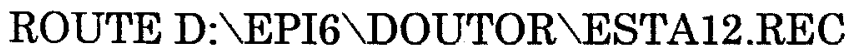

WRITE RECFILE PRONTUARIO WAZ1 HAZ1 WHZ1 WAZ2 HAZ2 WHZ2

WAZ3 HAZ3 WHZ3 WAZ4 HAZ4 WHZ4 WAZ5 HAZ5 WHZ5 WAZ6 HAZ6

WHZ6 WAZ7 HAZ7 WHZ7 WAZ8 HAZ8 WHZ8 WAZ9 HAZ9 WHZ9 WAZ10 HAZ10 WHZ10 WAZ11 HAZ11 WHZ11 WAZ12 HAZ12 WHZ12

CLOSE

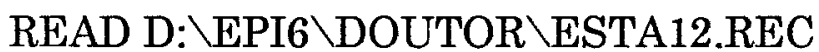


$\operatorname{read} \mathrm{d}: \backslash$ epi6 $\backslash$ doutor $\backslash$ medidas2.rec

define idadedias \#\#\#.\#\#

define idademes \#\#.\#

define p019 \#.\#\#

define e019 \#\#.\#

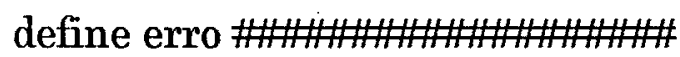

let erro $=000000000000000000$

* Para verificar cada data, basta substituir d01 pelas outras datas: d02, d03,

select

let $\mathrm{p} 019=\mathrm{p} 18$

let $\mathrm{e} 019=\mathrm{e} 18$

let idadedias $=\mathrm{d} 18$-datanasc

let idademes=idadedias/30.4

if idademes $>=6$ and idademes $<7$ and $(\mathrm{p} 019<6.0$ or p019 $>9.70$ or $\mathrm{e} 019<62$ or $\mathrm{e} 019>72$ ) then erro $=$ erro +1

if idademes $>=7$ and idademes $<8$ and $(\mathrm{p} 019<6.5$ or $\mathrm{p} 019>10.2$ or $\mathrm{e} 019<64$ or $\mathrm{e} 019>74)$ then erro $=$ erro +10

if idademes $>=8$ and idademes $<9$ and (p019<7.0 or p019 $>10.7$ or $\mathrm{e} 019<65$ or e019>76) then erro $=$ erro +100

if idademes $>=9$ and idademes $<10$ and $(\mathrm{p} 019<7.4$ or $\mathrm{p} 019>11.1$ or $\mathrm{e} 019<67$ or $\mathrm{e} 019>77$ ) then erro $=$ erro +1000

if idademes $>=10$ and idademes $<11$ and (p019<7.6 or p019>11.5 or e $019<68$ or $\mathrm{e} 019>78$ ) then erro $=$ erro +10000

if idademes $>=11$ and idademes $<12$ and $(\mathrm{p} 019<7.9$ or $\mathrm{p} 019>11.9$ or $\mathrm{e} 019<69$ or $\mathrm{e} 019>79$ ) then erro $=$ erro +100000

if idademes $>=12$ and idademes $<13$ and (p019<8.1 or p $019>12.2$ or $\mathrm{e} 019<70$ or $\mathrm{e} 019>81$ ) then erro $=$ erro +1000000

if idademes $>=13$ and idademes $<14$ and (p019<8.4 or p $019>12.5$ or $\mathrm{e} 019<71$ or $\mathrm{e} 019>82)$ then erro $=$ erro +10000000 
if idademes $>=14$ and idademes $<15$ and $(\mathrm{p} 019<8.6$ or $\mathrm{p} 019>12.8$ or $\mathrm{e} 019<72$ or $\mathrm{e} 019>83$ ) then erro $=$ erro +100000000

if idademes $>=15$ and idademes $<16$ and $(\mathrm{p} 019<8.7$ or p $019>13.1$ or $\mathrm{e} 019<73$ or $\mathrm{e} 019>84$ ) then erro $=$ erro +100000000

if idademes $>=16$ and idademes $<17$ and $(\mathrm{p} 019<8.9$ or p $019>13.3$ or $\mathrm{e} 019<74$ or e019>85) then erro $=$ erro +10000000000

if idademes $>=17$ and idademes $<18$ and (p019<9.0 or p019>13.6 or $\mathrm{e} 019<75$ or $\mathrm{e} 019>87)$ then erro $=$ erro +10000000000

if idademes $>=18$ and idademes $<19$ and (p019<9.2 or p019>13.8 or $\mathrm{e} 019<76$ or $\mathrm{e} 019>88)$ then erro $=$ erro +1000000000000

if idademes $>=19$ and idademes $<20$ and $(\mathrm{p} 019<9.3$ or p $019>14.0$ or $\mathrm{e} 019<77$ or $\mathrm{e} 019>89$ ) then erro $=$ erro +1000000000000

if idademes $>=20$ and idademes $<21$ and (p019 $<9.4$ or p $019>14.2$ or $\mathrm{e} 019<78$ or $\mathrm{e} 019>90$ ) then erro $=$ erro +100000000000000

if idademes $>=21$ and idademes $<22$ and (p019 $<9.6$ or p019 $>14.4$ or $\mathrm{e} 019<79$ or $\mathrm{e} 019>91)$ then erro $=$ erro +1000000000000000

if idademes $>=22$ and idademes $<23$ and (p019 $<9.7$ or p019 $>14.6$ or $\mathrm{e} 019<79.7$ or e $019>92)$ then erro=erro +1000000000000000

if idademes $>=23$ and idademes $<24$ and (p019 $<9.8$ or p019 $>14.8$ or $\mathrm{e} 019<80$ or e019>93) then erro $=$ erro +10000000000000000

if idademes $>=24$ and idademes $<25$ and (p019<10.0 or p $019>15.0$ or e $019<81$ or $\mathrm{e} 019>94$ ) then erro $=$ erro +100000000000000000

relate prontuario d: $\backslash$ epi $6 \backslash$ doutor $\backslash$ cri2.rec

select tempogesta $=9$ and erro $=1$

erase d: \epi6 \doutor $\backslash$ confere.txt

route d: \epi6 \doutor $\backslash$ confere.txt

list pesonasc estatura idademes p019 e019 select

select tempogesta $=9$ and erro $=10$

list pesonasc estatura idademes p019 e019

select

select tempogesta $=9$ and erro $=100$

list pesonasc estatura idademes p019 e019

select

select tempogesta $=9$ and erro $=1000$

list pesonasc estatura idademes p019 e019

select

select tempogesta $=9$ and erro $=10000$

list pesonasc estatura idademes p019 e019

select 
select tempogesta $=9$ and erro $=100000$

list pesonasc estatura idademes p019 e019 select

select tempogesta $=9$ and erro $=1000000$

list pesonasc estatura idademes p019 e019 select

select tempogesta $=9$ and erro $=10000000$

list pesonasc estatura idademes p019 e019 select

select tempogesta $=9$ and erro $=100000000$

list pesonasc estatura idademes p019 e019

select

select tempogesta $=9$ and erro $=1000000000$

list pesonasc estatura idademes p019 e019

select

select tempogesta $=9$ and erro $=10000000000$

list pesonasc estatura idademes p019 e019

select

select tempogesta $=9$ and erro $=100000000000$

list pesonasc estatura idademes p019 e019

select

select tempogesta $=9$ and erro $=1000000000000$

list pesonasc estatura idademes p019 e019

select

select tempogesta $=9$ and erro $=10000000000000$

list pesonasc estatura idademes p019 e019

select

select tempogesta $=9$ and erro $=100000000000000$

list pesonasc estatura idademes p019 e019

select

select tempogesta $=9$ and erro $=1000000000000000$

list pesonasc estatura idademes p019 e019

select

select tempogesta $=9$ and erro $=10000000000000000$

list pesonasc estatura idademes p019 e019

select

select tempogesta $=9$ and erro $=100000000000000000$

list pesonasc estatura idademes p019 e019

select

select tempogesta $=9$ and erro $=100000000000000000$

list pesonasc estatura idademes p019 e019

select

route screen 


\section{MODULOS DO ACCESS}

'ROTINA PARA PREPARAÇÃO DA TABELA

Sub EncheTab0

'Preenche a tabela PCCN

Dim Bd As Database, Pccn As TableDef, DOUTOR As TableDef

Dim CriPccn As Recordset, CriMed As Recordset

Dim Cont_CASE As Integer, Cont_ID As Integer, Cont_VISITA As Integer, Contador As Integer

Set $\mathrm{Bd}=$ CurrentDb

Set Pccn = Bd.TableDefs("PCCN")

Set DOUTOR = Bd.TableDefs("DOUTOR")

Set CriPccn = Bd. OpenRecordset("PCCN", DB_OPEN_TABLE)

Set CriMed = Bd.OpenRecordset("DOUTOR", DB_OPEN_TABLE)

Cont_CASE $=0$

Cont_ID $=0$

Cont_VISITA $=0$

'A rotina abaixo apaga todo o conteudo

'CriPccn.MoveFirst

'Do Until CriMed.EOF

- CriPccn.Delete

- CriPccn.MoveNext

'Loop

CriMed.MoveFirst

Do Until CriMed.EOF

Cont_ID $=$ Cont_ID +1

Contador $=0$

Cont_CASE $=0$

Cont_VISITA $=0$

For Contador $=1$ To 12

Cont_CASE $=$ Cont_CASE +1

Cont_VISITA $=$ Cont_VISITA +1

CriPccn.AddNew 


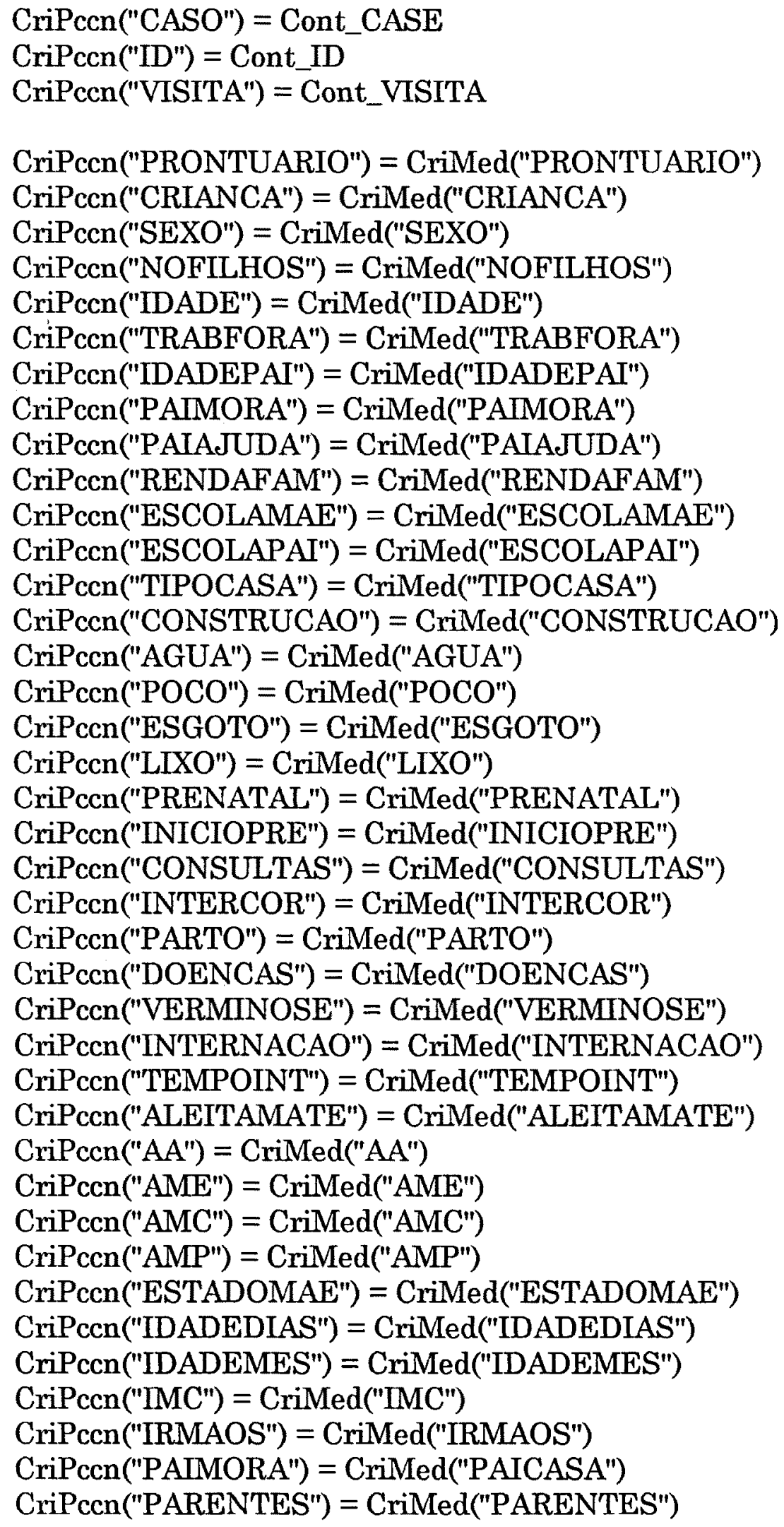




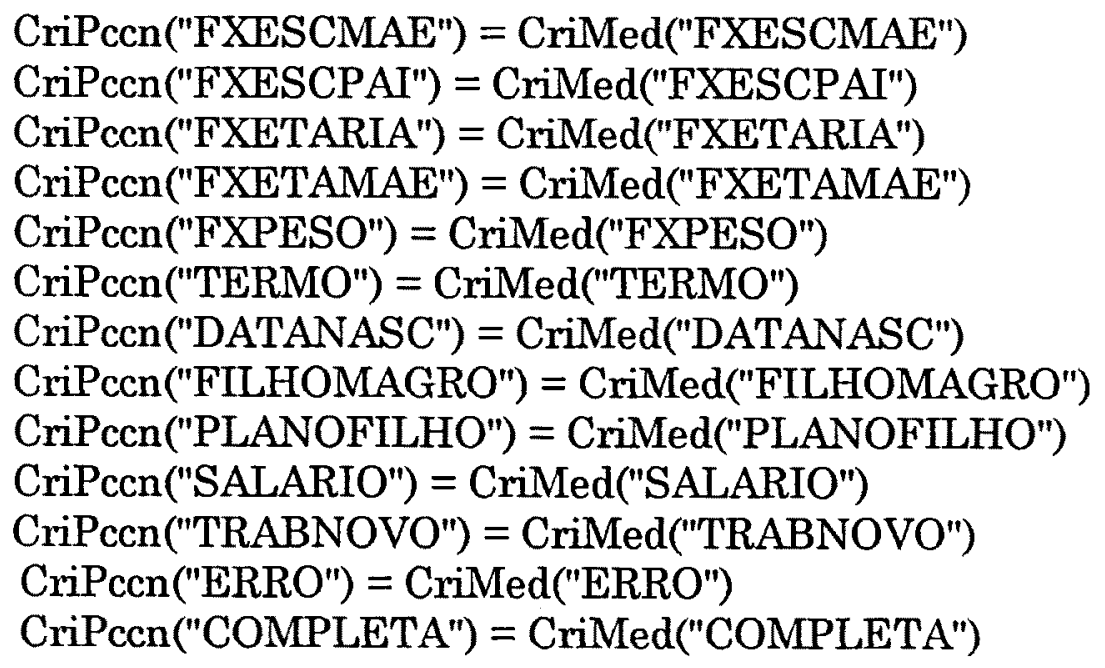

\section{Select Case Cont_CASE}

Case 1: CriPccn("WAZ") = CriMed("WAZ1"): CriPccn("HAZ") = CriMed("HAZ1"): CriPccn("WHZ") = CriMed("WHZ1"):

CriPccn("IDADEVISITA") = CriMed("DM01")

Case 2: CriPccn("WAZ") = CriMed("WAZ2"): CriPccn("HAZ") = CriMed("HAZ2"): CriPccn("WHZ") = CriMed("WHZ2"):

CriPccn("IDADEVISITA") = CriMed("DM02")

Case 3: CriPccn("WAZ") = CriMed("WAZ3"): CriPccn("HAZ") = CriMed("HAZ3"): CriPccn("WHZ") = CriMed("WHZ3"):

CriPccn("IDADEVISITA") = CriMed("DM03")

Case 4: CriPccn("WAZ") = CriMed("WAZ4"): CriPccn("HAZ") = CriMed("HAZ4"): CriPccn("WHZ") = CriMed("WHZ4"):

CriPccn("IDADEVISITA") = CriMed("DM04")

Case 5: CriPccn("WAZ") = CriMed("WAZ5"): CriPccn("HAZ") = CriMed("HAZ5"): CriPccn("WHZ") = CriMed("WHZ5"):

CriPccn("IDADEVISITA") = CriMed("DM05")

Case 6: CriPccn("WAZ") = CriMed("WAZ6"): CriPccn("HAZ") = CriMed("HAZ6"): CriPccn("WHZ") = CriMed("WHZ6"):

CriPccn("IDADEVISITA") = CriMed("DM06")

Case 7: CriPccn("WAZ") = CriMed("WAZ7"): CriPccn("HAZ") = CriMed("HAZ7"): CriPccn("WHZ") = CriMed("WHZ7"):

CriPccn("IDADEVISITA") = CriMed("DM07")

Case 8: CriPccn("WAZ") = CriMed("WAZ8"): CriPccn("HAZ") = CriMed("HAZ8"): CriPccn("WHZ") = CriMed("WHZ8"):

CriPccn("IDADEVISITA") = CriMed("DM08")

Case 9: CriPccn("WAZ") = CriMed("WAZ9"): CriPccn("HAZ") = CriMed("HAZ9"): CriPccn("WHZ") = CriMed("WHZ9"):

CriPccn("IDADEVISITA") = CriMed("DM09") 
Case 10: CriPccn("WAZ") = CriMed("WAZ10"): CriPccn("HAZ") = CriMed("HAZ10"): CriPccn("WHZ") = CriMed("WHZ10"):

CriPccn("IDADEVISITA") = CriMed("DM10")

Case 11: CriPccn("WAZ") = CriMed("WAZ11"): CriPccn("HAZ") = CriMed("HAZ11"): CriPccn("WHZ") = CriMed("WHZ11"):

CriPccn("IDADEVISITA") = CriMed("DM11")

Case 12: CriPccn("WAZ") = CriMed("WAZ12"): CriPccn("HAZ") = CriMed("HAZ12"): CriPccn("WHZ") = CriMed("WHZ12"):

CriPccn("IDADEVISITA") = CriMed("DM12")

End Select

CriPccn.Update

Next Contador

CriMed.MoveNext

Loop

MsgBox "Rodou EncheTabela"

CriPccn.Close

CriMed.Close

End Sub 
ROTINA PARA INSERÇÃO DOS VALORES DE PESO

Sub CopiaPeso0

'Preenche a tabela PCCN com os dados do peso

Dim Bd As Database, Pccn As TableDef, Peso As TableDef

Dim CriPccn As Recordset, CriMed As Recordset

Dim Cont_CASE As Integer, Cont_ID As Integer, Cont_VISITA As Integer,

Contador As Integer

Set $\mathrm{Bd}=$ CurrentDb

Set Pccn = Bd.TableDefs("PCCN")

Set Peso = Bd.TableDefs("PESO")

Set CriPccn = Bd.OpenRecordset("PCCN", DB_OPEN_TABLE)

Set CriMed = Bd.OpenRecordset("PESO", DB_OPEN_TABLE)

Cont_CASE $=0$

Cont_ID $=0$

Cont_VISITA $=0$

'A rotina abaixo apaga todo o conteudo

'CriPccn.MoveFirst

'Do Until CriMed.EOF

- CriPccn.Delete

- CriPccn.MoveNext

'Loop

CriMed.MoveFirst

CriPccn.MoveFirst

A: If CriMed("PRONTUARIO") = CriPccn("PRONTUARIO") Then CriPccn.Edit

CriPccn("PESONASC") = CriMed("PESONASC")

CriPccn.Update

End If

CriPccn.MoveNext

If CriPccn.EOF Then

GoTo B

End If

GoTo A 
B: CriMed.MoveNext

CriPccn.MoveFirst

If CriMed.EOF Then

GoTo C

End If

GoTo A

C: MsgBox "Rodou CopiaPeso"

CriPccn.Close

CriMed.Close

End Sub

' RO'TINA PARA INSERÇÃO DOS VALORES DE ESCORE Z

Sub CopiaEscore0

'Copia os Valores de Escore z de V12 para Doutor 1

Dim Bd As Database, DOUTOR As TableDef, V12 As TableDef

Dim RegDoc As Recordset, RegV12 As Recordset

Dim Cont_CASE As Integer, Cont_ID As Integer, Cont_VISITA As Integer,

Contador As Integer

Set $\mathrm{Bd}=$ CurrentDb

Set DOUTOR $=$ Bd.TableDefs("DOUTOR")

Set V12 = Bd.TableDefs("V12")

Set RegDoc = Bd.OpenRecordset("DOUTOR", DB_OPEN_TABLE)

Set RegV12 = Bd.OpenRecordset("V12", DB_OPEN_TABLE)

Cont_CASE $=0$

RegDoc.MoveFirst

RegV12.MoveFirst

Do Until RegDoc.EOF

Do Until RegV12.EOF

If RegV12("PRONTUARIO") = RegDoc("PRONTUARIO") Then

RegDoc.Edit

RegDoc("WAZ1") = RegV12("WAZ1")

RegDoc("HAZ1") = RegV12("HAZ1")

RegDoc("WHZ1") = RegV12("WHZ1") 


$$
\begin{aligned}
& \text { RegDoc("WAZ2") = RegV12("WAZ2") } \\
& \text { RegDoc("HAZ2") = RegV12("HAZ2") } \\
& \text { RegDoc("WHZ2") = RegV12("WHZ2") } \\
& \text { RegDoc("WAZ3") = RegV12("WAZ3") } \\
& \text { RegDoc("HAZ3") = RegV12("HAZ3") } \\
& \text { RegDoc("WHZ3") = RegV12("WHZ3") } \\
& \text { RegDoc("WAZ4") = RegV12("WAZ4") } \\
& \text { RegDoc("HAZ4") = RegV12("HAZ4") } \\
& \text { RegDoc("WHZ4") = RegV12("WHZ4") } \\
& \text { RegDoc("WAZ5") = RegV12("WAZ5") } \\
& \text { RegDoc("HAZ5") = RegV12("HAZ5") } \\
& \text { RegDoc("WHZ5") = RegV12("WHZ5") } \\
& \text { RegDoc("WAZ6") = RegV12("WAZ6") } \\
& \text { RegDoc("HAZ6") = RegV12("HAZ6") } \\
& \text { RegDoc("WHZ6") = RegV12("WHZ6") } \\
& \text { RegDoc("WAZ7") = RegV12("WAZ7") } \\
& \text { RegDoc("HAZ7") = RegV12("HAZ7") } \\
& \text { RegDoc("WHZ7") = RegV12("WHZ7") } \\
& \text { RegDoc("WAZ8") = RegV12("WAZ8") } \\
& \text { RegDoc("HAZ8") = RegV12("HAZ8") } \\
& \text { RegDoc("WHZ8") = RegV12("WHZ8") } \\
& \text { RegDoc("WAZ9") = RegV12("WAZ9") } \\
& \text { RegDoc("HAZ9") = RegV12("HAZ9") } \\
& \text { RegDoc("WHZ9") = RegV12("WHZ9") } \\
& \text { RegDoc("WAZ10") = RegV12("WAZ10") } \\
& \text { RegDoc("HAZ10") = RegV12("HAZ10") } \\
& \text { RegDoc("WHZ10") = RegV12("WHZ10") } \\
& \text { RegDoc("WAZ11") = RegV12("WAZ11") } \\
& \text { RegDoc("HAZ11") = RegV12("HAZ11") } \\
& \text { RegDoc("WHZ11") = RegV12("WHZ11") } \\
& \text { RegDoc("WAZ12") = RegV12("WAZ12") } \\
& \text { RegDoc("HAZ12") = RegV12("HAZ12") } \\
& \text { RegDoc("WHZ12") = RegV12("WHZ12") } \\
& \text { RegDoc.Update } \\
& \text { End If } \\
& \text { RegV12.MoveNext } \\
& \text { Loop } \\
& \text { RegDoc.MoveNext } \\
& \text { RegV12.MoveFirst } \\
&
\end{aligned}
$$


MsgBox "Rodou CopiaEscore"

RegDoc.Close

RegV12.Close

End Sub

'Apaga os registros de DOUTOR1 que não estão em V12

Dim Bd As Database, DOUTOR1 As TableDef, V12 As TableDef

Dim RegDoc As Recordset, RegV12 As Recordset

Dim Cont_CASE As Integer, Cont_ID As Integer, Cont_VISITA As Integer,

Contador As Integer

Set $\mathrm{Bd}=$ CurrentDb

Set DOUTOR1 = Bd.TableDefs("DOUTOR1")

Set V12 = Bd.TableDefs("V12")

Set RegDoc = Bd.OpenRecordset("DOUTOR1", DB_OPEN_TABLE)

Set RegV12 = Bd.OpenRecordset("V12", DB_OPEN_TABLE)

Cont_CASE $=0$

RegDoc.MoveFirst

RegV12.MoveFirst

Do Until RegDoc.EOF

Do Until RegV12.EOF

If RegV12("PRONTUARIO") = RegDoc("PRONTUARIO") Then

Cont_CASE $=1$

End If

RegV12.MoveNext

Loop

If Cont_CASE $=0$ Then

RegDoc.Delete

End If

RegDoc.MoveNext

RegV12.MoveFirst

Cont_CASE $=0$

Loop

MsgBox "Rodou DelRegDoutor1"

RegDoc.Close 
CriMed.Close

End Sub

'Preenche a tabela PCCN com os dados do peso

Sub CopiaPeso20

Dim Bd As Database, Pccn As TableDef, Peso As TableDef

Dim CriPccn As Recordset, CriPeso As Recordset

Dim Cont_CASE As Integer, Cont_ID As Integer, Cont_VISITA As Integer, Contador As Integer

Set $\mathrm{Bd}=$ CurrentDb

Set Pccn = Bd.TableDefs("Pccn")

Set Peso = Bd.TableDefs("Peso")

Set CriPccn = Bd.OpenRecordset("Pccn", DB_OPEN_TABLE)

Set CriPeso = Bd.OpenRecordset("Peso", DB_OPEN_TABLE)

Cont_CASE $=0$

Cont_ID $=0$

Cont_VISITA $=0$

'A rotina abaixo apaga todo o conteudo

'CriPccn.MoveFirst

'Do Until CriMed.EOF

' CriPccn.Delete

' CriPccn.MoveNext

'Loop

CriPeso.MoveFirst

CriPccn.MoveFirst

'CriPccn.MoveNext

Do Until CriPccn.EOF

Do Until CriPeso.EOF

If CriPccn("PRONTUARIO") = CriPeso("PRONTUARIO") Then

CriPccn.Edit

CriPccn("PESONASC") = CriPeso("PESONASC")

CriPccn.Update

CriPccn.MoveNext

CriPccn.Edit 
CriPccn("PESONASC") = CriPeso("PESONASC")

CriPccn.Update

CriPccn.MoveNext

CriPccn.Edit

CriPccn("PESONASC") = CriPeso("PESONASC")

CriPccn.Update

CriPccn.MoveNext

CriPccn.Edit

CriPccn("PESONASC") = CriPeso("PESONASC")

CriPccn.Update

CriPccn.MoveNext

CriPccn.Edit

CriPccn("PESONASC") = CriPeso("PESONASC")

CriPccn.Update

CriPccn.MoveNext

CriPccn.Edit

CriPccn("PESONASC") = CriPeso("PESONASC")

CriPccn.Update

CriPccn.MoveNext

CriPccn.Edit

CriPccn("PESONASC") = CriPeso("PESONASC")

CriPccn.Update

CriPccn.MoveNext

CriPccn.Edit

CriPccn("PESONASC") = CriPeso("PESONASC")

CriPccn.Update

CriPccn.MoveNext

CriPccn.Edit

CriPccn("PESONASC") = CriPeso("PESONASC")

CriPccn.Update

CriPccn.MoveNext

CriPccn.Edit

CriPccn("PESONASC") = CriPeso("PESONASC")

CriPccn.Update

CriPccn.MoveNext

CriPccn.Edit

CriPccn("PESONASC") = CriPeso("PESONASC")

CriPccn.Update

CriPccn.MoveNext

CriPccn.Edit

CriPccn("PESONASC") = CriPeso("PESONASC")

CriPccn.Update

CriPccn.MoveNext 


\section{End If}

CriPccn.MoveNext CriPccn.MoveNext

CriPccn.MoveNext

CriPccn.MoveNext

CriPccn.MoveNext

CriPccn.MoveNext

CriPccn.MoveNext

CriPccn.MoveNext

CriPccn.MoveNext

CriPccn.MoveNext

CriPccn.MoveNext

CriPccn.MoveNext

Loop

Loop

MsgBox "Rodou CopiaPeso2"

CriPccn.Close

CriPeso.Close

End Sub 
PROGRAMAS TIPO DO PARA O SOFTWARE STATA

\title{
ARQUIVO VAR_NOVA.DO
}

\author{
gen amp2=amp \\ recode amp2 $1 / \max =1$ \\ label define nas 0 "nao" 1 "sim" \\ label val amp2 nas \\ gen renda $3=$ renda 2 \\ recode renda3 $2 / 4=2$ \\ gen irmaos $2=$ irmaos \\ recode irmaos $23 / \max =3$ \\ label define irmao 3 ">2" \\ label var irmaos2 "numero de irmaos" \\ label val irmaos2 irmao \\ gen nofilho3= nofilho2 \\ recode nofilho $3 \mathrm{~min} / 3=14 / \mathrm{max}=2$ \\ gen escolamae2 = escolamae \\ recode escolamae 2 1/4=1 5/max=2 \\ label define escolamae2 1 "1-4" 2 "> 4" \\ label val escolamae2 escolamae2 \\ label var escolamae2 "anos de escolaridade da mae" \\ gen irmaos2 $=$ irmaos \\ recode irmaos $0 / 1=12 / 3=2 \quad 4 / \max =3$ \\ label define irmaos 1 "0-1" 2 "2-3" 3 "> 3 " \\ label val irmaos 2 irmaos \\ recode estadomae $0=$.
}




\title{
ARQUIVO VAR_NOVA2.DO
}

\author{
gen idade2=idade \\ recode idade $2 \mathrm{~min} / 19=120 / 40=241 / \max =3$ \\ label define idade2 1 "<20" 2 "20-40" 3 "> 40" \\ label val idade2 idade2 \\ gen escpai $2=$ escolapai \\ recode escpai2 $1 / 4=15 / \max =2$ \\ tab escpai2 \\ label define esc2 1 "1=4" 2 "> 4 \\ label val escpai2 esc2 \\ gen idadepai2 $=$ idadepai \\ recode idadepai $2 \mathrm{~min} / 19=120 / 40=241 / \max =3$ \\ label val idadepai2 idade 2 \\ gen rendaf $=$ renda 2 \\ recode rendaf $4=3$ \\ label define rendaf 3 ">= $3 \mathrm{sm} " 1$ "< $1 \mathrm{sm} " 2$ "1- $3 \mathrm{sm} "$ \\ label val rendaf rendaf \\ gen parente $2=$ parentes \\ recode parente $2 \min / 2=13 / \max =2$ \\ label define parente 1 "ate 2 " 2 " 3 ou +" \\ label val parente 2 parente \\ gen fxpeso $=$ pesonasc \\ recode fxpeso $\mathrm{min} / 2499.99=12500 / 2999.99=23000 / \mathrm{max}=3$ \\ label define fxpeso 1 "<2500" 2 "2500-2999" 3 ">=3000" \\ label val fxpeso fxpeso
}

xi:xtgee haz aleitamate, f(gaus) l(iden) i(id) $t$ (visita)

xi:xtgee haz internacao, $f$ (gaus) l(iden) $i$ (id) $t$ (visita)

xi:xtgee haz i.irmaos2, f(gaus) l(iden) i(id) t(visita)

xi:xtgee haz irmaos2, f(gaus) l(iden) i(id) $t$ (visita)

xi:xtgee haz i.escolamae2, f(gaus) l(iden) i(id) t(visita)

xi:xtgee haz escolamae2, f(gaus) l(iden) i(id) t(visita)

xi:xtgee haz i.idade2, f(gaus) l(iden) i(id) t(visita)

xi:xtgee haz idade2, f(gaus) l(iden) i(id) t(visita)

xi:xtgee haz trabfora, $f$ (gaus) l(iden) $i$ (id) $t$ (visita)

xi:xtgee haz nofilho3, f(gaus) l(iden) i(id) t(visita)

xi:xtgee haz i.escpai2, f(gaus) l(iden) i(id) t(visita)

xi:xtgee haz escpai2, f(gaus) l(iden) i(id) t(visita)

xi:xtgee haz i.idade2, f(gaus) l(iden) $i$ (id) t(visita)

xi:xtgee haz idade2, f(gaus) l(iden) i(id) t(visita)

xi:xtgee haz i.idadepai2, f(gaus) l(iden) i(id) t(visita) 


\begin{abstract}
xi:xtgee haz idadepai2, f(gaus) l(iden) i(id) t(visita) xi:xtgee haz paimora, $f$ (gaus) l(iden) $i$ (id) $t$ (visita) xi:xtgee haz paiajuda, f(gaus) l(iden) $i$ (id) $t$ (visita) xi:xtgee haz i.rendaf, f(gaus) l(iden) i(id) t(visita) xi:xtgee haz rendaf, $f$ (gaus) l(iden) $i($ id) $t$ (visita)

xi:xtgee haz parente2, f(gaus) l(iden) i(id) t(visita) xi:xtgee haz trabnovo, f(gaus) l(iden) i(id) t(visita) xi:xtgee haz fxpeso, f(gaus) l(iden) i(id) t(visita) xi:xtgee haz i.fxpeso, f(gaus) l(iden) i(id) t(visita) xi:xtgee haz termo, f(gaus) l(iden) $i$ (id) $t$ (visita)
\end{abstract}

\title{
‘ ARQUIVO DESCRITIVA2 ALL.DO
}

oneway haz idade2 if visita $==1$, tab oneway haz escpai2 if visita $==1$, tab oneway haz idadepai2 if visita $==1$, tab oneway haz rendaf if visita $==1$, tab oneway haz irmaos2 if visita $=1$, tab oneway haz nofilho3 if visita $==1$, tab oneway haz parente 2 if visita $==1$, tab oneway haz fxpeso if visita $==1$, tab oneway haz escolamae 2 if visita $==1$, tab 